\title{
Wind generation and the dynamics of electricity prices in Australia
}

\author{
Muthe Mathias Mwampashi*1, Christina Sklibosios Nikitopoulos ${ }^{1}$, Otto \\ Konstandatos $^{1}$, and Alan Rai ${ }^{1,2}$ \\ ${ }^{1}$ University of Technology Sydney, Finance Department, UTS Business School, P.O.Box 123 \\ Broadway NSW 200\%, Australia \\ ${ }^{2}$ Baringa Partners LLP, Level 36/1 Macquarie Pl, Sydney NSW 2000, Australia
}

$2^{\text {nd }}$ November 2020

\begin{abstract}
Australia's National Electricity Market (NEM) is experiencing one of the world's fastest and marked transitions toward variable renewable energy generation. This transformation poses challenges to system security and reliability and has triggered increased variability and uncertainty in electricity prices. By employing an exponential generalized autoregressive conditional heteroskedasticity $(\mathrm{eGARCH})$ model, we gauge the effects of wind power generation on the dynamics of electricity prices in the NEM. We find that a $1 \mathrm{GWh}$ increase in wind generation decreases daily prices up to $1.3 \mathrm{AUD} / \mathrm{MWh}$ and typically increases price volatility up to $2 \%$. Beyond consumption and gas prices, hydro generation also contributes to an increase in electricity prices and their volatility. The cross-border interconnectors play a significant role in determining price levels and volatility dynamics. This underscores the important role of strategic provisions and investment in the connectivity within the NEM to ensure the reliable and effective delivery of renewable energy generation. Regulatory interventions, such as the carbon pricing mechanism and nationwide lockdown restrictions due to COVID-19 pandemic, also had a measurable impact on electricity price dynamics.
\end{abstract}

Keywords: wind generation, electricity price volatility, merit order effect, hydro generation, interconnectors, carbon pricing mechanism, COVID-19

JEL: C22, C58, Q40, Q42,

${ }^{*}$ Corresponding author: Muthe.M. Mwampashi@student . uts . edu . au 


\section{Introduction}

In recent years, there has been a dramatic increase in variable renewable energy (VRE) generation in the Australian National Electricity Market (NEM), with rates ten times higher than the global average. ${ }^{1}$ This has been driven by high electricity prices, the declining cost of VRE, and government policy incentives, including the Renewable Energy Target (RET) scheme (Stocks et al., 2019; de Atholia et al., 2020; Simshauser and Gilmore, 2020). The RET consists of two sub-schemes, the Large-scale Renewable Energy Target (LRET) and the Small-scale Renewable Energy Scheme (SRES). The former provides an incentive for large-scale generation, such as VRE farms and hydro-electric power stations. The SRES incentivizes small-scale generation, such as rooftop solar, small-scale wind and hydro systems. The LRET aims at achieving 33,000 GWh of electricity sourced from large-scale renewable projects by 2020, which is equivalent to about $23.5 \%$ of Australia's electricity generation capacity (AER, 2018). This target was met in September 2019, one year ahead of schedule (CEC, 2020). Although this is a tremendous outcome, it has raised concern about the impact of VRE on the system security and reliability of the NEM.

The NEM is a diverse electricity market involving an interconnected network of states with very different generation mixes and VRE penetration rates. The surge in VRE has been associated with a marked reduction in greenhouse gas, electricity prices, and sustainability of the electricity energy sector. Compelling empirical evidence has demonstrated the negative impact of VRE output on the level of electricity prices known as merit order effect (MOE) (Forrest and MacGill, 2013; Cludius et al., 2014a; Ketterer, 2014; Clò et al., 2015; Kyritsis et al., 2017; Csereklyei et al., 2019; Maciejowska, 2020). However, one of the largest challenges currently facing the NEM is the assessment and management of electricity price volatility. This challenge primarily arises from the intermittent nature of VRE, which makes it harder to equilibrate supply and demand (Baldick, 2011; Hirth, 2013; Rai and Nunn, 2020; Kelley et al., 2020). The cyclic nature of demand and constraints in supply due to outages in transmission networks, strategic bidding practices, ramping up of plants, and volatility in fuel prices all combine so that electricity markets tend to exhibit substantially greater price variability than is typical in financial markets (Ward et al., 2019; Han et al., 2020). With the recent closure and mothballing of several coal-fired generators, price variability has become more pronounced in the NEM. Reacting to the sharp increase in VRE, the frequency of negative pricing increased substantially over the last few years. Between 2017-2020, major changes linked to policy uncertainties and the investment megacycle in the NEM jeopardized the power system's reliability and security and increased operator interventions in the security-constrained dispatch process (Simshauser and Gilmore, 2020). Higher volatility can result

\footnotetext{
${ }^{1}$ Between 2018 and 2020, Australia would install more than 16 GW of wind and solar, which is equivalent to an average rate of $220 \mathrm{~W}$ per person per year. This capacity is more than two and a half times that of Germany, the next fastest country in the installation of renewable electricity capacity, and is more than four to five times faster than the European Union, Japan, the United States, and China (Stocks et al., 2019; COAG, 2019).
} 
in higher wholesale contract prices and in turn, higher prices for end-consumers, offsetting some or all of the price reduction via the MOE.

Wind generation has been the dominant VRE. South Australia, with more than 50\% wind penetration, the highest in the NEM, is second only to Denmark in the world. ${ }^{2}$ Wind generation has been the main contributor to this increasing variation and negative prices. Therefore, it would be useful to focus on the effect of wind generation in the NEM and to comprehensively analyze the determinants of not only the MOE but also most importantly, the volatility dynamics of electricity prices. We also investigate the impact of government policies and regulations, including the Carbon Pricing Mechanism (CPM) and the COVID-19 lockdown restrictions on the price level and volatility dynamics.

This study aims to gauge the effects of increasing wind output on the level and volatility of wholesale electricity prices in the NEM. Variables such as electricity consumption and gas prices play an essential role in determining the dynamics of electricity prices. Natural gas-fired peak load generators are commonly the marginal producers of electricity in the NEM. They tend to drive prices. High gas prices in recent years due to the increase in the liquified natural gas (LNG) exports (resulting in an export-driven deficit in the local supply) account substantially for the upward movement in electricity prices in the NEM (Csereklyei et al., 2019; Simshauser and Gilmore, 2020). We consider two additional factors reflecting the integration of the generation mix and the market connectedness, and assess their contributions to the NEM dynamics. These factors are hydro generation and interconnector flow. To the best of our knowledge, this is the first study on the NEM that integrates the impact of hydro and interconnectors, which are two key contributors, especially in the current fast-transforming network of the NEM. Cross-border interconnectors offer a potential strategic solution to the intermittency of VRE by allowing pooling and sharing of available generation capacities (Du et al., 2017; Alasseur and Féron, 2018; Mountain and Percy, 2019; Rai and Nunn, 2020). Furthermore, it is well-known that hydro and pumped hydro generation increased significantly during the carbon pricing period, at the expense of gas and some coal plants (AER, 2014). Hydro is fast-start and flexible (like some gas plants), and thus this extra generation might have contributed to reducing prices and smoothing price volatility during this period. ${ }^{3}$ The changing energy landscape in the NEM also means that pumped hydropower generation is becoming increasingly important for supplementing generation from VRE (de Atholia

\footnotetext{
${ }^{2}$ South Australia is on track to meet its target to be self-sufficient in renewables by 2030 (AEMO, 2019c; Stocks et al., 2019). By the same year, Victoria and Queensland are each targeting a renewables share of $50 \%$. Perhaps the most interesting globally is Tasmania, which is on track to meet its $100 \%$ target as soon as 2022 (COAG, 2019). Recently, the large-scale solar penetration accounted for part of this transformation in the NEM's generation mix. Nonetheless, wind power generation still dominates across all states except Queensland (QLD) and has been the central concentration of LRTE scheme.

${ }^{3}$ Empirically, we use the aggregated regional output from run-of-river and pumped hydro plants. However, the two types of plants can have different impacts on prices and volatility. For instance, pumped hydro is like a battery, and therefore, can reduce down-and up-side volatility.
} 
et al., 2020; Huang et al., 2020).

We focus on the four most mature markets (in terms of wind generation) in the NEM, namely, New South Wales (NSW), South Australia (SA), Victoria (VIC), and Tasmania (TAS). In the spirit of Ketterer (2014), we apply the exponential generalized autoregressive conditional heteroskedasticity (eGARCH) model proposed by Nelson (1991) to study the electricity price and volatility dynamics. The main advantage of this approach is that both prices and volatility are modeled simultaneously while taking into account heteroskedasticity and the asymmetry effect, which are understood to be very important features of price volatility. In contrast to previous studies (Cutler et al., 2011; Forrest and MacGill, 2013; Rintamäki et al., 2017), we include the negative prices and price spikes without truncating or transforming the time series. We find both behaviors are pronounced and important in studying price dynamics in the NEM.

Using daily data (aggregated from high-frequency data) from the NEM from 2011 to 2020, we confirm the merit order effect of wind generation for all four regional markets. We also find evidence that electricity consumption, gas prices, and hydro generation are positively correlated to electricity prices. The high generation costs due to the prolonged period of dry conditions that stretched across much of Australia may explain the absence of the MOE for hydro generation. The interconnectors exhibit substantial but varying impacts on electricity prices depending primarily on the state's position (exporter or importer) as well as the thermal capacity of the respective interconnectors. In particular, all interconnector flows to NSW (Terranora (NSW-QLD), QNI (NSW-QLD), and VNI (VIC-NSW)) contribute substantially to lowering electricity prices. NSW is the most traditional importing region and has the largest capacity of interconnectors in the NEM. The impact of the other interconnectors is not consistent, reflecting the changing positions over time due to the increase in VRE penetration and the closure of coal-fired plants. In SA, the Heywood (VIC-SA) interconnector contributes to lowering electricity prices due to relatively high average imports from VIC, while Murraylink (VIC-SA) is positively related to price levels due to the high average exports to VIC. Similarly, the high average exports to SA and NSW via the Heywood interconnector and VNI respectively, contribute to lowering prices in VIC. Although the exports from TAS to VIC via the Basslink (TAS-VIC) interconnector are relatively higher over the sample period, we find evidence for a positive relationship with electricity prices in VIC and TAS.

In terms of price volatility, we find pronounced own-innovation and lagged volatility spillovers, and good news increases volatility more than bad news in NSW. Moreover, in states with high wind generation, its impact on price volatility is significant. Specifically, volatility increases by $2 \%$ and $1 \%$ in SA and VIC, respectively, for each $1 \mathrm{GWh}$ rise in daily wind generation. In contrast, we find strong evidence for the opposite effect in TAS, where an increase in wind generation by the same amount reduces price volatility by $5 \%$. Wind penetration exhibits a significant effect of 
the same sign for states with moderate penetration levels (around $13 \%$ in 2020); i.e., increasing wind penetration by $1 \%$ reduces and amplifies price volatility by the same magnitude in TAS and VIC, respectively. Electricity consumption, gas prices, and hydro generation increase the volatility of electricity prices. Higher volatility due to hydro generation follows from its dependence on weather conditions, which tends to vary over time. SA experiences a substantial impact of wind generation and gas prices on volatility compared to the other regions in the NEM, reflecting the heavy reliance on and relatively higher proportions of these variables in the region's generation mix. The interconnectors impact price volatility significantly, and their varying impacts reflect the increasing investments in VRE and the withdrawal of coal-fired generation in the connected markets. The VNI and Murraylink interconnectors increase price volatility in NSW and SA, respectively, and smooth out price volatility in VIC. The effect observed in NSW and SA may be linked primarily to the withdrawal of the Hazelwood power station, which removed $1600 \mathrm{MW}$ of brown coal generation in VIC (5\% of the NEM's total output). In contrast, the Heywood interconnector impacts VIC's price variability positively. Furthermore, the Basslink interconnector contributes significantly to reducing price volatility in TAS. Based on an outlier treatment analysis, we conclude that higher volatility in the NEM is associated with the high frequency of prices between $100 \mathrm{AUD} / \mathrm{MWh}$ and $500 \mathrm{AUD} / \mathrm{MWh}$ rather than extreme prices outside this range.

At the turn of this decade, two major regulatory measures impacted price and volatility dynamics in the NEM, the CPM and the COVID-19 lockdown restrictions. The former was part of the Australian Clean Energy Act and operated from July 1, 2012, to July 1, 2014. The legislation targeted at reducing greenhouse emissions in the electricity sector. Existing studies restricted their investigations to the impact of this reform on the level of electricity prices, electricity demand, and changes in the emissions intensity (O'Gorman and Jotzo, 2014; Nazifi, 2016; Maryniak et al., 2019). No studies examined the contribution of inter alia wind and hydro generation despite the increased investment in VRE and the competitiveness of hydro generation during this period. In addition, no known empirical research has focused on exploring the impact of the CPM along with price determinants on the volatility of electricity prices. The COVID-19 lockdown restrictions were more recent nationwide government measures imposed in late March 2020 to prevent the spread of the COVID-19 pandemic. To date, little is known about the impact of this pandemic on the energy sector. To our knowledge, this is the first study to shed light on how the dynamics of electricity prices and the associated determinants were affected by the imposition of these restrictions.

We find strong evidence that during the operation of the CPM, prices increased substantially in coal-dominant regions, namely, NSW and VIC, and less in renewables-rich states, that is, SA and TAS. Wind and hydro generation played an essential role by exerting substantial downward pressure on the level of electricity prices. SA and TAS, both of which had a relatively large share of wind generation during this period, experienced a more substantial impact. In the same line, wind generation contributed to a marginal reduction in price volatility. Moreover, we find evidence 
that electricity prices decreased during the COVID-19 lockdown restrictions period. The drop in prices primarily reflects the decline in demand, lower gas and coal prices, lower-priced offers, and increased renewable output. We observe no major changes associated with the merit order effect of wind generation and the marginal impact of the restrictions on price volatility.

These findings have significant implications for understanding the challenges associated with the recent influx of VRE in the NEM. In particular, the surge in wind generation has increased the variability and uncertainty of electricity prices, posing a significant risk to investors and consumers. The infrequent, very high, or low prices for very short periods call for well-established strategies for dealing with real-time power system security and reliability to be set. Priority should be given to investing in a more flexible system to accommodate the intermittency of the VRE sector, enhancing effective trade among regional markets through effective interconnections, and investing in electricity storage. Moreover, system architecture, regulation, and governance should be designed appropriately to deal with a range of potential future disruptions, such as COVID-19 pandemic.

The rest of the paper is structured as follows. In Section 2, we provide a review of relevant literature. In Section 3, we describe the data and the model for the dynamics of electricity prices. In Section 4, we discuss the effects of wind generation on electricity prices and volatility. In Section 5, we analyze the impact of federal regulatory measures on electricity dynamics. In Section 6, we provide concluding remarks and policy implications.

\section{Literature review}

The growth and increased investment in renewable energies have attracted theoretical and empirical interest in the MOE in renewables-rich countries, such as Germany, Denmark, and Australia. The literature has shown that near-zero marginal cost characteristics of wind generation manifest through the decrease in the level of electricity prices (Forrest and MacGill, 2013; Cludius et al., 2014a; Ketterer, 2014; Clò et al., 2015; Csereklyei et al., 2019). These findings are unlikely to be due to chance, as most authors came to the same conclusion. ${ }^{4}$ Although research on the subject has been mostly restricted to the MOE, several researchers investigated the impact of VRE on price volatility as either a stand-alone or integrated study with the MOE (Tveten et al., 2013; Pereira and Rodrigues, 2015; Ketterer, 2014; Rintamäki et al., 2017; Kyritsis et al., 2017; Maciejowska, 2020). In contrast, research findings regarding the volatility dynamics of electricity prices have been inconsistent and contradictory, and vary across countries and time of day (reflecting changes in demand profiles). We aim at establishing this relationship in the NEM. This study makes

\footnotetext{
${ }^{4}$ Several divergent accounts of the merit order have been observed. For instance, Bublitz et al. (2017) employed agent-based modeling and a regression approach to study the main price drivers in Germany from 2011 and 2015. In contrast to other studies, the findings indicate that fuel and carbon prices are still dominant, and reductions in their prices rather than the increase in renewable energy generation (wind and solar Photovoltaics (PV)) are responsible for the downward pressure on the electricity prices.
} 
contributions to the current literature in three major dimensions:

First, we conduct a comprehensive analysis of the impact of wind generation on the volatility of electricity prices in the NEM. To our knowledge, this is the first study of substantial duration (2011-2020) to examine the variability of electricity prices in Australia. Moreover, we add to previous empirical studies on the MOE by including recent years that witnessed large-scale VRE investments in the NEM (Simshauser and Gilmore, 2020). In particular, the share of electricity generation from VRE increased rapidly since 2018, breaking NEM records (de Atholia et al., 2020). One aspect overlooked by previous studies is cross-border interconnector flow and hydro generation. By controlling for these variables, this study provides a deeper understanding of the impact of VRE generation on prices and volatility. Existing literature in this area includes Woo et al. (2011), who investigated the four zone of Texas. Using an econometric analysis of high-frequency electricity prices, these authors found that an increase in wind generation results in a reduction in spot electricity prices, however, at the cost of increasing price volatility. Ketterer (2014) reached the same conclusion using GARCH modeling with daily electricity data in Germany. Kyritsis et al. (2017) applied GARCH-in-mean models to the German electricity market, grouping data into peak and off-peak periods. These authors confirmed the merit order effect and the negative and positive effects of solar and wind, respectively, in the volatility of electricity prices. In a similar context, Rintamäki et al. (2017) divided data into off-peak and peak hours and estimated the impact of renewable generation on electricity price levels in Germany and Denmark. Using an autoregressive moving average (SARMA) model, these authors found that wind power reduces the volatility of daily day-ahead electricity prices in Denmark, whereas it increases such volatility in Germany. Nonetheless, the authors found consistent increase in weekly volatility when wind generation increased. Maciejowska (2020) applied quantile regression and examined the interquantile range (IQR) variability, to examine the impact of wind and solar generation. The author found that during low demand for electricity, wind tends to increase price variability and reduces it during high demand. In contrast, when electricity demand is moderate, solar power tends to stabilize price variance. Similar studies are scant in the NEM. There are, however, a considerable number of studies that investigated the intra- and inter-relationships of wholesale electricity prices and price volatility between regional electricity markets (Worthington et al., 2005; Higgs, 2009; Ignatieva and Trück, 2016; Han et al., 2020). Most of these studies apply GARCH-based models finding the presence of significant own-mean spillovers and means spillovers from other lagged markets. The occurrence of shocks in one market affects the price volatility of not only that market but also other markets in the region, especially between adjoining and physically connected markets. We build on these findings with a somewhat similar methodological approach based on an eGARCH-type model to investigate prices and volatility. Where this analysis differs from other analyses, however, is by accounting for seasonality, electricity spikes, and explicit incorporation rather than removal of negative electricity prices. 
We provide a deeper insight into negative electricity prices in Australia, which appear far more frequently following the upsurge in VRE penetration in the NEM. To capture the volatility of electricity prices effectively, we include negative prices and price spikes in the empirical analysis without applying any truncation or transformation. This contrasts with much of the literature (Cutler et al., 2011; Forrest and MacGill, 2013; Cludius et al., 2014b; Ketterer, 2014), which applies statistical approaches to adjust prices spikes or truncates electricity prices based on the marginal cost of generation.

Second, this study is one of the first attempts to thoroughly examine the role of cross-border interconnectors and hydro generation in the NEM. Interconnectors are essential in optimizing the total generation supply through the transfer of energy between the major generation and demand centers. Denny et al. (2010) investigated the impacts of interconnectors in Ireland, which has one of the highest penetrations of wind generation in the world. The empirical findings suggest that the increase in interconnectors has the potential for reducing the level and variability of electricity prices. Similarly, Rai and Nunn (2020) examined the role of interconnectors in offsetting the challenges associated with higher penetration of wind generation specifically in SA. This study suggested that when interconnectors are unconstrained, and electricity demand between regional markets is imperfectly correlated, the competitive tension between connected states (SA and VIC) has potential to lower price levels and smooth out price volatility. The GARCH modeling with copulae by Ignatieva and Trück (2016) found a significant interdependence between markets that are well connected via interconnector transmission. This conclusion concurs with that of Han et al. (2020), who used more recent NEM data and found pronounced volatility spillovers between physically interconnected markets.

Third, we assess the extent to which federal regulatory measures, namely, the CPM and the COVID-19 lockdown restrictions, impacted the level and volatility of electricity prices. Existing research has been unable to confirm either the MOE of wind generation or its impact on volatility dynamics during the CPM period. However, several researchers demonstrated substantial changes in prices, demand, and emission intensity. Nazifi (2016) carried out an investigation in the NEM from 2010 to 2013 and concluded that carbon costs resulted in higher wholesale spot electricity prices and windfall profits for some generators. Beyond these effects, O'Gorman and Jotzo (2014) showed that electricity demand decreased by $3.8 \%$ and overall emission by $8.2 \%$, relative to the two-year period before its introduction. Han et al. (2020), in contrast, found that the CPM had an impact on dampening volatility spillover across the NEM. A recent analysis by the Australian Energy Market Operator (AEMO) also suggested a moderate reduction in electricity demand during the implementation of COVID-19 restrictions and lockdowns (AEMO, 2020e,f). A substantial reduction was observed in QLD and NSW due to the decrease in commercial demand and a limited increase in residential demand (due to mild weather conditions). 


\section{Data and methodology}

\subsection{Data and preliminary analysis}

We consider wind generation for four NEM regions, namely, NSW, SA, VIC, and TAS, and study the effect on the level and volatility of electricity prices from January 1, 2011, to May 31, 2020. The main datasets for this analysis were obtained from the NEM via NEOpoint (2020). We use daily data, aggregated from high-frequency (5- and 30-minute) wholesale electricity prices (depicted in Figure 1), electricity consumption, wind electricity generation, ${ }^{5}$ hydro generation, and interconnector flows (imports and exports). The daily gas price data for the same period for Adelaide and Sydney, representing SA and NSW, respectively, were obtained from the Short Term Trading Market (STTM) (AEMO, 2020g). The four-hourly gas price data for VIC were obtained from the Declared Wholesale Gas Market (DWGM) (AEMO, 2020c).

Wind generation in the NEM has increased significantly since 2010. As shown in Figure 2a, large-scale wind generation has grown exponentially across all states. The constant level of wind generation in SA between 2018 and 2019 is attributed to the federal government's RET of 33,000 gigawatt-hours of national electricity capacity being met in 2019, accounting for $23.5 \%$ of Australian electricity. In 2020, NSW, VIC, and SA made approximately equal contributions to wind generation in the NEM. The MOE of wind generation is well-established in the literature, and we expect to observe the same impact in the NEM. However, the influence of wind on volatility remains unclear. Generally, observations from similar studies in European markets, for instance, Mauritzen (2010), Woo et al. (2011), Ketterer (2014), Clò et al. (2015), Rintamäki et al. (2017), and Maciejowska (2020), suggest that wind generation has a significant positive impact on price volatility. From these studies, and based on recent findings by Rai and Nunn (2020) for the NEM, we infer that states with higher wind generation such as SA will exhibit a significant impact on volatility compared to states with lower wind generation such as NSW.

Two key factors driving the electricity price dynamics of the NEM are consumption and gas prices. Electricity consumption reflects demand profiles, which, given the non-storability of electricity, is expected to have a positive impact on prices across all NEM markets (Csereklyei et al., 2019; Forrest and MacGill, 2013). The latter is more pronounced in SA and VIC, where gas accounts for a substantial proportion of electricity generation. Notwithstanding this, Forrest and MacGill (2013) showed that the increase in wind generation displaces gas output in the two regions. The study by Csereklyei et al. (2019) suggested that the impact is still noteworthy. Since

\footnotetext{
${ }^{5}$ Except wind generation data series for TAS and VIC, no missing values were observed in the other variables. For the first region, the percentage of missing values is $0.92,0.03$, and 0.11 for the years 2011, 2012, and 2013, respectively. For the latter region, only two data points for the year 2011 are missing. We apply Kalman filters to impute the missing wind generation values. This approach often produces the best results when one deals with longer and more complex time series with trend and seasonality (Moritz and Bartz-Beielstein, 2017).
} 

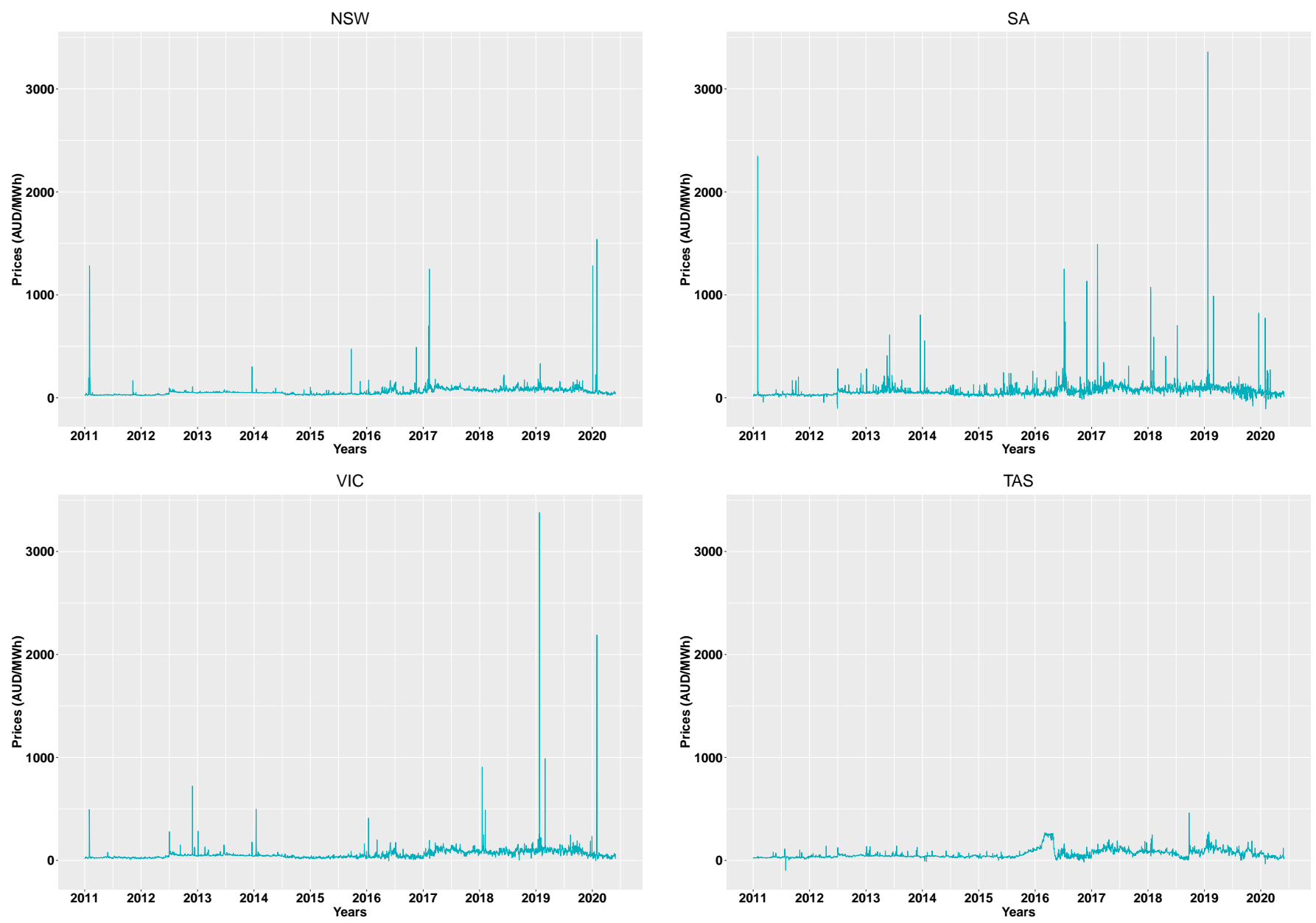

Figure 1: The equally weighted daily average spot price (regional reference price (RRP)) for NSW, SA, VIC, and TAS from January 1, 2011, to May 31, 2020. The RRP is estimated on a half-hour basis by averaging six dispatch electricity prices.

the second half of 2019 (see Figure 3), electricity prices have trended lower due to a combination of lower gas prices, decreasing consumption, and the influx of large-scale solar and wind generation as depicted in Figure 2a. ${ }^{6}$ The uptake of rooftop solar PV generation contributed significantly to reducing consumption by meeting more than $5.5 \%$ of Australia's energy demand. ${ }^{7}$ In the last three months of the sample period, the implementation of tighter pandemic restrictions due to COVID-19 may have accelerated the reduction in electricity consumption. Therefore, we examine the impact of wind generation on electricity prices and volatility dynamics while controlling for electricity consumption and gas prices.

Wind penetration is computed as the ratio between wind generation and consumption, and

\footnotetext{
${ }^{6}$ Detailed analysis of the price dynamics and its determinants during this period can be found in AEMO (2019b), AEMO (2020e), and AER (2020b).

${ }^{7}$ Australia is a global leader in solar PV generation, originating mainly from household rooftop installations. However, electricity generated from rooftop installations is not traded through the NEM. Given further that we estimate electricity consumption from grid demand (demand net of rooftop solar PV output), assessing the impact of rooftop solar generation on prices is beyond the scope of this study.
} 


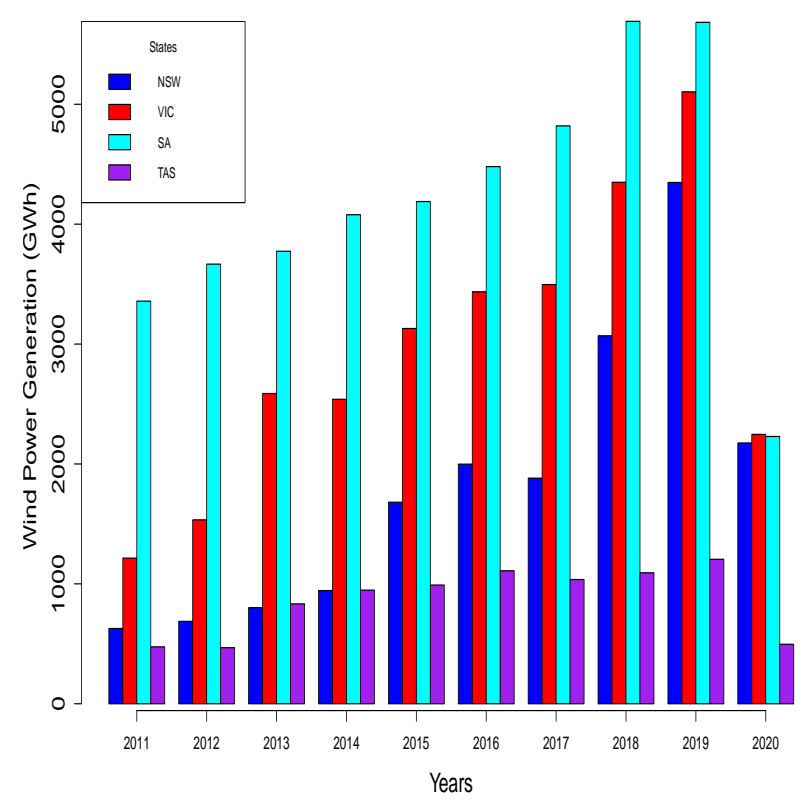

(a) Wind generation

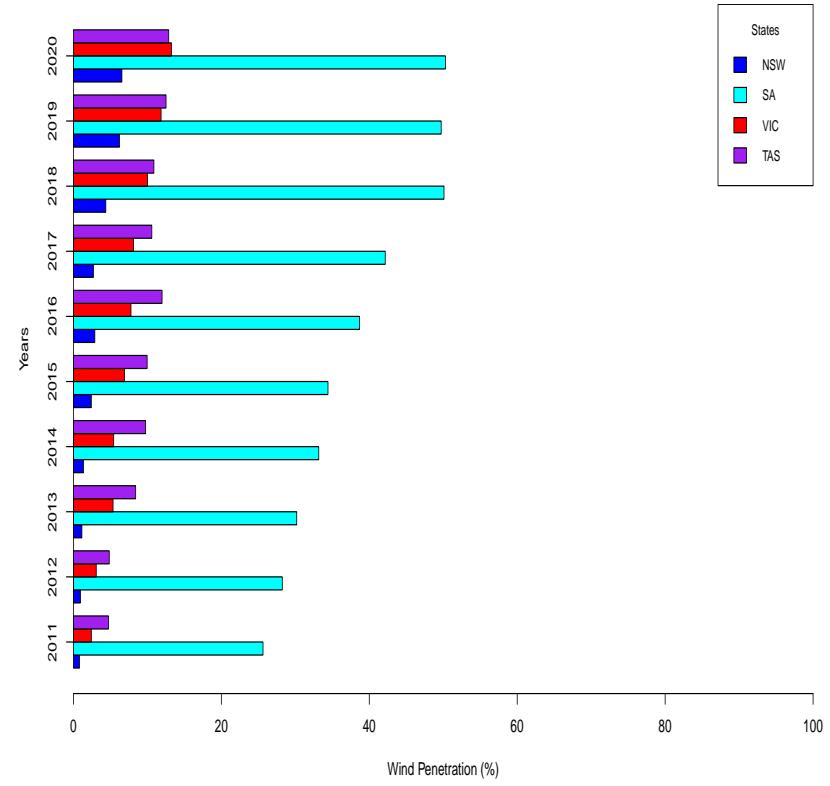

(b) Wind penetration

Figure 2: Large-scale wind generation (left panel) and wind penetration (right panel) for NSW, SA, VIC, and TAS, from 2011 to 2020. The year 2020 covers the sample period from January 1, 2020, to May 31, 2020 .

captures the correlation between the two variables. ${ }^{8}$ The same amount of wind generation could have a different impact on prices depending on the consumption levels over different times during the day. Wind penetration encompasses these effects and entails better predictions for price equilibrium. Figure $2 \mathrm{a}$ and $2 \mathrm{~b}$ show the significant increase in wind generation and penetration from 2011 to 2019. This increase varies significantly between states. SA is the leader in the uptake of wind energy. Its penetration was approximately $50.1 \%$ in 2018 and $49.7 \%$ in 2019, which are the highest levels across the NEM and the second highest worldwide following Denmark. The drop in penetration between 2018 and 2019 reflects increasing instances of wind curtailment/spilling in 2019.

In addition to these variables, we control for cross-border interconnector flow and hydro generation. The interconnectors allow for inter-regional trade, up to their physical capacity limits (see Table 9 in Appendix A) and electricity price variations among the regional markets (Brinsmead et al., 2014). There are six interconnectors, namely, Terranora (NSW-QLD), Queensland to New South Wales (QNI), Victoria to New South Wales (VNI), Basslink (T-V-MNSP1), Heywood

\footnotetext{
${ }^{8}$ Denoting the wind penetration by $w_{p}$, then if $w_{p}<1$, it implies that wind generation meets only a proportion of consumption, and $w_{p}=1$ indicates that wind generation meets the entire electricity consumption. If wind generation exceeds electricity consumption, then $w_{p}>1$. Generally, the higher the wind penetration, the higher the negative impact on the level of electricity prices. This stems from the fact that the inverse of consumption and wind generation are negatively correlated with prices.
} 


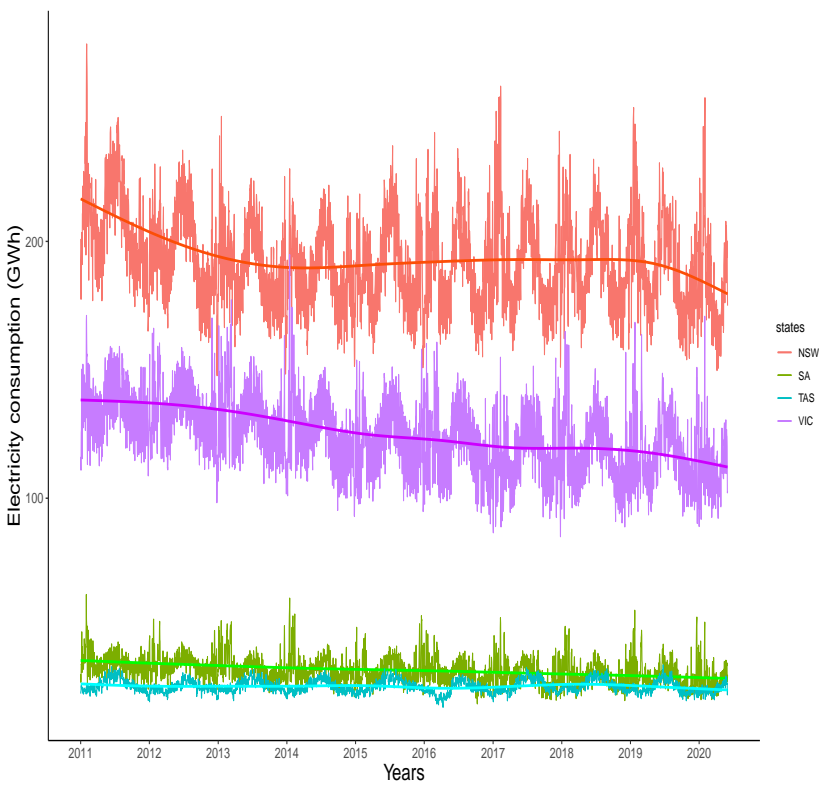

(a) Consumption

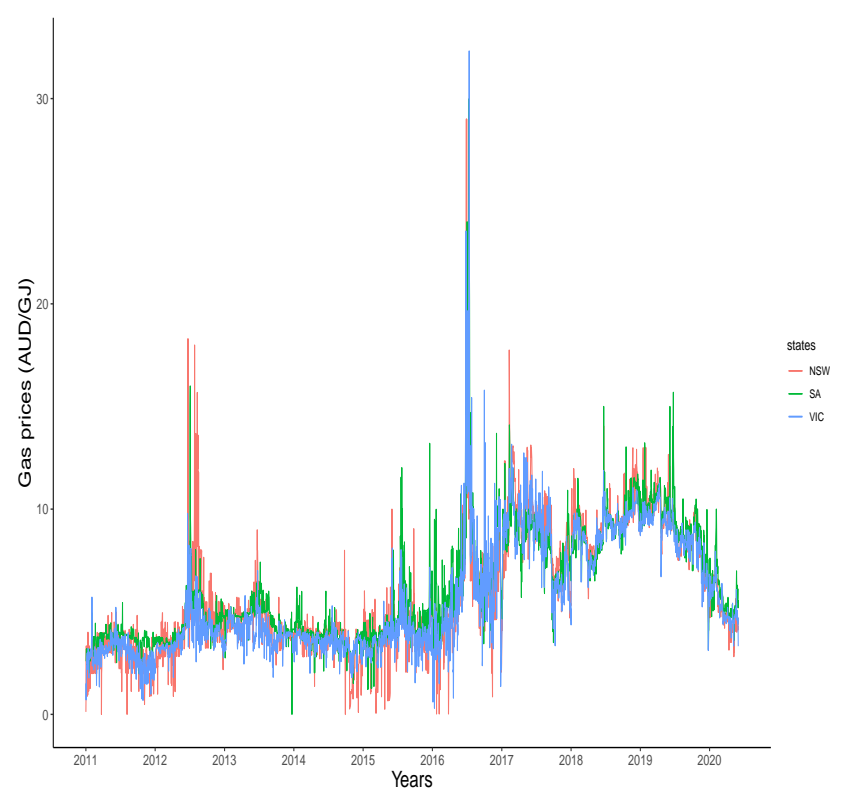

(b) Gas prices

Figure 3: The daily electricity consumption and gas for NSW, SA, VIC, and TAS from January 1, 2011, to May 31, 2020. The daily electricity consumption and daily gas prices are depicted in the left and right graphs, respectively.

(VIC-SA), and Murraylink (VIC-SA). The flow in these interconnectors can either be in a forward (export) or backward (import) direction. Evidence suggests that the interconnectors are among the essential determinants of price volatility in the NEM (Yan and Trück, 2020). This interrelationship was well-established by Han et al. (2020), who found volatility spillovers were more pronounced between adjoining and physically connected markets and less marked between geographically distant and unconnected markets. ${ }^{9}$ Rai and Nunn (2020) noted further that through the interconnectors, demand and supply between states with imperfectly correlated demand are equalized and thus, reduce price volatility. Figure 4 shows that NSW is a net importer of electricity from VIC and QLD. VIC experienced a significant drop in exports to NSW and SA in 2017 following the closure of the Hazelwood power station. ${ }^{10}$ We expect to observe varying impact of the interconnectors on prices depending on whether a state is an exporter or importer, and the capacity limit. Moreover, hydro generation influenced electricity price behavior in the NEM. The increase in prices observed in 2015-16 resulted from extended drought conditions, which depleted dam levels for hydro generation (see Figure 6 in Appendix A) (AER, 2015). The interrelation between carbon pricing and hydro generation is also of interest. Between 2012 and 2014, the noticeable upsurge and price plunge resulted from the introduction and repeal of carbon pricing (O'Gorman and Jotzo, 2014). The introduction triggered the competitiveness of hydro generators

\footnotetext{
${ }^{9}$ The most pronounced volatility spillover is observed between NSW and QLD, SA and VIC, NSW and VIC, and TAS and VIC. The spillover is less pronounced between SA and QLD, and TAS and QLD.

${ }^{10}$ The closure of the Hazelwood power station caused a decrease of around 5\% in the NEM's capacity (Burke et al., 2019; Mountain and Percy, 2019)
} 


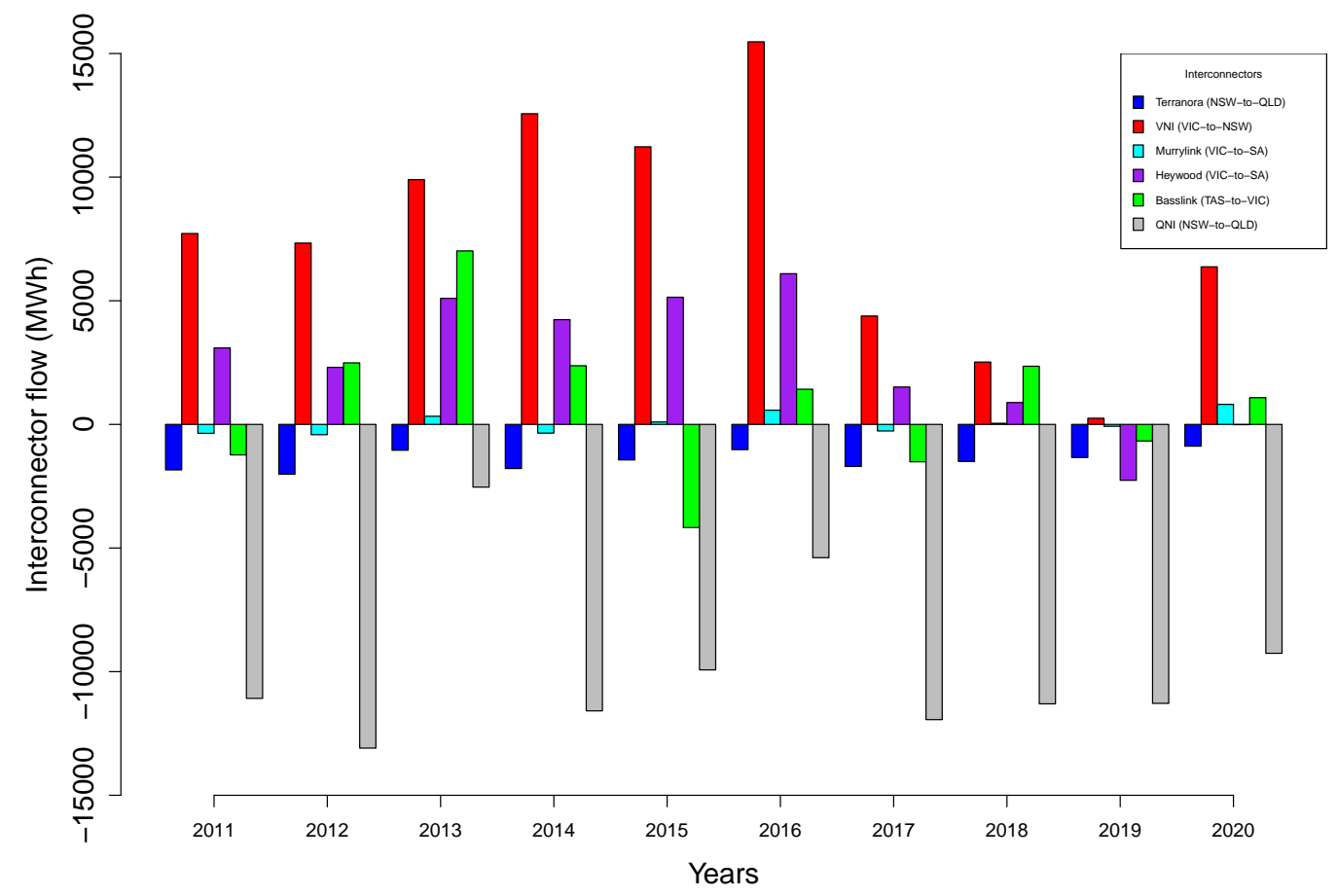

Figure 4: The average annual net interconnector flow for NSW, SA, VIC, and TAS. The year 2020 covers the sample period from January 1, 2020, to May 31, 2020. The positive sign indicates a forward flow (export to), and the negative sign indicates a backward flow (import from).

and contributed an approximate 36\% output rise in the NEM during 2012-13. This effect is evident in Figure 4 by the increase in exports from TAS to VIC from increased hydro generation. To the best of our knowledge, the impact of hydro generation and interconnectors in the NEM have not been studied previously despite being important determinants of price dynamics.

We include these variables in the analysis to ensure the estimated model does not suffer from endogeneity issues (Forrest and MacGill, 2013; Csereklyei et al., 2019). ${ }^{11}$ Negative prices in all four regions under study are stipulated mainly by wind generation, especially in SA (AER, 2020b). In QLD, negative prices arise from solar generation. As wind generation in QLD is marginal, we do not consider QLD. ${ }^{12}$ Genoese et al. (2010) showed that wind generation is the dominant factor for negative prices during off-peak periods (driven by low system load and low wind generation or low system load and high wind generation). Maciejowska (2020) also suggested that negative prices in Germany are due to wind generation only (not solar); corresponds to when demand is low,

\footnotetext{
${ }^{11}$ Large-scale solar generation represents the potential for omitted variable bias. It is excluded from the analysis, however, because data are available for only a few years (around five years for NSW, two years for VIC and SA, and none for TAS), and much of the impact is likely to emanate from rooftop solar PV for which data are harder to acquire. Rooftop solar generation meets around $20 \%$ of customers' needs and supplied around $5.2 \%$ (compare to $2.5 \%$ from solar farms) of the NEM's total electricity requirements in 2019 (AER, 2020b).

${ }^{12}$ The impact of solar generation is examined indirectly via the Terranora interconnector and the QNI. It is likely that part of the imports from QLD to NSW come from solar generation which tends to peak during the day.
} 
Table 1: Summary statistics of daily data (aggregated from high-frequency data) from January 1, 2011, to May 31, 2020.

\begin{tabular}{|c|c|c|c|c|c|c|c|c|c|c|}
\hline & Unit & Mean & Standard Dev & Skewness & Kurtosis & Median & Minimum & Maximum & $1^{\text {st }}$ Quartile & $3^{\text {rd }}$ Quartile \\
\hline & & \multicolumn{9}{|c|}{ NSW } \\
\hline Electricity Prices & AUD/MWh & 60.29 & 58.31 & 15.71 & 334.19 & 51.60 & 18.54 & 1539.50 & 35.77 & 74.30 \\
\hline Gas Prices & AUD/GJ & 5.89 & 2.93 & 0.90 & 5.25 & 4.96 & 0.00 & 29.00 & 3.70 & 8.35 \\
\hline Wind Generation & MWh & 5214.39 & 4964.22 & 1.56 & 5.63 & 3528.29 & -1.54 & 29825.40 & 1524.28 & 7448.58 \\
\hline Hydro Generation & MWh & 6515.69 & 4681.00 & 1.08 & 4.06 & 5349.38 & -0.27 & 29509.67 & 2833.44 & 9246.30 \\
\hline \multirow[t]{2}{*}{ Electricity Consumption } & MWh & 193819.00 & 18360.32 & 0.37 & 3.19 & 192326.00 & 147701.00 & 276893.00 & 181415.00 & 205921.00 \\
\hline & & \multicolumn{9}{|c|}{ SA } \\
\hline Electricity Prices & AUD/MWh & 69.85 & 99.64 & 17.41 & 460.48 & 54.36 & -107.16 & 3359.82 & 35.30 & 3359.82 \\
\hline Gas Prices & AUD/GJ & 6.16 & 2.67 & 1.17 & 6.28 & 5.15 & 0.00 & 29.99 & 3.95 & 8.38 \\
\hline Wind Generation & MWh & 12259.89 & 7343.318 & 0.73 & 2.80 & 10653.94 & 57.68 & 34363.58 & 6530.24 & 16956.66 \\
\hline \multirow[t]{2}{*}{ Electricity Consumption } & MWh & 33079.00 & 5372.77 & 0.79 & 4.50 & 32617.00 & 19907.00 & 62493.00 & 29377.00 & 36107.00 \\
\hline & & \multicolumn{9}{|c|}{ VIC } \\
\hline Electricity Prices & AUD/MWh & 60.24 & 82.23 & 25.68 & 915.22 & 47.96 & -6.35 & 3377.97 & 31.645 & 76.388 \\
\hline Gas Prices & AUD/GJ & 5.64 & 2.88 & 1.38 & 10.29 & 4.5 & 0.00 & 44.86 & 3.52 & 8.12 \\
\hline Wind Generation & MWh & 8647.77 & 6783.99 & 1.19 & 3.99 & 6597.15 & 30.54 & 35916.26 & 3467.95 & 12334.22 \\
\hline Hydro Generation & MWh & 7240.65 & 5338.39 & 0.92 & 3.18 & 5892.44 & -7.96 & 28751.15 & 2913.00 & 10515.92 \\
\hline \multirow[t]{2}{*}{ Electricity Consumption } & MWh & 125578.00 & 15168.02 & 0.11 & 2.81 & 125616.00 & 85021.00 & 194849.00 & 114356.00 & 136511.00 \\
\hline & & \multicolumn{9}{|c|}{ TAS } \\
\hline Electricity Prices & AUD/MWh & 61.79 & 43.22 & 2.25 & 10.70 & 44.97 & -94.67 & 461.64 & 34.78 & 82.02 \\
\hline Wind Generation & MWh & 2524.43 & 1764.81 & 0.71 & 2.55 & 2127.88 & -14.85 & 7436.14 & 1116.11 & 3686.50 \\
\hline Hydro Generation & MWh & 25429.00 & 8362.80 & -0.02 & 2.05 & 25565.00 & 5820.00 & 45120.00 & 18502.00 & 32332.00 \\
\hline Electricity Consumption & MWh & 26758.00 & 2471.89 & 0.35 & 2.79 & 26425.00 & 18558.00 & 35097.00 & 25001.00 & 28433.00 \\
\hline & & \multicolumn{9}{|c|}{ Interconnector Flow } \\
\hline Terranora (NSW-QLD) & MWh & -1491.50 & 716.83 & -0.13 & 2.94 & -1477.50 & -3852.80 & 926.10 & -1981.20 & -991.50 \\
\hline QNI (NSW-QLD) & MWh & -9769.00 & 6920.51 & 0.04 & 2.27 & -9604.00 & -25216.00 & 8617.00 & -15178.00 & -4694.00 \\
\hline VNI (VIC-NSW) & MWh & 7863.30 & 9079.41 & -0.04 & 2.27 & 8102.40 & -15983.40 & 30337.50 & 896.30 & 14764.40 \\
\hline Basslink (T-V-MNSP1) & MWh & 904.50 & 6466.18 & -0.19 & 2.09 & 390.50 & -11472.00 & 14149.30 & -3631.50 & 6404.10 \\
\hline Heywood (VIC-SA) & MWh & 2772.90 & 4868.45 & -0.30 & 2.58 & 3038.00 & -11668.90 & 14142.20 & -562.10 & 6474.40 \\
\hline Murraylink (VIC-SA) & MWh & -9.47 & 1173.49 & 0.57 & 4.31 & -77.71 & -3611.30 & 5040.13 & -720.07 & 573.44 \\
\hline
\end{tabular}

The summary statistics of wind generation, hydro generation, electricity consumption, and interconnector flow are estimated by aggregating the 5 -minute data series in megawatts divided by 12 . The rationale behind this approach is to convert the given data series, which relates to power, into energy in megawatt hours. The summary statistics for the electricity prices are estimated from the daily averaged spot price or the regional reference price (RRP). The letters $\mathrm{T}$ and $\mathrm{V}$ in the interconnector flow stand for Tasmania and Victoria, respectively. The acronym MNSP stands for market network service provider, i.e., merchant or economically unregulated.

typically on weekends or public holidays. Furthermore, negative prices in Europe occur at night when wind generation is occasionally high (Paraschiv et al., 2014; Deschatre and Veraart, 2017). Thus, based on the available empirical evidence, we exclude large-scale solar from the analysis for two main reasons. First, we exclude QLD, and second, large-scale solar penetration in other NEM regions historically has been very low. We expect the omission of large-scale solar to have only a modest impact on the analysis. We recognize that coal prices can also affect the level and volatility of electricity prices because coal generators set electricity prices $50 \%$ to $60 \%$ of the time, even in SA (AER, 2020a). The importance of coal as a price-setter in non-coal dominant regions, such as SA, reflects the market's inter-connectedness, and thus, the impact of coal prices in NSW or VIC can be felt in neighboring NEM regions. However, we omitted coal prices from the analysis for the following three reasons. 
First, coal prices are unavailable at the same time-frequency as our model (i.e., daily). Second, there is a wide variation in coal generators' fuel prices. This price variation is not just due to brown versus black coal generators. There is also a significant variation in coal prices paid across black coal plants. For example, AEMO shows a coal price range of 1.2 AUD/GJ to 3.99 AUD/GJ across black coal plants for the financial year 2020. This price variation reflects different grades of black coal used across the black coal fleet. Furthermore, the variation reflects differing degrees of exposure to international export prices, due to legacy long-term black coal contracts and differing degrees of exposure to spot versus forward export prices. For instance, NSW black coal generators obtain their coal at a discount through a long-standing contract, most of which will expire by 2022 to 2025 (ABC, 2018). Thus, there is no single black coal price within a particular region (AEMO, 2020b). Third, gas prices are the de facto electricity price-setter even when gas plants are not running, due to instances of black coal generators "shadow pricing" gas in their spot market offers (i.e., black coal plant offering their capacity at prices just below the short-run marginal cost (SRMC) of the gas plant) (AEMO, 2018). This means that excluding coal prices is unlikely to have a severe impact on this analysis, as electricity spot prices are based on the bids of generators, which as the "shadow pricing" dynamic illustrates, can be, and often are, above generators' SRMCs.

The descriptive statistics of electricity prices and exogenous variables considered in this analysis, namely, electricity consumption, wind generation, gas prices, hydro generation, and interconnector flows, are summarized in Table 1 . We observe a considerable variation in the level and volatility of electricity prices in all the markets. During the sample period, NSW is a net importer of electricity. This is consistent for all three interconnectors, that is, Terranora, QNI, and VNI. VIC is a net exporter of electricity to NSW and SA, through the VNI, and Heywood, interconnectors, respectively. However, VIC imports only $9 \%$ of the total exports from SA and TAS via the Murraylink and Basslink interconnector.

Figure 1 illustrates that extreme price spikes characterize the Australian electricity market. It is common in merit order effect studies to treat these observations as outliers (Cutler et al., 2011; Forrest and MacGill, 2013; Cludius et al., 2014b) and truncate prices series based on the marginal costs of generation. ${ }^{13}$ We do not truncate the series and include all the observations to capture the volatility of prices more effectively. ${ }^{14}$ Furthermore, we apply a two-stage method similar to

\footnotetext{
${ }^{13}$ The rationale behind this approach is that the truncated series represents the typical conditions of the market rather than times when the market is operating under extreme conditions. Factors such as capacity-limited generation, low renewable output, technical limits on the interconnectors, the restriction on the import capacities, as well as an unexpected and substantial change in demand are among the factors accounting for this market extremity (Geman and Roncoroni, 2006; Weron, 2007; Ward et al., 2019; Yan and Trück, 2020).

${ }^{14}$ We find a slight difference between the actual price series and the one obtained by top capping prices at 500 AUD/MWh, which is the highest short-run marginal costs of generation in the NEM. Only 20, 8 , and 6 observations in SA, VIC, and NSW exceed this threshold. As a robustness check, however, we run a separate analysis and treat price spikes as outliers (Ruiz et al., 2001; Mugele et al., 2005; Bierbrauer et al., 2007; Ketterer, 2014). The technical details of the approach employed for this adjustment are given in section A.2 of Appendix A. We will present the results of this approach and show how the two treatments of price spikes affect the empirical analysis.
} 
those of Thomas and Mitchell (2005) and Ketterer (2014) and adjust the seasonal and trend effect using ordinary least squares (OLS) before fitting the proposed models. ${ }^{15}$ The filtered series is a more robust explanator of the impact of the exogenous variables on electricity prices without the noise emerging from seasonality and trends. The approach, results, and statistical tests of the time series adjusted for the seasonal and trend effect for all the variables are presented in sections A.3 and A.4 in Appendix A.

\subsection{Negative prices in the NEM}

Negative prices may occur when periods of relatively low demand coincide with a high supply of and restrictions on inter-regional power flows (Forrest and MacGill, 2013; AEMO, 2019a). Before 2012-13, negative prices occurred overnight or in the early hours of the morning, due to low demand combined with the inflexibility of brown-coal electricity generation. Recently, negative prices have been observed during the middle parts of the day when generators, including intermittent renewable energy and coal-fired generators, compete to dispatch their energy. The system operator (AEMO) ensures the expected demand for electricity is met in the most cost-efficient way using an algorithm that dispatches generators from the cheapest to the most expensive. As the former sources have zero marginal cost, they are prioritized in the dispatch process. This, in turn, reduces demand for thermal generators and forces the plant back to its minimum stable generation level. The intermittent nature of solar PV generation, for instance, means that it cannot meet peak demand in the late afternoon and evening when solar radiation is low or not available. This calls for the supply from base-load generators and from more flexible sources (i.e., open-cycle gas turbines (OCGTs), combined cycle gas turbines (CCGTs), and hydro). Base-loads have low operating costs with high start-up and shutdown costs, making frequent shutdowns uneconomical to meet the variable demand. To guarantee dispatch and keep the plant running, coal-fired generators typically bid their minimum stable megawatts at the floor price.

As noted above, negative prices are an important feature of the electricity market in Australia. Over the 2011-2020 period, SA was the first state to experience negative prices when low demand coincided with high wind generation (see Figure 1). The current minimum price (market price floor) in the NEM is set at $-1,000$ AUD/MWh. During negative price periods, wind typically drives negative prices in SA, while brown coal is typically pushed down by wind in VIC. The 5-minute negative dispatch periods increased significantly between July and November in 2019 for SA and VIC, reaching more than 600 in October 2019 and February 2020 (Cornwall Insight, 2020). Storage technologies, such as pumped hydro and battery storage, capitalize on low price periods.

\footnotetext{
${ }^{15}$ Our approach differs from that of Ketterer (2014) in two ways. First, the seasonal noises are removed in the independent and dependent variables, which is more econometrically sounding. Second, we adjust for the trend effect in all variables and on either side of the equation.
} 
These low or negative price periods occur more regularly and last longer, e.g., on July 21, 2019, the spot prices in SA remained in negative territory for 4.5 hours and in VIC for 1.5 hours. ${ }^{16}$

The treatment of negative prices varies. Many researchers either truncate prices series (Cutler et al., 2011; Forrest and MacGill, 2013; Cludius et al., 2014b) or simply remove them from the analysis (Rintamäki et al., 2017). ${ }^{17}$ Given the increasing frequency of negative price periods and a desire to more accurately capture NEM dynamics, we contend that it is important to include them in any analysis. ${ }^{18}$ Similar to Kyritsis et al. (2017) and Thomas et al. (2011), we find these values are valid observations, and ultimately, their inclusion will shed more light on the empirical analysis. We further observe a clear link between wind generation and negative prices. In particular, SA and TAS, with higher wind penetrations, exhibit more incidents of negative prices compared to states with lower wind penetration, such as VIC. We observed zero negatives price cases in NSW, the state with the lowest wind penetration. The absence of negative prices in NSW may also be due to the relative flexibility of the region's thermal plants and lower minimum stable generation levels.

\subsection{Modeling level and volatility of electricity prices}

We model the effects of various exogenous variables, such as wind generation and consumption, on the level and volatility of electricity prices, using an ARX-eGARCHX ${ }^{19}$ model specification:

\footnotetext{
${ }^{16}$ This event occurred at 1:15 pm on Sunday, July 21, 2019, when low demand coincided with high generation from wind and solar and unrestricted transfer of electricity across the interconnectors.

${ }^{17}$ This approach eases the application of the log transformation, which, in turn, stabilizes the variance and simplifies the interpretation of the estimated coefficients as elasticity (Weron, 2007; Ketterer, 2014; Rintamäki et al., 2017).

${ }^{18}$ We initially attempted to employ an alternative transformation that allows one to retain zero-value and nonpositive observations while maintaining an approximate interpretation of the model results as elasticity and stabilizes the variance, in particular, the approach based on the inverse hyperbolic sine transformation (Burbidge et al., 1988; Schneider, 2011; Uniejewski et al., 2017; Ziel and Weron, 2018). However, the direct application of this approach suppresses the upward spikes at the cost of amplifying the downward spikes (Schneider, 2011). By doing so, the resulting transformations fail to preserve the characteristics of the original time series. Although the transformation proposed by Schneider (2011) resolved this challenge, its application to the variables of interest complicates the interpretation of the model output.

${ }^{19} \mathrm{Few}$ researchers on the subject have been able to investigate the impact on price behaviors as an integrated study. For instance, Woo et al. (2011) and Ketterer (2014) applied the AR-GARCH, Kyritsis et al. (2017) applied the GARCH-in-mean models, and Maciejowska (2020) applied the quantile regression model. Furthermore, previous volatility studies in the NEM found that the GARCH specification does not adequately accommodate the skewed and fat-tailed characteristics of electricity prices. In particular, Higgs and Worthington (2005) and Thomas and Mitchell (2005) found the skewed Student asymmetric power ARCH (APARCH) and eGARCH, respectively, to be the appropriate choices.
} 
$P_{t}=\mu+\sum_{i=1}^{m} \phi_{i} P_{t-i}+\sum_{j=1}^{n} \xi_{j}^{\prime} \boldsymbol{v}_{t-j}+\epsilon_{t}$,
$\epsilon_{t}=z_{t} \sigma_{t} \quad$ with $\log _{e}\left(\sigma_{t}^{2}\right)=\omega+\sum_{i=1}^{p}\left(\alpha_{i} z_{t-i}+\gamma_{i}\left(\left|z_{t-i}\right|-\mathbb{E}\left|z_{t-i}\right|\right)\right)+\sum_{j=1}^{q} \beta_{j} \log _{e}\left(\sigma_{t-j}^{2}\right)+\sum_{k=1}^{r} \delta_{k}^{\prime} \boldsymbol{v}_{t-k}$,

where equation (1) is the autoregressive (AR) structure of the conditional expectation, and equation (2) is the eGARCH model of the conditional variance with exogenous variables. ${ }^{20} P_{t-i}$, $i=1, \ldots, k$, are lags of the electricity prices, $\boldsymbol{v}_{t}$ is an $m \times 1$ vector of variables, and $\xi$ and $\delta$ are the $m \times 1$ vector of positive coefficients. $\sigma_{t}$ represents a time-dependent standard deviation, $\omega$ is the intercept, and the parameters $\alpha_{i}$ and $\gamma_{j}$ capture the sign and size effect of the standardized innovations on volatility. The expected value of the absolute standardized innovation is defined as $\mathbb{E}\left[z_{t}\right]=\int_{-\infty}^{\infty}|z| f(z, 0,1, \ldots) d z$, and volatility persistence is given by $\sum_{j=1}^{q} \beta_{j}$ (Ghalanos, 2020). The autoregressive term is included to capture the serial correlation in prices; where applicable, the order is chosen to minimize the Bayesian information criterion (BIC).

Compared to vanilla GARCH, the eGARCH model considers the variance of $\log _{e}\left(\sigma_{t}^{2}\right)$, which guarantees that the conditional variance is positive regardless of the estimated coefficient values (Zivot, 2009). With no restrictions in the model, likelihood maximization tends to yield faster and more reliable optimizations results. Furthermore, electricity prices are characterized by some forms of non-linear dynamics, exhibiting strong dependence on price variability on its past (Weron, 2007). Using the eGARCH model, which accounts for heteroskedasticity, provides a more accurate tool of the heteroskedasticity in the errors and in turn, an efficient estimator of the coefficients in the equation. The proposed eGARCH model is also used to examine the sign effect in the electricity market. ${ }^{21}$ In contrast, autoregressive moving average (ARMA)-type models, such as that of Rintamäki et al. (2017), are limited by the constant variance assumption, which is inconsistent with volatility dynamics observed in electricity markets.

\section{Wind generation and electricity dynamics in the NEM}

We estimate separate regressions of the AR-eGARCH and ARX-eGARCHX specifications using a single autoregressive component and the Student distribution of the standardized residuals for each state. The technical details regarding the optimal ARMA structure and the distribution of

\footnotetext{
${ }^{20}$ The eGARCH model is the modification of the standard GARCH model proposed by Nelson (1991) which allows for the leverage effect to better capture temporal variations in market volatility.

${ }^{21}$ Empirical studies in financial time series often find evidence that negative shocks tend to have a more substantial impact on volatility than positive shocks of the same magnitude (Zivot, 2009).
} 
the standardized residuals are given in Appendix B. Tables 2 to 5 present the regression estimates for the four states, namely, NSW, SA, VIC, and TAS, respectively. ${ }^{22}$

\subsection{Effects on the level of electricity prices}

All coefficients for wind generation for all four states are consistently negative and statistically significant even after controlling for consumption, gas prices, hydro generation, and the interconnectors flow (see the top panel of Tables 2-5). These results confirm the merit order effect of wind generation. We observe a considerable reduction in SA where an increase in daily wind generation by 1 GWh per day reduces prices by approximately 1.3 AUD/MWh, followed by TAS (0.6 AUD/MWh), VIC (0.6 AUD/MWh), and NSW (0.5 AUD/MWh). The pronounced effect in SA, the second in the world in wind generation, underscores the role wind generation plays in reducing electricity prices (Forrest and MacGill, 2013; Cludius et al., 2014a; Bell et al., 2017). According to AER (2018), in 2018 wind generation met about $40 \%$ of SA's electricity requirements. The fact that wind generation continues during periods of low electricity demand is also likely to account for the substantial reduction in the region's electricity prices (Bell et al., 2015). Csereklyei et al. (2019) observed a similar effect in the Australian market with the daily merit order of wind turbines, being statistically significantly larger in SA and lower in VIC with no firm evidence in NSW. Numerically, our estimated coefficients exceed the daily merit order from this study by 0.3 AUD/MWh for NSW and VIC, and by 0.4 AUD/MWh for SA. We account for the difference in the magnitude and statistically significance of our results to the sample period under the analysis and the fact that our model includes the interconnectors and hydro generation.

We reassert that electricity prices increase with consumption (Forrest and MacGill, 2013; Ketterer, 2014; Clò et al., 2015; Csereklyei et al., 2019). We observe a stronger impact in states with lower consumption profiles (SA and TAS) and less impact in states with larger consumption profiles (NSW and VIC). On this basis, we find compelling evidence that an increase in daily electricity consumption by 1 GWh per day in Model I increases prices in NSW and VIC by approximately 0.2 AUD/MWh. SA and TAS, states with lower demand profiles, experience approximately nine- and five-time increases, respectively. Similar to electricity consumption, gas prices have a positive and statistically significant effect on electricity prices in the NEM. We observe from Models I and J

\footnotetext{
${ }^{22}$ Each table shows the estimated coefficients and the corresponding $p$ values (in parentheses) for the mean and variance equations, the estimated shape parameters of the Student distribution, Akaike information criterion (AIC), and the BIC. We investigate the adequacy of the model fit using the weighted Ljung-Box test and the weighted Lagrange multiplier test (ARCH-LM tests) (Fisher and Gallagher, 2012). The former is the portmanteau test with the null of adequate ARMA fit, and the latter adequately fitted the ARCH process (Ghalanos, 2020). Overall, the weighted Ljung-Box test and the weighted ARCH-LM test suggested that there is no evidence of remaining autocorrelation and ARCH effects. We also inspect the autocorrelation function (ACF) and partial autocorrelation (PACF) of the standardized residuals and the squared standardized residuals, which suggests little autocorrelation and the absence of a particular pattern due to a non-stationary or seasonal time series. We run the empirical analysis using the rugarch package in the R programming language (R Core Team, 2019; Ghalanos, 2020)
} 
that increasing the daily gas price by $1 \mathrm{AUD} / \mathrm{GJ}$ raises electricity prices in the range 6 AUD/MWh to $7 \mathrm{AUD} / \mathrm{MWh}$ for SA. We find less evidence to support the positive effect in NSW. SA is the state most affected by gas prices, exceeding VIC by approximately 5 AUD/MWh to 6 AUD/MWh as SA relies more on gas-powered generation than any other region across the NEM. ${ }^{23}$ Between 2014 and 2018, Australia witnessed a threefold increase in gas prices (see Figure 3b), which had a notable impact on electricity prices. The lower magnitude compared to the estimated coefficients in Csereklyei et al. (2019) may be explained by several factors, in particular the significant decrease in gas prices after 2019 onward and the displacement of gas output due to marked investment in renewable energy generation.

The impact of hydro generation on electricity prices is consistently positive and statistically significant. This impact is substantial in NSW and VIC, where an increase in hydro generation of $1 \mathrm{GWh}$ per day drives up the prices by approximately 0.4 AUD/MWh to 0.7 AUD/MWh. We account for this effect by the reduced availability of lower-priced hydro generation due to persistent drought periods (Csereklyei et al., 2019). The operation of hydropower is primarily limited by the availability of water, which tends to raise the effective price of the service (HT, 2019).

The cross-border interconnectors flow exhibits a differential effect on the level of electricity prices across the NEM. Our analysis in Models I and J assumes that the two models have limited omitted variable bias. We find statistical evidence that the Terranora, QNI, and VNI reduced the price of electricity in NSW. Interestingly, the Terranora interconnector exhibits a substantial price reduction despite its lower nominal capacity. This may be because NSW traditionally is a net importer of electricity across the NEM due to the relatively high cost of fuel. VIC exports to NSW have been higher and frequent compared to NSW exports to VIC, even after the closure of the Hazelwood power station (Mountain and Percy, 2019). Moreover, QNI and VNI have higher nominal capacities compared to other interconnectors in the NEM. The fact that two interconnectors link NSW to QLD is an added advantage. QLD has been a net electricity exporter in the NEM due to the state's surplus capacity and traditionally low fuel prices (AER, 2018). The exports from QLD to NSW doubled in the year after the Hazelwood power plant closed.

The Heywood and Murraylink interconnectors in SA significantly impact the level of electricity prices, with Murraylink having a positive effect and the Heywood interconnector having a negative impact. The Heywood interconnector has a relatively sizeable nominal capacity, which allows more cheap brown coal exports from VIC than Murraylink. SA has traditionally been an importer of electricity because the state lacks a low-cost local supply. The recent influx of wind generation,

\footnotetext{
${ }^{23}$ Gas generation is preferred in SA as it is a flexible source of energy and thus, is often employed as a supplement to the intermittent wind generation. According to AER (2018), about $56 \%$ of SA local generation in $2017-18$ was powered by gas. It is considered a transition fuel toward a lower carbon economy and accounted for more generation during the carbon pricing period from July 2012 to June 2014. However, this pace slowed following the abolition of carbon pricing in 2014, along with other factors, such as the lack of new gas supplies (AER, 2017).
} 
however, has made SA more self-sufficient. Generally, the effective trade between VIC and SA is limited by the low thermal capabilities of the Heywood and Murraylink interconnectors (Bell et al., 2015). We also observe that VIC, the most interconnected state in the region, experiences price reduction from the Heywood and VNI interconnectors. VIC traditionally has been a net exporter of electricity due to its low-cost brown coal generation. Nevertheless, the recent challenges associated with the closure of significant coal plants, such as the Hazelwood power station in March 2017, impacted VIC's position. Furthermore, the effect of the Basslink interconnector is positive and statistically significant for VIC and TAS. This reflects the changing position of both states during the sample period. The position of TAS tends to vary over time, depending on market conditions. During the carbon pricing period, the region was a net exporter of electricity. This position changed in late 2015 following the abolition of carbon pricing and the persistence of drought conditions. Favorable conditions such as the resumption of the Basslink interconnector to VIC and favorable conditions for hydroelectricity generation made the state a net exporter of electricity.

In summary, we find that beyond the customary factors of consumption and gas prices, hydro and interconnectors play an essential role in determining the merit order effect associated with wind generation in the NEM. We now analyze the impact of these factors on the volatility of electricity prices.

\subsection{Volatility dynamics}

The bottom panels of Tables 2-5 present the impact on the estimated variance equation. The first four rows capture the characteristics of NEM volatility dynamics.

The coefficients of the own-innovation or ARCH spillovers $(\gamma)$ and the lagged volatility or GARCH spillovers $(\beta)$ are large, relatively stable across the models, and statistically significant. The estimated innovation spillovers for NSW, SA, VIC, and TAS are 0.5875, 0.5079, 0.4225, and 1.4055, respectively (see Model I). Therefore, the memory of previous surprises or innovation has a substantial impact on future volatility for TAS, NSW, and SA, and is slightly lower in VIC. Similarly, the last period's volatility shocks exhibit a considerable effect on its future electricity price volatility in TAS (0.8284). The impact is almost half this in other regions, i.e., VIC (0.4708), SA (0.4440), and NSW (0.3697). ${ }^{24}$ Considering Models I and J, we find the estimated innovation spillovers exceed the volatility spillovers in NSW only. The opposite effect is observed in VIC and TAS; the results for SA are inconclusive. The estimated innovation spillovers exceed those observed in the German market (Ketterer, 2014; Kyritsis et al., 2017). Kyritsis et al. (2017), for

\footnotetext{
${ }^{24}$ These results are generally in keeping with the previous study by Higgs and Worthington (2005), who found the ARCH and GARCH effects 0.4376 and 0.3677 for NSW, 0.2530 and 0.5422 for SA, and 0.5761 and 0.3057 for VIC, respectively. We attribute the difference between the estimated coefficients from this study to the difference in the sample period and the fact they applied the high-frequency data in the empirical analysis.
} 
instance reported innovation spillovers of 0.226 , while the estimated volatility spillover is closer to VIC and SA and is 0.447 . The sign effect parameter $\alpha$ is positive and statistically significant for NSW. This means positive shocks tend to exert more impact on electricity price volatility than negative shocks of the same magnitude. This provides evidence for the reverse leverage effect in the NEM. Knittel and Roberts (2005) noted that a positive shock to prices signifies an unexpected positive demand shock, which, given the convexity of the marginal cost, tends to exert more upward pressure on prices than the negative shocks. The present results corroborate the results of Higgs and Worthington (2005) and Thomas and Mitchell (2005). In addition to the Australian market, Knittel and Roberts (2005) found similar behavior for California electricity prices in the US. Contrary to these studies, however, we find the estimated coefficients for the other states are not statistically significant (at the 5\% level). Positive and negative shocks have marginal differential effects on price volatility in all of the Australian states except NSW.

\subsection{Effects on volatility of electricity prices}

In the second panel in Tables 2-5 (the fifth row), the impact of wind generation on electricity price volatility is presented. The estimated coefficients (Model I) are positive and statistically significant at the $1 \%$ and $10 \%$ levels for SA and VIC, respectively. The effect is more pronounced in SA, where a 1 GWh increase in daily wind generation amplifies daily price volatility by $2 \%$. The increase in VIC differs moderately and is $1 \%$ lower. In contrast, we find strong evidence for the opposite effect in TAS, with a 5\% decrease for each 1 GWh increase. NSW experiences a marginal and not statistically significant decrease in price volatility. SA is well-known for its relatively higher

and more volatile electricity prices compared to other markets in the NEM. The price volatility stems from the intermittent and uncertain nature of wind generation, which varies during the day and seasons of the year. VRE generation is typically negatively correlated with demand (Hirth, 2013; Rai and Nunn, 2020). Consequently, adding VRE to the generation mix makes it harder to equilibrate supply with demand and in turn, increases price volatility. Focusing on the European market, Rintamäki et al. (2017) found that wind power decreases daily electricity price volatility in Denmark but increases daily volatility in Germany (Ketterer, 2014; Kyritsis et al., 2017).

We find strong statistical evidence that electricity consumption increases price volatility in NSW, SA, and VIC. SA experiences a far higher impact, where a 1 GWh increase in daily electricity consumption increases the daily price volatility by $6 \%$. This increase is approximately three and six times the effect experienced in VIC and NSW, respectively. The impact of consumption in the smallest NEM market, TAS, is marginal and not statistically significant. The importance of gas in the SA generation mix is reflected in price volatility. We find strong statistical evidence that a 1 AUD/GJ increase in the daily gas price increases the daily price volatility by $11 \%$ in $\mathrm{SA}$ and marginally in NSW and VIC, i.e., around 6\%. The higher magnitude of volatility in SA follows 
its relatively higher reliance on gas-powered generation in the NEM. Contrasting with Denmark and Germany, gas prices seem to play a crucial role in influencing the volatility of electricity prices in Australia. Rintamäki et al. (2017) found no statistically significant effect of daily gas prices on the volatility of prices in Denmark and Germany. Our results demonstrate further that price volatility increases with hydro generation. A more substantial effect is apparent in regions where hydro generation accounts for a smaller proportion of the generation mix, namely, NSW and VIC. Although more than $80 \%$ of the electricity generation in TAS comes from hydro, we find no evidence of a positive impact on price volatility.

Similar to the mean equation, the interconnector's influence on the volatility of electricity prices is significant across the states. In NSW, we find strong evidence that the VNI interconnector contributes to increasing daily price volatility. In contrast, we find no evidence for a negative effect of the Terranora interconnector and the QNI. The Heywood and Murraylink interconnectors in SA appear to positively influence price volatility. Nevertheless, we find less evidence for the Murraylink interconnector. These results also suggest the impact on VIC moves in the opposite direction by reducing price volatility. We observe the same effect for the VNI interconnector, particularly in Model J. However, we find some evidence that the Heywood interconnector increases price volatility. Although the influence of the Basslink interconnector in VIC is not statistically significant, it appears to have a negative impact on price volatility in TAS. The effect observed for the VNI in NSW and the Heywood interconnector in SA may be linked to VIC having the highest net volatility spillover in the NEM (Han et al., 2020). The interconnectors joining VIC to other regions likely were greatly impacted by the closure of the Hazelwood power station in VIC. According to Cornwall Insight (2020), the closure of base-load coal generation has the potential to increase volatility to the same extent as renewable generation. Similarly, QLD and TAS have the lowest net volatility spillovers, which explain the lack of significance of the Terranora and QNI interconnectors in NSW and the Basslink interconnector in VIC.

We find evidence that the variability in consumption, fuel prices, interconnector flow, and wind generation output introduce volatility in NEM electricity prices. ${ }^{25}$ Higher volatility is associated with the high frequency of prices between 100 AUD/MWh to 500 AUD/MWh, rather than with more frequent extreme prices (Rai and Nunn, 2020). This range is above the market cap on prices typically excluded in studies after treatment for outliers. In Appendix C, we consider the $3 \times M A D$ adjustment for outliers excluding prices above around 150 AUD/MWh. We find no significant impact on the effect of wind generation on volatility in SA. This finding highlights the importance of considering the whole range of electricity prices, and it provides empirical evidence that the increased volatility is caused by the higher number of instances where prices fall within the $100 \mathrm{AUD} / \mathrm{MWh}$ to $500 \mathrm{AUD} / \mathrm{MWh}$ range.

\footnotetext{
${ }^{25}$ Other reasons include strategic bidding practices and plant ramping, which are beyond the scope of this study (Ward et al., 2019)
} 


\subsection{The role of wind penetration}

Different wind penetration levels have very different distributional properties, with reductions in mean prices and standard deviations expected as wind penetration increases (Jonsson et al., 2010). We undertake a similar preliminary analysis for all states by dividing the data into intervals based on wind penetration. The properties of the empirical price distributions are given in Table 8. It is apparent that prices decrease with wind penetration for NSW, VIC, and TAS. SA exhibits the same pattern for higher penetration levels. Nevertheless, we see no clear pattern in the standard deviation. Its magnitude, however, is relatively lower with higher levels of wind penetration.

The results summarized in Tables 2 to 5 concur with this analysis and suggest a consistent effect of wind penetration on the level of electricity prices across states. In particular, increasing wind penetration by $1 \%$ in Model J leads to a statistically significant reduction in the level of electricity prices by 0.9 AUD/MWh and 0.7 AUD/MWh in NSW and VIC, respectively. The magnitude of this reduction is relatively lower in SA and TAS, where the same increase in wind penetration reduces prices by $0.5 \mathrm{AUD} / \mathrm{MWh}$ and $0.3 \mathrm{AUD} / \mathrm{MWh}$, respectively. The impact of wind penetration on price volatility is not uniform across the states. In TAS, price volatility decreases by $1 \%$ for the same percentage increase in wind penetration. We observe a similar effect in SA (Model E). However, the coefficient becomes non-statistically significant after controlling for other explanatory variables in Model J. Based on this model, we find less evidence that increasing wind penetration by $1 \%$ in VIC increases price volatility by the same magnitude. The estimated effect in NSW is not statistically significant in either model.

We compare these results with the impact of wind generation in Model B, where SA experiences the largest price reduction and volatility, while the other states experience moderate reductions. However, after accounting for the effects of consumption (via the wind penetration measure), the increase in the proportion of consumption served by wind generation is associated with a higher statistically significant impact on electricity prices in NSW and VIC, and much lower in SA and TAS. An explanation is that NSW and VIC have $15 \%$ or lower wind penetration, while SA sits at around $50 \%$. This also explains why there is a positive impact on price volatility in VIC, whereas a higher level of wind penetration in TAS shows the opposite effect.

In the last decade, the NEM experienced substantial investment in renewable energy. In the next section, we investigate how the impact of wind penetration developed during this period. 


\subsection{The evolution of the impact of wind penetration}

To study the evolution of the impact of wind penetration, we construct a rolling regression with a three-year window. ${ }^{26}$ The results for the evolution of the impact of wind penetration in the mean and variance of the daily electricity prices are given in Figure 5. Note that the coefficients are re-estimated in windows moved forward one observation in time.

The negative impact of wind penetration is observed for all four states and trended higher over the years. The evolution is relatively stable for states with higher wind penetration and relatively unstable for states with lower penetration levels. According to Marshman et al. (2020), the size of the wind penetration coefficient depends on which generators are marginal at the times of wind output. For instance, if it is relatively high SRMC CCGTs, then the wind penetration coefficient will be high; if it is coal (especially brown coal), then the coefficient is lower. NSW and VIC experienced the highest electricity price reduction for a given increase in wind penetration over time. This impact is likely triggered by the large increase in wind installations enhanced by LRTE (Stocks et al., 2019) along with higher gas prices, which peaked in 2016, and the higher cost of hydro generation due to the persistent drought periods. The decrease in the magnitude, especially for NSW from late 2015 to late 2017, likely reflects a changing displacement effect, with CCGTs first displaced, moving the bid to black coal once gas generators have been fully displaced. The impact of moving the Hazelwood offline is evident in VIC by the reduction and swings in the MOE in early 2017 (Burke et al., 2019; Mountain and Percy, 2019). ${ }^{27}$ Similar reasons may account for the reduced MOE in SA from late 2015 to the end of 2017, specifically, the unexpected and sudden closure of Playford B (240 MWh) and Northern (546 MW) (Rai and Nunn, 2020). TAS is less affected by either factor due to the large proportion of renewables in the generation mix.

We observe a variation in price volatility over the years for NSW and VIC, with the lowest penetration levels. ${ }^{28}$ From mid-2017 onward, the increase in wind penetration is associated with a reduction in price volatility. This period coincided with the marked increase in investment in large-scale renewable energy between 2016 and 2019 (de Atholia et al., 2020). The same argument as in subsection 4.4 could explain this phenomenon; namely, price volatility tends to be lower for higher penetration levels. The pattern in SA, however, suggests that this is not always the case. In particular, the increase in wind penetration lowers price volatility to a specific level (in this case, around annual wind penetration of 50\%) and then regresses to the previous phenomena. One explanation is that incumbent thermal plants remain online up to a certain penetration rate

\footnotetext{
${ }^{26}$ We also estimated the coefficients using the four-year rolling window and obtained a similar impact of wind penetration over the years.

${ }^{27}$ According to AER (2018) during 2017-18, VIC recorded the highest average prices that were about $43 \%$ higher than the year earlier and 30\% higher than in any year since the NEM began.

${ }^{28}$ The $p$ values from Figure 14 in Appendix C indicate, however, the estimated coefficients for all states are generally not statistically significant, especially between 2016 and 2019, with the slight exception of SA.
} 

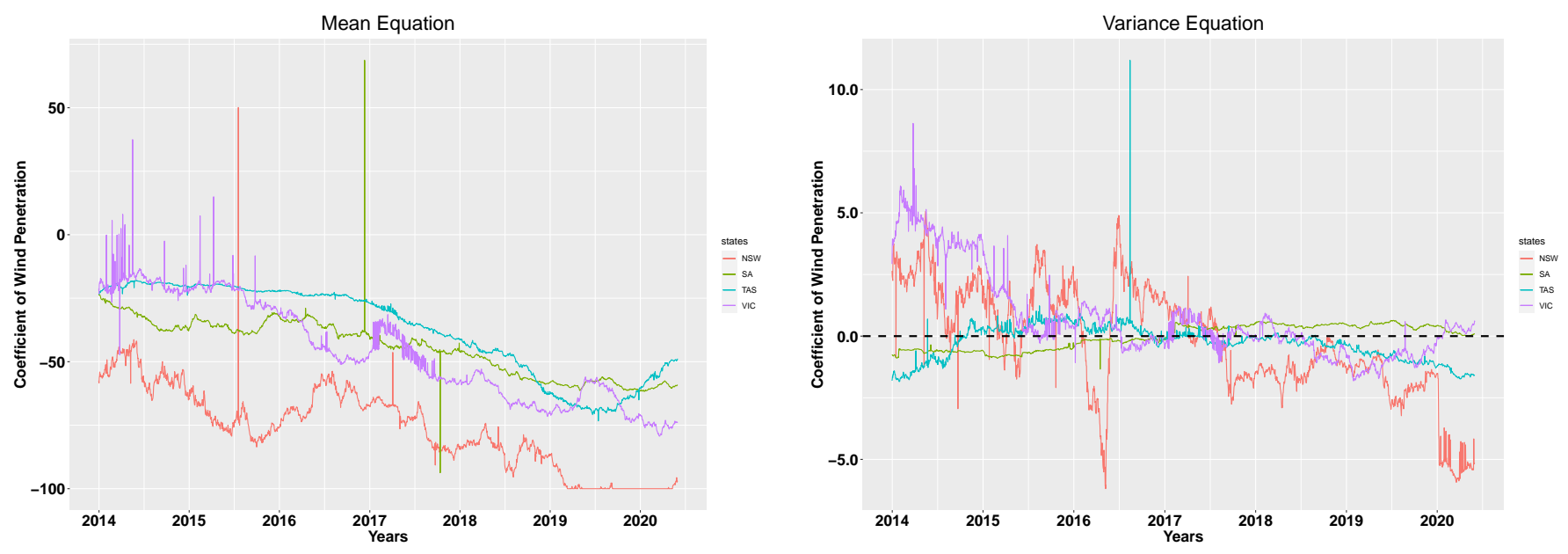

Figure 5: Evolution of the impact of wind penetration from 2014 to May 2020 for NSW, SA, VIC, and TAS. The coefficients are estimated using the rolling regression with three-year windows while controlling for gas prices, hydro generation, and the interconnectors. The graph on the left shows the effect on the price level, and the graph on the right shows the effect on the price volatility.

(50\% to 60\%), thus smoothing out the price volatility from the higher wind output (Marshman et al., 2020). After thermal plants are offline, the price firming they provide ceases, and prices become more volatile, leading to an increase in the wind penetration coefficient. Kyritsis et al. (2017) observed a similar pattern in the daily variance in electricity prices in Germany, where wind penetration reduces the variance to around the $20 \%$ level but then reverts to the increasing pattern.

These results provide important insights into the expected changes in price behaviors as a result of government programs that target supporting renewable electricity growth. We find that increasing wind penetration in states with an annual wind share of less than 15\%, i.e., NSW and VIC, tends to result in price swings, which are currently biased below zero. States with high wind penetration, i.e., SA and TAS, tend to exhibit a marginal reduction in price volatility.

\section{$5 \quad$ Regulatory implications}

The NEM has experienced two significant shocks since 2010 which had a material impact on electricity dynamics, the CPM and the COVID-19 lockdown restrictions. The CPM was a federal government regulation based on emission control policies, whereas the lockdown restrictions consisted of state government measures to control the spread of COVID-19. We analyze the impact of these two regulatory shocks on the NEM and then discuss their implications. 


\subsection{Carbon Pricing Mechanism (CPM)}

The CPM was introduced by the Australian government in July 2012, pricing carbon at 23 AUD/tonne of the equivalent emitted carbon dioxide. The scheme was repealed in June 2014. The CPM was the central component of the Clean Energy Future Plan aimed at reducing the emission of carbon and other greenhouse gases to at least 5\% below 2000 levels by 2020 (AER, 2013). The pricing also aimed at shifting the reliance from coal-fired generation toward sustainable and renewable energy (Maryniak et al., 2019). At the time the scheme was terminated, the output from coal-fired generators had decreased by around 25\% (16\% from brown and $9 \%$ from black coal-fired generators), and the market share of coal generation had dropped markedly, reaching a historical proportion of $73.6 \%$ of NEM output in 2013-14 (AER, 2015). These changes, combined with the reduction in demand, reduced carbon emissions from electricity sector by $10.3 \%$ during the two years the CPM was implemented.

Table 6 provides a state-by-state breakdown of the regressions incorporating the dummy variable $D_{c a}$ to examine the effect of the CPM on prices where $D_{c a}=1$ during the CPM period, extending from the introduction of the CPM scheme on July 1, 2012, until it was repealed on July 1, 2014, and zero otherwise. We seek statistically significant differences between the times when the scheme was in operation $\left(D_{c a}=1\right)$ and when it was not $\left(D_{c a}=0\right)$, corresponding to the times before its introduction and after the repeal.

We find strong evidence that during the CPM period, electricity prices increased statistically significantly across all markets in the NEM. The price intensification was much higher in NSW and VIC and relatively lower in SA and TAS. The generation mix in the former states is dominated by coal-fired generators statistically significantly impacted by the introduction of carbon pricing. Most of the older and higher-cost plants were forced to periodically shut down and then return, for example, during high demand periods in summer. The increased reliance on flexible and expensive sources of generation, such as gas, triggered price increases. The reduced competitiveness of coalfired generators and the imposition of the RET accelerated the increase in wind generation. We find statistically significant evidence that during the CPM period, wind generation caused a decrease in electricity prices across all states in the NEM. The largest reduction occurred in SA and TAS, and despite a greater increase in prices following the implementation of the CPM, we observe a significant reduction in VIC and NSW, which had relatively lower levels of wind generation. ${ }^{29}$ The results show that increasing wind generation by $1 \mathrm{GWh}$ during the CPM period reduced prices by 0.9 AUD/MWh and 0.5 AUD/MWh in SA and TAS and approximately 0.1 AUD/MWh and 0.2 AUD/MWh in NSW and VIC, respectively. Likewise, wind penetration had a dampening effect on the level of electricity prices with a greater reduction observed in VIC and moderate reduction in SA and TAS. We find no statistical evidence for this effect in NSW, likely reflecting the smallest

\footnotetext{
${ }^{29}$ In SA, wind penetration increased from $28 \%$ to $33 \%$ during this period but was below $5 \%$ in VIC and NSW.
} 
share of demand served by wind generation. During the CPM period, wind generation accounted for $0.94 \%$ and $1.15 \%$ of consumption in NSW and $3.09 \%$ and $5.36 \%$ in VIC for the years 2012 and 2013, respectively.

The results further suggest a positive relationship between prices and consumption, and we found that this effect was stronger when the CPM was not implemented compared to the CPM period. This likely reflects the weakened commercial and residential demand due to higher electricity costs, lower demand from the manufacturing sector, and increased uptake of rooftop solar PV generation. The CPM pushed electricity demand down by $3.8 \%$ across the NEM (O'Gorman and Jotzo, 2014). Changes in weather conditions might also have contributed to reducing electricity demand. Further, we find statistically significant evidence that gas contributed to increasing electricity prices during the CPM period in VIC. ${ }^{30}$ Last, it is evident that in virtually all states in the NEM the competitiveness of hydro was enhanced. We find statistically significant evidence that increasing hydro generation by 1 GWh during the CPM period reduced prices by 0.2 AUD/MWh in TAS and evidence of a more moderate reduction in NSW (0.1 AUD/MWh). The effect in VIC was not statistically significant, particularly after controlling for other variables (see Model Q).

We find a statistically significant decrease in price volatility during the CPM period (see Model $\mathrm{K}$ ). The coefficients, however, are not statistically significant after controlling for other variables (see Model Q). This suggests the possibility of omitted variable bias, namely, the effect attributed to volatility in the regression may have been due to the effects of the omitted variables. The influence of wind generation on price volatility during the CPM period is marginal and evident in only SA, which had relatively higher levels of wind uptake. In particular, increasing wind generation during the CPM period by $1 \mathrm{GWh}$ reduced the volatility of electricity prices by $0.2 \%$. The imposition of carbon pricing stimulated investment in wind generation and supplied about 28\%, 30\%, and $33 \%$ of the output in SA in the years 2012, 2013, and 2014, respectively. Furthermore, we find statistically significant evidence that volatility increased during the CPM period, specifically $1 \%$ for each $1 \mathrm{GWh}$ increase in hydro generation for NSW. Although there is less statistical evidence for the coefficient of the interaction term in TAS and not statistically significant during the nonCPM period, higher prices in other regions during the CPM period increased the competitiveness of hydro generation making TAS a net exporter of electricity in 2012-13. The impact of gas prices and electricity consumption is not statistically significant for all states in the NEM.

These findings have implications for the debate regarding the appropriate policy responses required to combat climate change and the security of the NEM. During the CPM period, the costs of generation from fossil fuel and electricity prices increased substantially across all markets in the NEM. However, the carbon pricing mechanism allowed an efficient market determination for the amount of wind generation in the electricity mix. Without this policy and the LRET in place,

${ }^{30}$ The impact in NSW and SA is not statistically significant. 
the market risks running into a trauma (Wood and Blowers, 2016; Simshauser and Gilmore, 2020). The LRET is a typical government intervention aimed at reducing greenhouse gas emissions by subsidizing large-scale renewable generation (Cludius et al., 2014a). The goal of the LRET is to produce 33,000 GWh of electricity by 2020 regardless the need for additional supply. When demand has trended lower, this additional supply, which also varies over time due to the intermittent nature of wind and solar, adds challenges to system reliability and security, as well as electricity prices. The frequent occurrence of negative prices, resulting from increasing supply from renewable energy, is likely to affect investment and divestment in the energy sector. ${ }^{31}$ In addition, the LRET is not technology-neutral and does not allow for abatement to occur from existing plants (i.e., only new renewable energy can drive abatement under the LRET). Thus, it is more costly and has more side effects compared to an emissions intensity scheme (EIS) or a carbon price. Technically, policies offering greater flexibility for generators to adjust their emissions, such as an EIS, are likely to perform best under uncertainty compared to mechanisms that are not technology-neutral (ACC, 2017). Future climate change policies, therefore, must operate in a broader spectrum of considerations for energy policies to maintain safe and reliable energy systems.

\subsection{COVID-19 and the NEM}

A significant discussion of immediate interest is centered on the novel coronavirus (COVID-19) and its socioeconomic impacts. In Australia, the first person tested positive in VIC on January 25, 2020. The number of cases increased sharply, forcing government responses in increased pandemic restrictions and lockdowns from late March 2020. To evaluate the impact of these restrictions on the energy sector, and specifically, on the dynamics of electricity prices, we introduce the dummy variable $D_{c o}$, taking value one $\left(D_{c o}=1\right)$ during the lockdown period from March 23, 2020, to May 31, 2020, after which the tightest restrictions were lifted in all states, and zero otherwise. The results obtained are summarized in Table 7.

The results provide evidence of a statistically significant difference in the average levels of prices between the lockdown and non-lockdown period. Looking at Model W, which includes all the variables, we find strong evidence that prices decreased substantially in NSW during the lockdown periods. The price reduction may have been driven by several factors, including lower gas and coal prices, the decline in demand, lower-priced offers, and increased renewable output (AEMO, 2020e,f). Focusing on the latter factor, we find statistically significant evidence that wind generation reduced electricity prices in SA and VIC during the lockdown period. Wind penetration

\footnotetext{
${ }^{31}$ The increase in renewable energy has also been associated with more frequent instances of VRE curtailment in the NEM. Typically, this intervention occurs during low daytime demand, transmission outages, and extended periods of negative spot prices (AER, 2020b). Nevertheless, curtailment is not a problem but reflects market economics, and the fact that remote generators challenge the system strength means that it cannot be completely avoided (Simshauser and Gilmore, 2020).
} 
has the same sign effect, although the interaction term is statistically significant only in SA. From the beginning of 2020 until the end of the sample period, SA and VIC lead in terms of wind penetration with around $50.29 \%$ and $13.24 \%$, respectively.

During the pandemic, demand decreased noticeably in NSW by $5 \%$ in April after the government imposed tighter pandemic restrictions. Easing of restrictions in conjunction with cooler weather conditions which increased residential demand brought the reduction level to about $1 \%$ during May and June (AEMO, 2020f). Despite the observed reductions, we find strong evidence that consumption increased electricity prices during the lockdown period in NSW. The impact of consumption in other regions was not statistically significant. Overall, VIC experienced a moderate operational demand reduction, ${ }^{32}$ whereas SA experienced a considerable increase in demand. This was due to the greater proportion of residential demand, which exceeds the commercial load. No concrete evidence of demand change was established in TAS. A visual inspection of Figure 3a suggests further that the trend of consumption reduction after the imposition of a strict nationwide lockdown on March 23, 2020, to May 31, 2020, did not diverge substantially from the pre-lockdown period. The impact of gas during the lockdown period is not evident in any state, including SA and VIC, both of which have a large proportion of gas in their generation mix. Since the start of 2020, gas prices have been offered in the markets at increasingly lower prices and reached the historically lowest levels in all markets across the NEM (AEMO, 2020f). The lower gas prices have been associated with falling gas prices in the international market and increased gas production in QLD. Although high rainfall allowed increased output from hydro, we find some evidence that the marginal increase is associated with higher electricity prices in NSW. We find no statistical evidence to back up the positive and negative impacts in VIC and TAS, respectively.

These results suggest further that price volatility during the lockdown period was higher in SA. ${ }^{33}$ As pointed out previously, SA is characterized by extreme and volatile prices compared with other markets in the NEM. The effect of wind generation and penetration during the lockdown period was not evident across the markets. Similarly, we find no evidence for the impact of electricity consumption. The marginal increase in hydro generation in VIC reduced volatility (see Model W); nonetheless, the interaction term is not statistically significant after controlling for other electricity price determinants. Moreover, we find modest evidence for the effect of gas prices in NSW and SA. In both states, the results reveal that the marginal increase in gas prices during the lockdown period was associated with higher price volatility. These dynamics may be the aftermath of the COVID-19 pandemic, which caused price volatility in international gas prices, especially the Japan Korea Marker (JKM) LNG prices.

Overall, we find that the COVID-19 pandemic and the associated restrictions had a moderate

\footnotetext{
${ }^{32}$ The imposition of the second statewide restrictions due to the second wave of infections in VIC in early July is expected to have an additional impact on the demand.

${ }^{33}$ The effects in other markets are not statistically significant.
} 
impact on the NEM with a direct impact reflected in the reduction in demand and electricity prices. Furthermore, no major changes were associated with the merit order effect of wind generation during the lockdown period. The effect on volatility was unremarkable across all regional markets. Nonetheless, sustained lower demand and prices are likely to hurt new investment projects, including renewable energy and coal-fired generators. Therefore, the system architecture, regulation, and governance should be designed so that they are flexible enough to accommodate a range of potential future challenges. With the pandemic's disruption of the economy, and with the threat of future disruptions due to climate change and other unforeseen events, accelerating market reforms aimed at improving market operations and resiliency in the NEM should be the focus.

\section{Conclusion and policy implications}

The Australian electricity market (NEM) is experiencing one of the fastest-growing VRE generations in the world, raising new challenges to system security and reliability. This transformation has manifested in an extended period of negative prices and increased uncertainty and variability of electricity prices. Despite increased generation from solar generation recently, wind generation still leads this evolution and accounts for most of these variations. This necessitates a re-evaluation of the market dynamics and their determinants. We conditioned on a set of factors not previously considered, such as hydro generation and interconnectors, to model and evaluate the impact of wind generation on the dynamics of electricity prices and simultaneously capture the MOE and volatility dynamics. The results suggest that wind generation contributes to a statistically significant reduction in electricity prices in the NEM. Electricity consumption, gas prices, and hydro generation are positively related not only to electricity prices but also to their price volatility. The impact of wind generation on volatility dynamics is more pronounced in states with high wind penetration, such as South Australia, Tasmania, and Victoria. ${ }^{34}$ Thus, we conclude that states with high wind penetration are more susceptible to variation in electricity prices. The six crossborder interconnectors have a measurable impact on price levels and volatility, an impact that depends on a state's position as an importer or exporter of electricity and the thermal capacity of the respective interconnector. The impact also depends on the extent to which the increase in VRE and the closure of coal-fired generators affects the respective connected markets.

We investigated the impact of two federal policies imposed on the dynamics of electricity prices; the pricing mechanism and the nationwide lockdown restrictions in Australia due to COVID-19. We find that during the carbon pricing period, wind generation led to a marked merit order effect in the NEM with a negative impact on electricity price volatility. During the COVID-19 lockdown,

\footnotetext{
${ }^{34}$ Specifically, volatility increases with high wind generation in South Australia and Victoria and decreases in Tasmania. The effect of wind penetration moves in the same direction and is statistically significant in states with moderate penetration levels, which are Victoria and Tasmania.
} 
we report a reduction in electricity prices, mostly due to the decline in electricity demand, yet only a marginal impact on volatility.

These findings provide insights into the complexity associated with the recent transformation in the NEM due to the fast-evolving generation mix. Based on our empirical analysis, this transformation accounts for a substantial increase in the variability and therefore, uncertainty in electricity prices. Negative prices have become a common feature in the NEM, and the magnitude of these instances has become more persistent and more pronounced. Price volatility potentially signals the need for new investment; such volatility characterized by infrequent, very high, or low prices for very short periods poses a considerable risk to investors and consumers (Han et al., 2020). The retirement of coal-fired generators (sometimes earlier than expected) poses further challenges in the market and has the potential to amplify price shocks in the future. ${ }^{35}$ The level and volatility of wholesale electricity prices impact end-consumer prices and electricity bills. Evidence suggests that the costs the RET accounted for a substantial portion of the increase in residential prices, among other factors. These costs are passed on to consumers in the form of retail electricity price premiums, offsetting the MOE (Cludius et al., 2014a). Despite the expected drop in residential prices in the next two years driven mostly by high VRE generation (AEMC, 2019), the increasing price volatility has potential to counteract the anticipated trend by exerting upward pressure on the wholesale price contract. One of the major key challenges to the system operator going forward is managing the variability and uncertainty of prices, as the high penetration of wind and solar generation potentially endangers the system security and reliability (Simshauser and Gilmore, 2020).

As wind penetration continues to increase across the NEM, more investment in fast-start, firm, and flexible (dispatchable) capacity will be needed in coal-generation dominant regions, i.e., NSW and VIC, to meet the lost output from wind generation. ${ }^{36}$ In contrast, SA and TAS have a large proportion of gas and hydro generation, respectively, which serve to keep the system stable and secure. Eventually, the increase in wind generation in the NEM has the potential to displace intermediate as well as peaking generators (i.e., OCGTs have been less impacted than CCGTs by the entry of wind generation) (Forrest and MacGill, 2013; Marshman et al., 2020). This brings the market to a delicate balance. Furthermore, the demand patterns of electricity have been changing considerably in the NEM due to the changes behind the metered resources, especially rooftop solar PV generation. Thus, the new plant design and the demand side offer potential for system flexibility beyond the traditional fuel-type-based flexibility. The importance of having a flexible

\footnotetext{
${ }^{35}$ Many coal-fired powers plants are expected to wind up withdrawing around 63\% (15 GW) of capacity from the NEM by 2040. More than $30 \mathrm{GW}$ of large-scale renewable energy will be required by then to replace the lost output (AEMO, 2020a).

${ }^{36}$ AGL Energy is planning to replace the Liddell power station in NSW beyond its announced retirement in 2022 with these sorts of technologies (a mix of renewable generation, high-efficiency gas peaking capacity, battery storage, and an upgrade of its Bayswater power station (AER, 2020b).
} 
system can be further supplemented by effective market connectedness and storage technologies.

Effective market trade in the NEM has been restricted by the thermal, voltage, and transient stability limitations of the cross-border interconnectors leading to different inter-state, volatile, and unnecessarily high electricity prices (Ignatieva and Trück, 2016; Bell et al., 2017). Furthermore, the NEM is not as heavily connected as other renewable-rich countries such as Denmark, ${ }^{37}$ nor is the NEM connected to its own northern and western territories. Therefore, the NEM is solely dependent on local supply. As the market transitions to renewables, heavy investment in interconnectors is very important to keep the system stable and secure (Denny et al., 2010). Ultimately, this will reduce pressure on prices and enhance the efficient use of renewable energy generators. In the same vein, the changing energy landscape in the NEM is associated with the reversal of the flow direction in the existing interconnectors. For instance, VIC, which was a net exporter, has been increasingly reliant on NSW, SA, and TAS to supplement VIC's supply during peak periods. ${ }^{38}$ To ensure maximum benefits from these interconnectors, future investments must align and account for the long-term ability of the states to deliver renewable energy generation and for future market conditions.

Investment in pumped hydro and battery storage has been slow compared to the speed at which the market is transitioning to renewable energy. Nonetheless, future developments and proposed storage projects are expected to shape the energy landscape and perhaps reduce the price swings currently observed in the NEM. SA, for instance, installed the world's largest lithiumion battery at the Hornsdale windfarm (170 MW), which has played a substantial role in lowering the cost of frequency control services in the region (AER, 2020b). It is projected that battery storage installations will increase from nearly zero in 2020 to about 5.6 GW by 2036-37. Major proposed pumped hydro energy projects include the expansion of the Snowy Hydro Scheme, which will increase capacity by 50\% (up to $2000 \mathrm{MW}$ ) and the Tasmanian hydroelectric system (2500 $\mathrm{MW}$. Renewable hydrogen is also expected to provide vital support for increasing surplus from VRE generation and the potential for energy exports in Australia (COAG, 2019). Thus, the infrastructure and the expansion of the electricity grid and an effective mix of technology will be central to the transition from fossil fuel to clean energy generation.

Finally, the increase in price volatility from the increasing reliance on weather-based renewable energy sources underscores the importance of appropriate methods for data treatment and modeling. Misspecification may potentially underestimate price volatility leading to inaccurate derivative pricing and hedging strategies. Policies informed by any such misspecifications risk may fail to address the current challenges associated with higher penetration of VRE production in the

\footnotetext{
${ }^{37}$ Denmark, which leads with the highest penetration of wind generation, is strongly interconnected with central European and Scandinavian power systems, which offers strong support for balancing the system (AEMO, 2020d)

${ }^{38}$ Its exports to SA, for instance, have decreased substantially from an average of between $220 \mathrm{MW}$ and $270 \mathrm{MW}$ to 41 MW (Cornwall Insight, 2020)
} 
NEM. 
Table 2: The effect of wind generation, electricity consumption, gas prices, hydro generation, and interconnectors flow on New South Wales' electricity price behavior. The effect on price levels is given by the mean equation and on price volatility by the variance equation.

\begin{tabular}{|c|c|c|c|c|c|c|c|c|c|c|}
\hline & Model A & Model B & Model C & Model D & Model E & Model F & Model G & Model H & Model I & Model J \\
\hline \multicolumn{11}{|c|}{ Mean Equation } \\
\hline$\mu$ & 54.3343 & 57.1014 & -8.2404 & -2.9146 & 56.6694 & 50.5466 & 49.4523 & 50.3224 & 2.2736 & 47.1826 \\
\hline \multirow{2}{*}{$\phi_{1}$} & 0.8385 & 0.8445 & $\begin{array}{r}0.1214) \\
0.8488\end{array}$ & 0.8556 & 0.8456 & $\begin{array}{r}0.8349 \\
0.800)\end{array}$ & 0.8414 & $\begin{array}{r}0.8535 \\
0.800)\end{array}$ & $\begin{array}{r}(0.5702) \\
0.8607\end{array}$ & $\begin{array}{r}(0.0000) \\
0.8539\end{array}$ \\
\hline & $(0.0000)$ & $(0.0000)$ & $(0.0000)$ & $(0.0000)$ & $(0.0000)$ & $(0.0000)$ & $(0.0000)$ & $(0.0000)$ & $(0.0000)$ & $(0.0000)$ \\
\hline \multirow[t]{2}{*}{ wind } & & -5.8979 & & -5.5736 & & & & & -4.5167 & \\
\hline & & $(0.0000)$ & & $(0.0000)$ & & & & & $(0.0000)$ & \\
\hline \multirow[t]{2}{*}{ consumption } & & & 3.2269 & 3.0795 & & & & & 2.4622 & \\
\hline & & & $(0.0000)$ & $(0.0000)$ & & & & & $(0.0000)$ & \\
\hline wind $_{\text {pen }}$ & & & & & $\begin{array}{r}-100.0000 \\
(0.0000)\end{array}$ & & & & & $\begin{array}{r}-92.4660 \\
(0.0000)\end{array}$ \\
\hline \multirow[t]{2}{*}{ gas } & & & & & & 0.63661 & & & 0.2021 & 0.3489 \\
\hline & & & & & & $(0.0000)$ & & & $(0.1513)$ & $(0.0164)$ \\
\hline \multirow[t]{2}{*}{ hydro } & & & & & & & 7.6019 & & 4.0481 & 6.6880 \\
\hline & & & & & & & $(0.0000)$ & & $(0.0000)$ & $(0.0000)$ \\
\hline \multirow[t]{2}{*}{ exim $_{\text {terra }}$} & & & & & & & & -11.7043 & -11.0483 & -11.4251 \\
\hline & & & & & & & & $(0.0178)$ & $(0.0143)$ & $(0.0107)$ \\
\hline \multirow[t]{2}{*}{$\operatorname{exim}_{Q N I}$} & & & & & & & & -3.4987 & -1.6940 & -2.1430 \\
\hline & & & & & & & & $(0.0000)$ & $(0.0143)$ & $(0.0146)$ \\
\hline \multirow[t]{3}{*}{$\operatorname{exim}_{V N I}$} & & & & & & & & -1.2123 & -0.7607 & -0.8209 \\
\hline & & & & & & & & $(0.0000)$ & $(0.0007)$ & $(0.0014)$ \\
\hline & \multicolumn{9}{|c|}{ Variance Equation } & \\
\hline \multirow[t]{2}{*}{$\omega$} & 2.5631 & 2.6162 & -1.1792 & -1.3694 & 2.6427 & 2.2504 & 2.18344 & 2.3460 & -0.8407 & 1.7301 \\
\hline & $(0.0000)$ & $(0.0000)$ & $(0.0210)$ & $(0.0091)$ & $(0.0000)$ & $(0.0000)$ & $(0.0000)$ & $(0.0000)$ & $(0.1252)$ & $(0.0000)$ \\
\hline \multirow[t]{2}{*}{$\alpha$} & 0.1470 & 0.1404 & 0.1585 & 0.1479 & 0.1402 & 0.1356 & 0.14700 & 0.1537 & 0.1364 & 0.1233 \\
\hline & $(0.0001)$ & $(0.0003)$ & $(0.0000)$ & $(0.0001)$ & $(0.00037)$ & $(0.0005)$ & $(0.0000)$ & $(0.0000)$ & $(0.0001)$ & $(0.0006)$ \\
\hline \multirow[t]{2}{*}{$\beta$} & 0.4819 & 0.4707 & 0.4235 & 0.4113 & 0.4696 & 0.4685 & 0.45716 & 0.4575 & 0.3697 & 0.3961 \\
\hline & $(0.0000)$ & $(0.0000)$ & $(0.0000)$ & $(0.0000)$ & $(0.0000)$ & $(0.0000)$ & $(0.0000)$ & $(0.0000)$ & $(0.0000)$ & $(0.0000)$ \\
\hline$\gamma$ & 0.5553 & 0.5791 & 0.5801 & 0.5944 & 0.5812 & 0.5623 & 0.6012 & 0.5073 & 0.5875 & 0.5926 \\
\hline & $(0.0000)$ & $(0.0000)$ & $(0.0000)$ & $(0.0000)$ & $(0.0000)$ & $(0.0000)$ & $(0.0000)$ & $(0.0000)$ & $(0.0000)$ & $(0.0000)$ \\
\hline wind & & -0.0143 & & 0.0004 & & & & & -0.0238 & \\
\hline & & $(0.8583)$ & & $(0.9960)$ & & & & & $(0.7892)$ & \\
\hline consumption & & & 0.2028 & 0.2147 & & & & & 0.1388 & \\
\hline & & & $(0.0000)$ & $(0.0000)$ & & & & & $(0.0000)$ & \\
\hline wind $_{\text {pen }}$ & & & & & -1.2349 & & & & & -1.3381 \\
\hline & & & & & $(0.4163)$ & & & & & $(0.4252)$ \\
\hline gas & & & & & & 0.0620 & & & 0.0639 & 0.0676 \\
\hline & & & & & & $(0.0003)$ & & & $(0.0010)$ & $(0.0004)$ \\
\hline hydro & & & & & & & 0.6120 & & 0.4857 & 0.5909 \\
\hline & & & & & & & $(0.0000)$ & & $(0.0000)$ & $(0.0000)$ \\
\hline exim $_{\text {terra }}$ & & & & & & & & -0.83015 & -1.0180 & -0.9218 \\
\hline & & & & & & & & $(0.2384)$ & $(0.1931)$ & $(0.2248)$ \\
\hline $\operatorname{exim}_{Q N I}$ & & & & & & & & -0.0759 & -0.0892 & -0.1038 \\
\hline & & & & & & & & $(0.2813)$ & $(0.2607)$ & $(0.1763)$ \\
\hline $\operatorname{exim}_{V N I}$ & & & & & & & & 0.1082 & 0.1378 & 0.1039 \\
\hline & & & & & & & & $(0.0027)$ & $(0.0008)$ & $(0.0086)$ \\
\hline Shape & 2.7368 & 2.6903 & 2.8627 & 2.8229 & 2.6902 & 2.7712 & 2.9984 & 2.8153 & 3.1373 & 3.0807 \\
\hline & $(0.0000)$ & $(0.0000)$ & $(0.0000)$ & $(0.0000)$ & $(0.0000)$ & $(0.0000)$ & $(0.0000)$ & $(0.0000)$ & $(0.0000)$ & $(0.0000)$ \\
\hline Log Likelihood & -12615.46 & -12522.92 & -12423.65 & -12330.16 & -12507.30 & -12600.20 & -12493.69 & -12519.98 & -12231.91 & -12323.42 \\
\hline $\mathrm{AIC}$ & 7.3408 & 7.2881 & 7.2304 & 7.1772 & 7.2790 & 7.3331 & 7.2711 & 7.2887 & 7.1259 & 7.1779 \\
\hline $\mathrm{BIC}$ & 7.3533 & 7.3042 & 7.2465 & 7.1968 & 7.2951 & 7.3491 & 7.2872 & 7.3120 & 7.1634 & 7.2119 \\
\hline$Q(20)$ & 1.35009 & 1.4802 & 4.4455 & 4.5792 & 1.4659 & 1.2747 & 1.2306 & 1.2688 & 3.8520 & 1.4159 \\
\hline & $(0.8815)$ & $(0.8515)$ & $(0.1630)$ & $(0.1474)$ & $(0.8549)$ & $(0.8977)$ & $(0.9066)$ & $(0.8989)$ & $(0.2500)$ & $(0.8667)$ \\
\hline$Q^{2}(36)$ & 0.0051 & 0.0052 & 0.0131 & 0.0134 & 0.0052 & 0.0051 & 0.0034 & 0.0046 & 0.0057 & 0.0035 \\
\hline & $(1.0000)$ & $(1.0000)$ & $(1.0000)$ & $(1.0000)$ & $(1.0000)$ & $(1.0000)$ & $(1.0000)$ & $(1.0000)$ & $(1.0000)$ & $(1.0000)$ \\
\hline ARCH-LM Test & 0.0027 & 0.0028 & 0.0066 & 0.0075 & 0.0028 & 0.0025 & 0.0021 & 0.0025 & 0.0035 & 0.0022 \\
\hline & $(1.0000)$ & $(1.0000)$ & $(1.0000)$ & $(1.0000)$ & $(1.0000)$ & $(1.0000)$ & $(1.0000)$ & $(1.0000)$ & $(1.0000)$ & $(1.0000)$ \\
\hline Observations & 3439 & 3439 & 3439 & 3439 & 3439 & 3439 & 3439 & 3439 & 3439 & 3439 \\
\hline
\end{tabular}

Wind generation, electricity consumption, hydro generation, and the cross-border interconnector flows are scaled by $10^{4}$ to clarify the presentation of the results. The corresponding coefficients should, therefore, be multiplied by $0.1 \mathrm{AUD} / \mathrm{MWh}$ and 0.1 for a $1 \mathrm{GWh}$ increase in either variable for the mean equation and the variance equation, respectively. AIC denotes the Akaike information criterion, BIC is the Bayesian information criterion and ARCH $\mathrm{LM}$ is the Lagrange multiplier test for ARCH effect. The $p$ values are in parentheses. 
Table 3: The effect of wind generation, electricity consumption, gas prices, and interconnectors flow on South Australia's electricity price behavior. The effect on price levels is given by the mean equation and on price volatility by the variance equation.

\begin{tabular}{|c|c|c|c|c|c|c|c|c|c|}
\hline & Model A & Model B & Model C & Model D & Model E & Model F & Model H & Model I & Model J \\
\hline & \multicolumn{9}{|c|}{ Mean Equation } \\
\hline$\mu$ & $\begin{array}{r}61.2996 \\
(0.0000)\end{array}$ & $\begin{array}{l}80.0152 \\
(0.0000)\end{array}$ & $\begin{array}{r}-36.9771 \\
(0.0000)\end{array}$ & $\begin{array}{l}14.2491 \\
(0.0000)\end{array}$ & $\begin{array}{r}79.6139 \\
(0.0000)\end{array}$ & $\begin{array}{r}10.955 \\
(0.0000)\end{array}$ & $\begin{array}{r}59.8263 \\
(0.0000)\end{array}$ & $\begin{array}{r}-15.2729 \\
(0.1289)\end{array}$ & $\begin{array}{r}38.9298 \\
(0.0000)\end{array}$ \\
\hline$\phi_{1}$ & $\begin{array}{r}0.5842 \\
(0.0000)\end{array}$ & $\begin{array}{r}0.6290 \\
(0.0000)\end{array}$ & $\begin{array}{r}0.6023 \\
(0.0000)\end{array}$ & $\begin{array}{r}0.6400 \\
(0.0000)\end{array}$ & $\begin{array}{r}0.6311 \\
(0.0000)\end{array}$ & $\begin{array}{c}0.47087 \\
(0.0000)\end{array}$ & $\begin{array}{r}0.6105 \\
(0.0000)\end{array}$ & $\begin{array}{r}0.5474 \\
(0.0000)\end{array}$ & $\begin{array}{r}0.5114 \\
(0.0000)\end{array}$ \\
\hline wind & & $\begin{array}{r}-15.1445 \\
(0.0000)\end{array}$ & & $\begin{array}{r}-12.5028 \\
(0.0000)\end{array}$ & & & & $\begin{array}{r}-12.7961 \\
(0.0000)\end{array}$ & \\
\hline consumption & & & $\begin{array}{c}30.1136 \\
(0.0000)\end{array}$ & $\begin{array}{r}19.0979 \\
(0.0000)\end{array}$ & & & & $\begin{array}{l}17.8255 \\
(0.0000)\end{array}$ & \\
\hline wind $_{\text {pen }}$ & & & & & $\begin{array}{c}-47.5034 \\
(0.0000)\end{array}$ & & & & $\begin{array}{r}-45.6440 \\
(0.0000)\end{array}$ \\
\hline gas & & & & & & $\begin{array}{r}8.3650 \\
(0.0000)\end{array}$ & & $\begin{array}{r}6.1472 \\
(0.0000)\end{array}$ & $\begin{array}{r}7.0736 \\
(0.0000)\end{array}$ \\
\hline exim $_{\text {heyw }}$ & & & & & & & $\begin{array}{r}6.3609 \\
(0.0000)\end{array}$ & $\begin{array}{r}-11.1388 \\
(0.0000)\end{array}$ & $\begin{array}{r}-10.0847 \\
(0.0000)\end{array}$ \\
\hline \multirow[t]{2}{*}{ exim $_{\text {murry }}$} & & & & & & & $\begin{array}{r}83.4109 \\
(0.0000)\end{array}$ & $\begin{array}{c}44.4606 \\
(0.0000)\end{array}$ & $\begin{array}{l}46.0293 \\
(0.0000)\end{array}$ \\
\hline & \multicolumn{9}{|c|}{ Variance Equation } \\
\hline$\omega$ & $\begin{array}{r}3.2552 \\
(0.0000)\end{array}$ & $\begin{array}{r}3.7145 \\
(0.0000)\end{array}$ & $\begin{array}{r}1.1663 \\
(0.0001)\end{array}$ & $\begin{array}{r}1.1381 \\
(0.0002)\end{array}$ & $\begin{array}{r}4.6687 \\
(0.0000)\end{array}$ & $\begin{array}{c}1.99188 \\
(0.0000)\end{array}$ & $\begin{array}{r}3.4616 \\
(0.0000)\end{array}$ & $\begin{array}{r}0.6852 \\
(0.0234)\end{array}$ & $\begin{array}{r}2.6630 \\
(0.0000)\end{array}$ \\
\hline$\alpha$ & $\begin{array}{r}-0.0792 \\
(0.0768)\end{array}$ & $\begin{array}{r}-0.0117 \\
(0.8154)\end{array}$ & $\begin{array}{r}-0.0371 \\
(0.3172)\end{array}$ & $\begin{array}{r}0.0166 \\
(0.6854)\end{array}$ & $\begin{array}{r}0.0609 \\
(0.0000)\end{array}$ & $\begin{array}{r}-0.1642 \\
(0.0000)\end{array}$ & $\begin{array}{r}-0.0306 \\
(0.5237)\end{array}$ & $\begin{array}{r}-0.0353 \\
(0.3722)\end{array}$ & $\begin{array}{l}-0.1067 \\
(0.0185)\end{array}$ \\
\hline$\beta$ & $\begin{array}{r}0.5587 \\
(0.0000)\end{array}$ & $\begin{array}{r}0.4903 \\
(0.0000)\end{array}$ & $\begin{array}{r}0.4515 \\
(0.0000)\end{array}$ & $\begin{array}{r}0.4455 \\
(0.0000)\end{array}$ & $\begin{array}{r}0.3610 \\
(0.0000)\end{array}$ & $\begin{array}{r}0.63140 \\
(0.0000)\end{array}$ & $\begin{array}{r}0.5145 \\
(0.0000)\end{array}$ & $\begin{array}{r}0.4440 \\
(0.0000)\end{array}$ & $\begin{array}{r}0.4883 \\
(0.0000)\end{array}$ \\
\hline$\gamma$ & $\begin{array}{r}0.5016 \\
(0.0000)\end{array}$ & $\begin{array}{r}0.4881 \\
(0.0000)\end{array}$ & $\begin{array}{r}0.5864 \\
(0.0000)\end{array}$ & $\begin{array}{r}0.5568 \\
(0.0000)\end{array}$ & $\begin{array}{r}0.5597 \\
(0.0000)\end{array}$ & $\begin{array}{c}0.45263 \\
(0.0000)\end{array}$ & $\begin{array}{r}0.5099 \\
(0.0000)\end{array}$ & $\begin{array}{r}0.5079 \\
(0.0000)\end{array}$ & $\begin{array}{r}0.4737 \\
(0.0000)\end{array}$ \\
\hline wind & & $\begin{array}{r}-0.0134 \\
(0.7470)\end{array}$ & & $\begin{array}{r}0.1025 \\
(0.0222)\end{array}$ & & & & $\begin{array}{r}0.1893 \\
(0.0013)\end{array}$ & \\
\hline consumption & & & $\begin{array}{r}0.7805 \\
(0.0000)\end{array}$ & $\begin{array}{r}0.7555 \\
(0.0000)\end{array}$ & & & & $\begin{array}{r}0.6329 \\
(0.0000)\end{array}$ & \\
\hline wind $_{\text {pen }}$ & & & & & $\begin{array}{r}-0.2684 \\
(0.0277)\end{array}$ & & & & $\begin{array}{r}0.1095 \\
(0.5157)\end{array}$ \\
\hline gas & & & & & & $\begin{array}{c}0.10863 \\
(0.0000)\end{array}$ & & $\begin{array}{r}0.1061 \\
(0.0000)\end{array}$ & $\begin{array}{r}0.1333 \\
(0.0000)\end{array}$ \\
\hline exim $_{\text {heyw }}$ & & & & & & & $\begin{array}{r}0.1301 \\
(0.1386)\end{array}$ & $\begin{array}{r}0.0990 \\
(0.2998)\end{array}$ & $\begin{array}{r}0.1245 \\
(0.1721)\end{array}$ \\
\hline exim $_{\text {murry }}$ & & & & & & & $\begin{array}{r}0.8512 \\
(0.0162)\end{array}$ & $\begin{array}{r}0.6424 \\
(0.1009)\end{array}$ & $\begin{array}{r}0.6636 \\
(0.0741)\end{array}$ \\
\hline Shape & $\begin{array}{r}2.3979 \\
(0.0000)\end{array}$ & $\begin{array}{r}2.3159 \\
(0.0000)\end{array}$ & $\begin{array}{r}2.7174 \\
(0.0000)\end{array}$ & $\begin{array}{r}2.5587 \\
(0.0000)\end{array}$ & $\begin{array}{r}2.3492 \\
(0.0000)\end{array}$ & $\begin{array}{r}2.4694 \\
(0.0000)\end{array}$ & $\begin{array}{r}2.3487 \\
(0.0000)\end{array}$ & $\begin{array}{r}2.6372 \\
(0.0000)\end{array}$ & $\begin{array}{r}2.4139 \\
(0.0000)\end{array}$ \\
\hline log likelihood & -16092.81 & -15629.53 & -15746.19 & -15438.66 & -15574.91 & -15966.86 & -15648.23 & -15297.49 & -15394.90 \\
\hline$A I C$ & 9.3631 & 9.0948 & 9.1627 & 8.9850 & 9.0630 & 9.2910 & 9.1069 & 8.9064 & 8.9618 \\
\hline$B I C$ & 9.3756 & 9.1109 & 9.1787 & 9.0046 & 9.0791 & 9.3071 & 9.1265 & 8.9367 & 8.9886 \\
\hline$Q(20)$ & $\begin{array}{r}0.0366 \\
(0.9978)\end{array}$ & $\begin{array}{r}0.4685 \\
(0.9949)\end{array}$ & $\begin{array}{r}6.5090 \\
(0.0299)\end{array}$ & $\begin{array}{r}5.7500 \\
(0.0576)\end{array}$ & $\begin{array}{r}0.4493 \\
(0.9955)\end{array}$ & $\begin{array}{r}0.6080 \\
(0.9881)\end{array}$ & $\begin{array}{r}0.6111 \\
(0.9879)\end{array}$ & $\begin{array}{r}5.8930 \\
(0.0510)\end{array}$ & $\begin{array}{r}0.8018 \\
(0.9720)\end{array}$ \\
\hline$Q^{2}(36)$ & $\begin{array}{r}0.0367 \\
(1.0000)\end{array}$ & $\begin{array}{r}0.0347 \\
(1.0000)\end{array}$ & $\begin{array}{r}0.0668 \\
(1.0000)\end{array}$ & $\begin{array}{r}0.0743 \\
(1.0000)\end{array}$ & $\begin{array}{r}0.0315 \\
(1.0000)\end{array}$ & $\begin{array}{r}0.0389 \\
(1.0000)\end{array}$ & $\begin{array}{r}0.03403 \\
(1.0000)\end{array}$ & $\begin{array}{r}0.1023 \\
(1.0000)\end{array}$ & $\begin{array}{r}0.03706 \\
(1.0000)\end{array}$ \\
\hline ARCH-LM Test & $\begin{array}{r}0.0307 \\
(1.0000)\end{array}$ & $\begin{array}{r}0.0282 \\
(1.0000)\end{array}$ & $\begin{array}{r}0.0417 \\
(0.9999)\end{array}$ & $\begin{array}{r}0.0476 \\
(0.9999)\end{array}$ & $\begin{array}{r}0.0232 \\
(1.0000)\end{array}$ & $\begin{array}{r}0.0326 \\
(1.0000)\end{array}$ & $\begin{array}{r}0.0273 \\
(1.0000)\end{array}$ & $\begin{array}{r}0.0694 \\
(0.9997)\end{array}$ & $\begin{array}{r}0.0288 \\
(1.0000)\end{array}$ \\
\hline Observations & 3439 & 3439 & 3439 & 3439 & 3439 & 3439 & 3439 & 3439 & 3439 \\
\hline
\end{tabular}

Wind generation, electricity consumption, hydro generation, and the cross-border interconnector flows are scaled by $10^{4}$ to clarify the presentation of the results. The corresponding coefficients should, therefore, be multiplied by $0.1 \mathrm{AUD} / \mathrm{MWh}$ and 0.1 for a $1 \mathrm{GWh}$ increase in either variable for the mean equation and the variance equation, respectively. AIC denotes the Akaike information criterion, BIC is the Bayesian information criterion and ARCH $\mathrm{LM}$ is the Lagrange multiplier test for ARCH effect. The $p$ values are in parentheses. 
Table 4: The effect of wind generation, electricity consumption, gas prices, hydro generation, and interconnectors flow on Victoria's electricity price behavior. The effect on price levels is given by the mean equation and on price volatility by the variance equation.

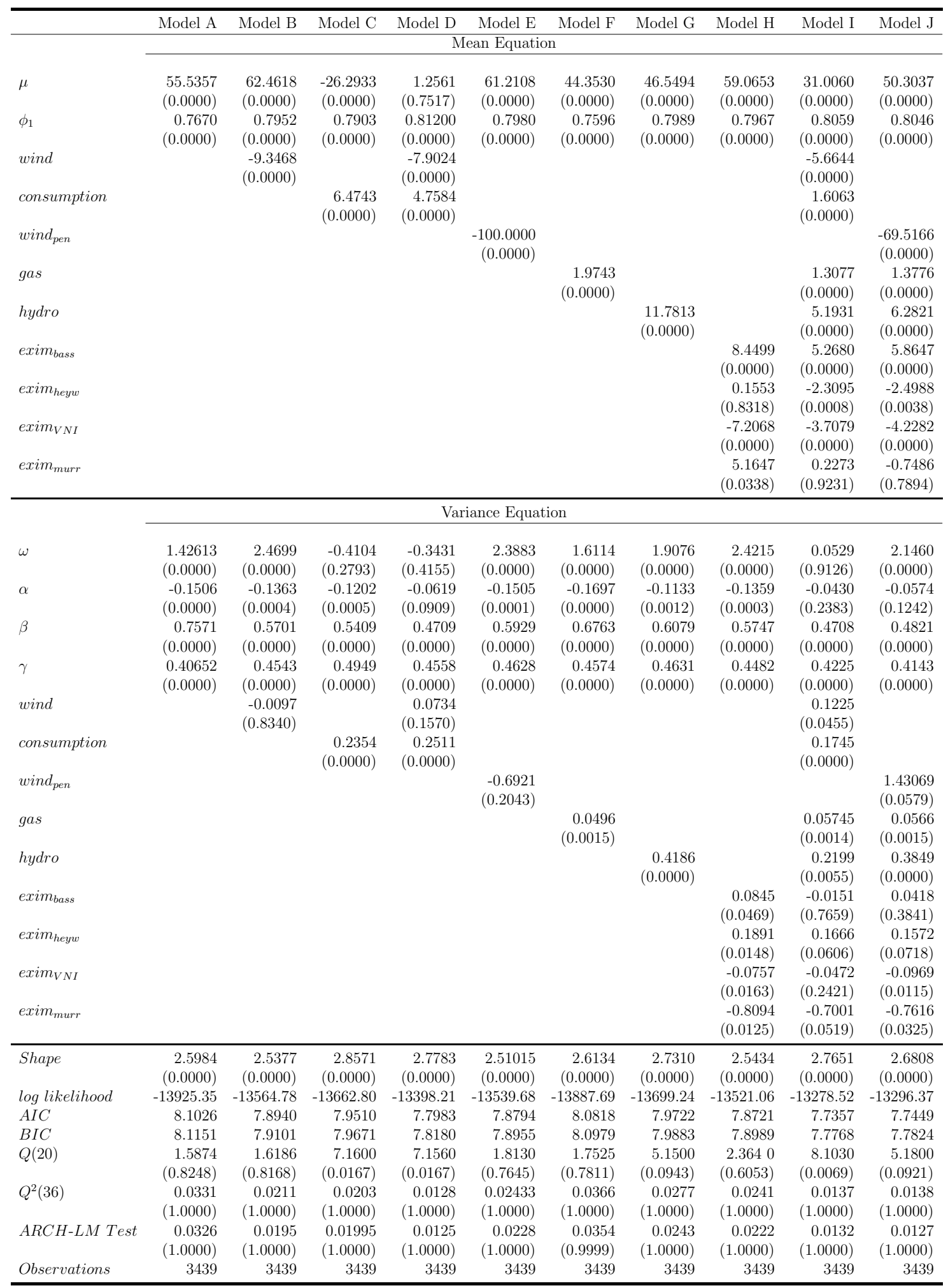

Wind generation, electricity consumption, hydro generation, and the cross-border interconnector flows are scaled by $10^{4}$ to clarify the presentation of the results. The corresponding coefficients should, therefore, be multiplied by $0.1 \mathrm{AUD} / \mathrm{MWh}$ and 0.1 for a $1 \mathrm{GWh}$ increase in either variable for the mean equation and the variance equation, respectively. AIC denotes the Akaike information criterion, BIC is the Bayesian information criterion and $\mathrm{ARCH}$ LM is the Lagrange multiplier test for ARCH effect. The $p$ values are in parentheses. 
Table 5: The effect of wind generation, electricity consumption, hydro generation, and interconnectors flow on Tasmania's electricity price behavior. The effect on price levels is given by the mean equation and on price volatility by the variance equation.

\begin{tabular}{|c|c|c|c|c|c|c|c|c|c|}
\hline & Model A & Model B & Model C & Model D & Model E & Model G & Model H & Model I & Model J \\
\hline & \multicolumn{9}{|c|}{ Mean Equation } \\
\hline$\mu$ & $\begin{array}{r}59.7511 \\
(0.0000)\end{array}$ & $\begin{array}{c}62.1004 \\
(0.0000)\end{array}$ & $\begin{array}{r}20.9592 \\
(0.0000)\end{array}$ & $\begin{array}{c}33.1653 \\
(0.0000)\end{array}$ & $\begin{array}{r}62.0528 \\
(0.0000)\end{array}$ & $\begin{array}{r}58.5080 \\
(0.0000)\end{array}$ & $\begin{array}{c}59.4424 \\
(0.0000)\end{array}$ & $\begin{array}{c}33.0415 \\
(0.0000)\end{array}$ & $\begin{array}{r}61.3706 \\
(0.0000)\end{array}$ \\
\hline$\phi_{1}$ & $\begin{array}{r}0.9569 \\
(0.0000)\end{array}$ & $\begin{array}{r}0.9634 \\
(0.0000)\end{array}$ & $\begin{array}{r}0.9631 \\
(0.0000)\end{array}$ & $\begin{array}{r}0.9642 \\
(0.0000)\end{array}$ & $\begin{array}{r}0.9639 \\
(0.0000)\end{array}$ & $\begin{array}{r}0.9576 \\
(0.0000)\end{array}$ & $\begin{array}{r}0.9572 \\
(0.0000)\end{array}$ & $\begin{array}{r}0.9643 \\
(0.0000)\end{array}$ & $\begin{array}{r}0.9648 \\
(0.0000)\end{array}$ \\
\hline wind & & $\begin{array}{r}-10.5035 \\
(0.0000)\end{array}$ & & $\begin{array}{r}-5.7509 \\
(0.0000)\end{array}$ & & & & $\begin{array}{r}-5.8390 \\
(0.0000)\end{array}$ & \\
\hline consumption & & & $\begin{array}{c}14.6485 \\
(0.0000)\end{array}$ & $\begin{array}{r}10.4509 \\
(0.0000)\end{array}$ & & & & $\begin{array}{r}10.1070 \\
(0.0000)\end{array}$ & \\
\hline wind $_{\text {pen }}$ & & & & & $\begin{array}{r}-27.6488 \\
(0.0000)\end{array}$ & & & & $\begin{array}{r}-28.3447 \\
(0.0000)\end{array}$ \\
\hline \multicolumn{10}{|l|}{ gas } \\
\hline hydro & & & & & & $\begin{array}{r}1.4388 \\
(0.0042)\end{array}$ & & $\begin{array}{r}1.1169 \\
(0.0028)\end{array}$ & \\
\hline \multirow[t]{2}{*}{ exim $_{\text {bass }}$} & & & & & & & $\begin{array}{r}1.8034 \\
(0.0000)\end{array}$ & & $\begin{array}{r}2.3559 \\
(0.0000)\end{array}$ \\
\hline & \multicolumn{9}{|c|}{ Variance Equation } \\
\hline$\omega$ & $\begin{array}{r}0.9585 \\
(0.0000)\end{array}$ & $\begin{array}{r}1.19689 \\
(0.0000)\end{array}$ & $\begin{array}{r}0.5208 \\
(0.1670)\end{array}$ & $\begin{array}{r}1.0607 \\
(0.0116)\end{array}$ & $\begin{array}{r}1.1939 \\
(0.0000)\end{array}$ & $\begin{array}{r}0.9182 \\
(0.0000)\end{array}$ & $\begin{array}{r}1.0341 \\
(0.0000)\end{array}$ & $\begin{array}{r}1.0414 \\
(0.0123)\end{array}$ & $\begin{array}{r}1.2614 \\
(0.0000)\end{array}$ \\
\hline$\alpha$ & $\begin{array}{r}0.0443 \\
(0.3139)\end{array}$ & $\begin{array}{r}0.0102 \\
(0.8328)\end{array}$ & $\begin{array}{r}0.0245 \\
(0.6562)\end{array}$ & $\begin{array}{r}0.0072 \\
(0.8927)\end{array}$ & $\begin{array}{r}0.0090 \\
(0.8553)\end{array}$ & $\begin{array}{r}0.0388 \\
(0.3743)\end{array}$ & $\begin{array}{r}0.0370 \\
(0.4130)\end{array}$ & $\begin{array}{r}0.0053 \\
(0.9210)\end{array}$ & $\begin{array}{r}-0.0012 \\
(0.9824)\end{array}$ \\
\hline$\beta$ & $\begin{array}{r}0.8393 \\
(0.0000)\end{array}$ & $\begin{array}{r}0.8212 \\
(0.0000)\end{array}$ & $\begin{array}{r}0.8296 \\
(0.0000)\end{array}$ & $\begin{array}{r}0.8247 \\
(0.0000)\end{array}$ & $\begin{array}{r}0.8214 \\
(0.0000)\end{array}$ & $\begin{array}{r}0.8431 \\
(0.0000)\end{array}$ & $\begin{array}{r}0.8293 \\
(0.0000)\end{array}$ & $\begin{array}{r}0.8284 \\
(0.0000)\end{array}$ & $\begin{array}{r}0.8129 \\
(0.0000)\end{array}$ \\
\hline$\gamma$ & $\begin{array}{r}1.1081 \\
(0.0000)\end{array}$ & $\begin{array}{r}1.2804 \\
(0.0000)\end{array}$ & $\begin{array}{r}1.4478 \\
(0.0002)\end{array}$ & $\begin{array}{r}1.4148 \\
(0.0002)\end{array}$ & $\begin{array}{r}1.2978 \\
(0.0000)\end{array}$ & $\begin{array}{r}1.1035 \\
(0.0000)\end{array}$ & $\begin{array}{r}1.1548 \\
(0.0000)\end{array}$ & $\begin{array}{r}1.4055 \\
(0.0002)\end{array}$ & $\begin{array}{r}1.3963 \\
(0.0000)\end{array}$ \\
\hline wind & & $\begin{array}{r}-0.4278 \\
(0.0022)\end{array}$ & & $\begin{array}{r}-0.4689 \\
(0.0014)\end{array}$ & & & & $\begin{array}{r}-0.4580 \\
(0.002)\end{array}$ & \\
\hline consumption & & & $\begin{array}{r}0.2109 \\
(0.1059)\end{array}$ & $\begin{array}{r}0.0592 \\
(0.6703)\end{array}$ & & & & $\begin{array}{r}0.0502 \\
(0.7175)\end{array}$ & \\
\hline wind $_{\text {pen }}$ & & & & & $\begin{array}{r}-1.0598 \\
(0.0031)\end{array}$ & & & & $\begin{array}{r}-0.9282 \\
(0.0114)\end{array}$ \\
\hline hydro & & & & & & $\begin{array}{r}0.0267 \\
(0.5531)\end{array}$ & & $\begin{array}{r}0.0252 \\
(0.5995)\end{array}$ & \\
\hline exim $_{\text {bass }}$ & & & & & & & $\begin{array}{c}-0.0799 \\
(0.0130)\end{array}$ & & $\begin{array}{r}-0.0642 \\
(0.0569)\end{array}$ \\
\hline Shape & $\begin{array}{r}2.2463 \\
(0.0000)\end{array}$ & $\begin{array}{r}2.1931 \\
(0.0000)\end{array}$ & $\begin{array}{r}2.1387 \\
(0.0000)\end{array}$ & $\begin{array}{r}2.1502 \\
(0.0000)\end{array}$ & $\begin{array}{c}2.18611 \\
(0.0000)\end{array}$ & $\begin{array}{r}2.2457 \\
(0.0000)\end{array}$ & $\begin{array}{r}2.2280 \\
(0.0000)\end{array}$ & $\begin{array}{r}2.1512 \\
(0.0000)\end{array}$ & $\begin{array}{r}2.1590 \\
(0.0000)\end{array}$ \\
\hline log likelihood & -12907.05 & -12777.51 & -12756.38 & -12724.31 & -12768.23 & -12900.76 & -12893.77 & -12719.80 & -12748.20 \\
\hline$A I C$ & 7.5104 & 7.4362 & 7.4239 & 7.4064 & 7.4308 & 7.5079 & 7.5038 & 7.4049 & 7.4203 \\
\hline$B I C$ & 7.5229 & 7.4523 & 7.4400 & 7.4261 & 7.4469 & 7.5239 & 7.5199 & 7.4282 & 7.4399 \\
\hline$Q(20)$ & $\begin{array}{r}58.2400 \\
(0.0000)\end{array}$ & $\begin{array}{r}57.6400 \\
(0.0000)\end{array}$ & $\begin{array}{r}56.7400 \\
(0.0000)\end{array}$ & $\begin{array}{r}58.8500 \\
(0.0000)\end{array}$ & $\begin{array}{r}57.4000 \\
(0.0000)\end{array}$ & $\begin{array}{r}58.9100 \\
(0.0000)\end{array}$ & $\begin{array}{r}55.8200 \\
(0.0000)\end{array}$ & $\begin{array}{r}59.0600 \\
(0.0000)\end{array}$ & $\begin{array}{r}54.1700 \\
(0.0000)\end{array}$ \\
\hline$Q^{2}(36)$ & $\begin{array}{r}2.4107 \\
(0.8507)\end{array}$ & $\begin{array}{r}3.0359 \\
(0.7530)\end{array}$ & $\begin{array}{r}3.1623 \\
(0.7319)\end{array}$ & $\begin{array}{r}3.4111 \\
(0.6896)\end{array}$ & $\begin{array}{r}3.0462 \\
(0.7513)\end{array}$ & $\begin{array}{r}2.3314 \\
(0.8620)\end{array}$ & $\begin{array}{r}2.5383 \\
(0.8320)\end{array}$ & $\begin{array}{r}3.3242 \\
(0.7045)\end{array}$ & $\begin{array}{r}3.3007 \\
(0.7084)\end{array}$ \\
\hline ARCH-LM Test & $\begin{array}{r}1.6395 \\
(0.7930)\end{array}$ & $\begin{array}{r}1.9827 \\
(0.7210)\end{array}$ & $\begin{array}{r}2.0895 \\
(0.6984)\end{array}$ & $\begin{array}{r}2.2262 \\
(0.6695)\end{array}$ & $\begin{array}{r}1.9853 \\
(0.7204)\end{array}$ & $\begin{array}{r}1.5842 \\
(0.8043)\end{array}$ & $\begin{array}{r}1.7353 \\
(0.7731)\end{array}$ & $\begin{array}{r}2.1572 \\
(0.6840)\end{array}$ & $\begin{array}{r}2.1791 \\
(0.6794)\end{array}$ \\
\hline Observations & 3439 & 3439 & 3439 & 3439 & 3439 & 3439 & 3439 & 3439 & 3439 \\
\hline
\end{tabular}

Wind generation, electricity consumption, hydro generation, and the cross-border interconnector flows are scaled by $10^{4}$ to clarify the presentation of the results. The corresponding coefficients should, therefore, be multiplied by $0.1 \mathrm{AUD} / \mathrm{MWh}$ and 0.1 for a $1 \mathrm{GWh}$ increase in either variable for the mean equation and the variance equation, respectively. AIC denotes the Akaike information criterion, BIC is the Bayesian information criterion and $\mathrm{ARCH}$ LM is the Lagrange multiplier test for ARCH effect. The $p$ values are in parentheses. 


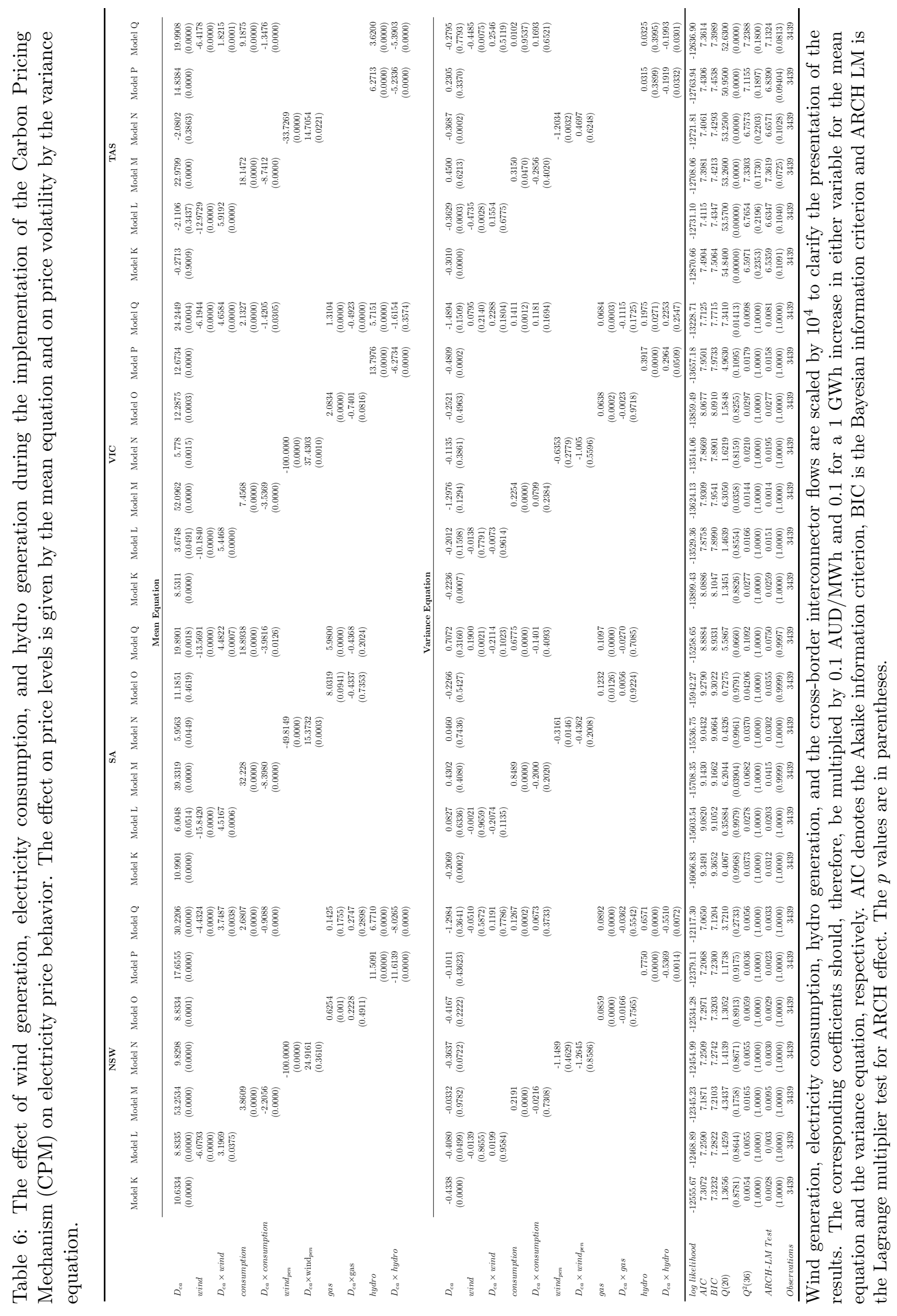




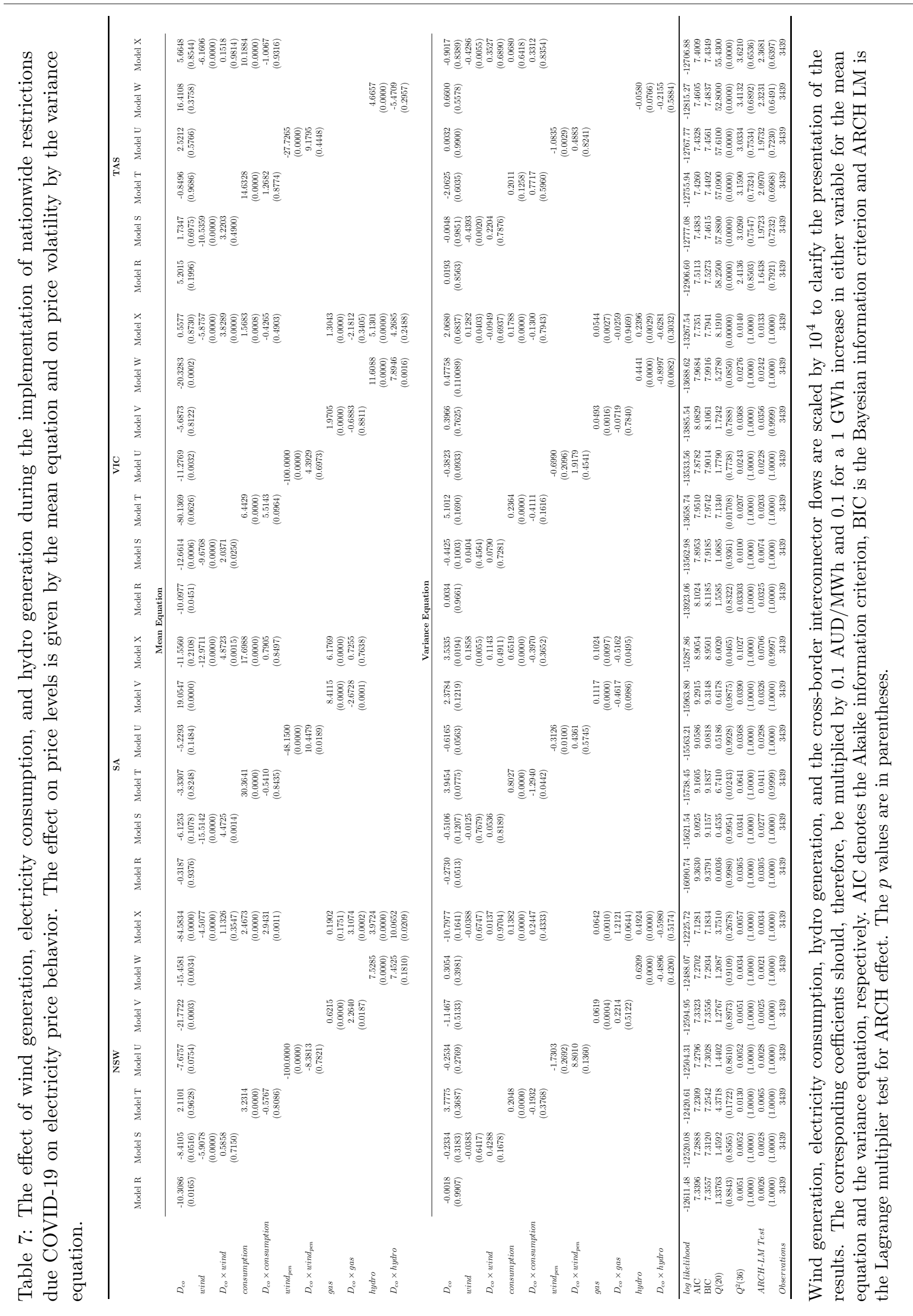


Table 8: Price distribution properties for different wind penetration levels.

\begin{tabular}{|c|c|c|c|c|c|c|c|c|c|c|c|c|c|}
\hline \multirow[t]{2}{*}{ Wind Penetration } & $<5 \%$ & $5 \%-15 \%$ & & $<5 \%$ & $5 \%-10 \%$ & $10 \%-15 \%$ & $15 \%-30 \%$ & & $<5 \%$ & $5 \%-10 \%$ & $10 \%-15 \%$ & $15 \%-20 \%$ & $20 \%-35 \%$ \\
\hline & \multicolumn{2}{|c|}{ NSW } & & \multicolumn{4}{|c|}{ VIC } & \multicolumn{6}{|c|}{ TAS } \\
\hline Mean & 61.39 & 50.48 & & 66.68 & 63.06 & 49.27 & 34.40 & & 70.20 & 62.74 & 59.45 & 54.21 & 48.85 \\
\hline Standard Deviation & 56.73 & 15.88 & & 36.15 & 113.38 & 20.35 & 20.54 & & 37.73 & 28.43 & 27.44 & 34.08 & 32.74 \\
\hline Skewness & 18.11 & 0.89 & & 8.32 & 21.82 & 0.10 & -0.19 & & 2.56 & 1.73 & 1.45 & 1.42 & 1.47 \\
\hline Kurtosis & 389.69 & 3.98 & & 120.21 & 554.18 & 5.58 & 0.18 & & 16.56 & 7.42 & 6.78 & 5.15 & 5.66 \\
\hline Observations & 3092 & 347 & & 1259 & 1405 & 535 & 240 & & 890 & 1081 & 776 & 421 & 271 \\
\hline \multirow[t]{2}{*}{ Wind Penetration } & $<5 \%$ & $5 \%-10 \%$ & $10 \%-15 \%$ & $15 \%-20 \%$ & $20 \%-25 \%$ & $25 \%-30 \%$ & $30 \%-35 \%$ & $35 \%-40 \%$ & $40 \%-45 \%$ & $45 \%-50 \%$ & $>50 \%$ & & \\
\hline & \multicolumn{11}{|c|}{ SA } & & \\
\hline Mean & 112.38 & 89.81 & 99.92 & 82.12 & 69.49 & 85.58 & 67.98 & 64.78 & 61.83 & 58.90 & 44.91 & & \\
\hline Standard Deviation & 124.29 & 63.16 & 104.86 & 53.41 & 149.58 & 197.77 & 49.95 & 27.96 & 38.32 & 27.77 & 29.78 & & \\
\hline Skewness & 6.41 & 6.32 & 6.09 & 6.87 & 11.75 & 12.92 & 9.08 & 2.76 & 3.10 & 0.24 & 1.78 & & \\
\hline Kurtosis & 47.53 & 51.49 & 46.52 & 73.27 & 162.08 & 192.26 & 117.24 & 19.19 & 24.02 & 6.18 & 21.91 & & \\
\hline Observations & 131 & 161 & 201 & 305 & 332 & 368 & 296 & 242 & 224 & 201 & 978 & & \\
\hline
\end{tabular}




\section{References}

ABC, 2018. How China's push for cleaner air is pushing up Australian power prices. https://www.abc.net.au/news/2018-11-22/ chinese-push-for-cleaner-air-pushes-up-australian-power-prices/10513730, Accessed October 2020.

ACC, 2017. Towards the next generation: Delivering affordable, secure and lower emissions power. Climate Change Authority (ACC).

AEMC, 2019. Residential electricity price trends 2019. Australian Energy Market Commission (AEMC).

AEMO, 2017. Interconnector capabilities for the National Electricity Market. https: //www.aemo.com.au/-/media/Files/Electricity/NEM/Security_and_Reliability/ Congestion-Information/2017/Interconnector-Capabilities.pdf, Accessed February 2020 .

AEMO, 2018. Wholesale electricity market performance report. https://www.aer.gov . $\mathrm{au} /$ system/files/Wholesale $\% 20$ electricity $\% 20$ market $\% 20$ performance $\% 20$ report $\% 20-\%$ 20December\%202018_0.pdf, Accessed October 2020.

AEMO, 2019a. Energy dynamics Q3 2019: Market insights and WA market operations. https:// WWw. aemo.com.au/-/media/Files/Media_Centre/2019/QED-Q3-2019.pdf, Accessed January 2020 .

AEMO, 2019b. Quarterly energy dynamics Q4 2019. https://www.aemo.com.au/-/media/ files/major-publications/qed/2019/qed-q4-2019.pdf, Accessed August 2020.

AEMO, 2019c. South Australian electricity report. aemo.com.au/-/ media/Files/Electricity/NEM/Planning_and_Forecasting/SA_Advisory/2019/ 2019-South-Australian-Electricity-Report.pdf, Accessed February 2020.

AEMO, 2020a. Battery storage: Charged and ready to go? https://aemo.com.au/newsroom/ news-updates/battery-storage, Accessed August 2020.

AEMO, 2020b. Coal and biomass price. https://aemo.com.au/-/media/files/ electricity/nem/planning_and_forecasting/inputs-assumptions-methodologies/ 2020/2019-input-and-assumptions-workbook-v1-5-jul-20.xlsx, Accessed October 2020.

AEMO, 2020c. Declared Wholesale Gas Market (DWGM). https://www.aemo.com.au/Gas/ Declared-Wholesale-Gas-Market-DWGM/Data/VIC-Wholesale-Price-and-Withdrawals, Accessed December 2019. 
AEMO, 2020d. Maintaining power system security with high penetrations of wind and solar generation. https://www.aemo.com.au/-/media/Files/Electricity/NEM/Security_and_ Reliability/Future-Energy-Systems/2019/AEMO-RIS-International-Review-Oct-19. pdf, Accessed August 2020.

AEMO, 2020e. Quarterly energy dynamics Q1 2020. https://aemo.com.au/-/media/files/ major-publications/qed/2020/qed-q1-2020.pdf?la=en, Accessed August 2020.

AEMO, 2020f. Quarterly energy dynamics Q2 2020. https://aemo.com.au/-/media/files/ major-publications/qed/2020/qed-q2-2020.pdf?la=en, Accessed August 2020.

AEMO, 2020g. Short Term Trading Market (STTM). https://www.aemo.com.au/Gas/ Short-Term-Trading-Market-STTM/Data, Accessed December 2019.

AER, 2013. State of the energy market. https://www.aer.gov.au/publications/ state-of-the-energy-market-reports/state-of-the-energy-market-2013, Accessed December 2019.

AER, 2014. State of the energy market. https://www.aer.gov.au/publications/ state-of-the-energy-market-reports/state-of-the-energy-market-2014, Accessed December 2019.

AER, 2015. State of the energy market. https://www.aer.gov.au/publications/ state-of-the-energy-market-reports/state-of-the-energy-market-2015, Accessed December 2019.

AER, 2017. State of the energy market. https://www.aer.gov.au/publications/ state-of-the-energy-market-reports/state-of-the-energy-market-2017, Accessesd December 2019.

AER, 2018. State of the energy market. https://www.aer.gov.au/publications/ state-of-the-energy-market-reports/state-of-the-energy-market-2018, Accessed December 2019.

AER, 2020a. Quarterly price setter and average price set by fuel source - South Australia. https://www.aer.gov.au/wholesale-markets/wholesale-statistics/ quarterly-price-setter-and-average-price-set-by-fuel-source-south-australia, Accessed October 2020.

AER, 2020b. State of the energy market. https://www.aer.gov.au/publications/ state-of-the-energy-market-reports/state-of-the-energy-market-2020, Accessed August 2020 . 
Alasseur, C., Féron, O., 2018. Structural price model for coupled electricity markets. Energy Economics 75, 104-119.

de Atholia, T., Flannigan, G., Lai, S., 2020. Renewable energy investment in Australia. Reserve Bank of Australia Bulletin, 36-46.

Auer, B.R., 2014. Daily seasonality in crude oil returns and volatilities. Energy Economics 43, $82-88$.

Baldick, R., 2011. Wind and energy markets: A case study of Texas. IEEE Systems Journal 6, $27-34$.

Bell, W.P., Wild, P., Foster, J., Hewson, M., 2015. Wind speed and electricity demand correlation analysis in the Australian National Electricity Market: Determining wind turbine generators' ability to meet electricity demand without energy storage. Economic Analysis and Policy 48, $182-191$.

Bell, W.P., Wild, P., Foster, J., Hewson, M., 2017. Revitalising the wind power induced merit order effect to reduce wholesale and retail electricity prices in Australia. Energy Economics 67, $224-241$.

Bierbrauer, M., Menn, C., Rachev, S.T., Trück, S., 2007. Spot and derivative pricing in the EEX power market. Journal of Banking \& Finance 31, 3462-3485.

Black, A.J., 2006. Macroeconomic risk and the Fama-French three-factor model. Managerial Finance 32, 505-517.

Brinsmead, T.S., Hayward, J., Graham, P., 2014. Australian electricity market analysis report to 2020 and 2030. CSIRO Technical Report No. EP141067.

Bublitz, A., Keles, D., Fichtner, W., 2017. An analysis of the decline of electricity spot prices in Europe: Who is to blame? Energy Policy 107, 323-336.

Burbidge, J.B., Magee, L., Robb, A.L., 1988. Alternative transformations to handle extreme values of the dependent variable. Journal of the American Statistical Association 83, 123-127.

Burke, P.J., Best, R., Jotzo, F., 2019. Closures of coal-fired power stations in Australia: Local unemployment effects. Australian Journal of Agricultural and Resource Economics 63, 142-165.

Byström, H.N., 2005. Extreme value theory and extremely large electricity price changes. International Review of Economics \& Finance 14, 41-55.

Castagneto Gissey, G., 2014. Electricity and energy price interactions in modern EU markets. Imperial College London. 
CEC, 2020. Renewable energy target. https://www.cleanenergycouncil.org.au/ advocacy-initiatives/renewable-energy-target, Accessed August 2020.

Clò, S., Cataldi, A., Zoppoli, P., 2015. The merit-order effect in the Italian power market: The impact of solar and wind generation on national wholesale electricity prices. Energy Policy 77, $79-88$.

Cludius, J., Forrest, S., MacGill, I., 2014a. Distributional effects of the Australian Renewable Energy Target (RET) through wholesale and retail electricity price impacts. Energy Policy 71, $40-51$.

Cludius, J., Hermann, H., Matthes, F.C., Graichen, V., 2014b. The merit order effect of wind and photovoltaic electricity generation in Germany 2008-2016: Estimation and distributional implications. Energy Economics 44, 302-313.

COAG, 2019. Australia's national hydrogen strategy. https://www.industry.gov.au/sites/ default/files/2019-11/australias-national-hydrogen-strategy.pdf, Accessed August 2020 .

Cornwall Insight, 2020. State of the market. 2020 Energy Master Class. https://www. bakermckenzie.com/en/locations/asia-pacific/australia, Accessed July 2020.

Csereklyei, Z., Qu, S., Ancev, T., 2019. The effect of wind and solar power generation on wholesale electricity prices in Australia. Energy Policy 131, 358-369.

Cutler, N.J., Boerema, N.D., MacGill, I.F., Outhred, H.R., 2011. High penetration wind generation impacts on spot prices in the Australian national electricity market. Energy Policy 39, 59395949.

Denny, E., Tuohy, A., Meibom, P., Keane, A., Flynn, D., Mullane, A., O'malley, M., 2010. The impact of increased interconnection on electricity systems with large penetrations of wind generation: A case study of Ireland and Great Britain. Energy Policy 38, 6946-6954.

Deschatre, T., Veraart, A.E., 2017. A joint model for electricity spot prices and wind penetration with dependence in the extremes, in: Forecasting and Risk Management for Renewable Energy, Springer. pp. 185-207.

Dickey, D.A., Fuller, W.A., 1979. Distribution of the estimators for autoregressive time series with a unit root. Journal of the American Statistical Association 74, 427-431.

Du, P., Baldick, R., Tuohy, A., 2017. Integration of large-scale renewable energy into bulk power systems. Springer.doi 10, 978-3. 
Engle, R.F., 1982. Autoregressive conditional heteroscedasticity with estimates of the variance of United Kingdom inflation. Econometrica 50, 987-1007.

Fisher, T.J., Gallagher, C.M., 2012. New weighted portmanteau statistics for time series goodness of fit testing. Journal of the American Statistical Association 107, 777-787.

Forrest, S., MacGill, I., 2013. Assessing the impact of wind generation on wholesale prices and generator dispatch in the Australian National Electricity Market. Energy Policy 59, 120-132.

Geman, H., Roncoroni, A., 2006. Understanding the fine structure of electricity prices. The Journal of Business 79, 1225-1261.

Genoese, F., Genoese, M., Wietschel, M., 2010. Occurrence of negative prices on the German spot market for electricity and their influence on balancing power markets, in: 2010 7th International Conference on the European Energy Market, IEEE. pp. 1-6.

Ghalanos, A., 2020. Introduction to the rugarch package (Version 1.4-3). https: //cran.r-project.org/web/packages/rugarch/vignettes/Introduction_to_the_ rugarch_package.pdf, Accessed August 2020.

Hair, J.F., Black, W.C., Babin, B.J., Anderson, R.E., Tatham, R.L., et al., 2019. Multivariate data analysis. Hampshire, UK: Cengage Learning, EMEA.

Han, L., Kordzakhia, N., Trück, S., 2020. Volatility spillovers in Australian electricity markets. Energy Economics 90, 104782.

Hickey, E., Loomis, D.G., Mohammadi, H., 2012. Forecasting hourly electricity prices using ARMAX-GARCH models: An application to MISO hubs. Energy Economics 34, 307-315.

Higgs, H., 2009. Modelling price and volatility inter-relationships in the Australian wholesale spot electricity markets. Energy Economics 31, 748-756.

Higgs, H., Worthington, A.C., 2005. Systematic features of high-frequency volatility in Australian electricity markets: Intraday patterns, information arrival and calendar effects. The Energy Journal 26, 23-41.

Hirth, L., 2013. The market value of variable renewables: The effect of solar wind power variability on their relative price. Energy Economics 38, 218-236.

HT, 2019. Battery of the Nation: Understanding reliability in the future NEM. Hydro Tasmania.

Huang, B., Chen, Y., Baldick, R., 2020. A configuration based pumped storage hydro model in MISO day-ahead market. ArXiv preprint arXiv:2009.04944. 
Ignatieva, K., Trück, S., 2016. Modeling spot price dependence in Australian electricity markets with applications to risk management. Computers \& Operations Research 66, 415-433.

Jonsson, T., Pinson, P., Madsen, H., 2010. On the market impact of wind energy forecasts. Energy Economics 32, S313-S320.

Kelley, M.T., Baldick, R., Baldea, M., 2020. An empirical study of moving horizon closed-loop demand response scheduling. Journal of Process Control 92, 137-148.

Ketterer, J.C., 2014. The impact of wind power generation on the electricity price in Germany. Energy Economics 44, 270-280.

Knittel, C., Roberts, M., 2005. An empirical examination of structured electricity prices. Energy Economics 27, S791-S817.

Kwiatkowski, D., Phillips, P.C., Schmidt, P., Shin, Y., 1992. Testing the null hypothesis of stationarity against the alternative of a unit root. Journal of Econometrics 54, 159-178.

Kyritsis, E., Andersson, J., Serletis, A., 2017. Electricity prices, large-scale renewable integration, and policy implications. Energy Policy 101, 550-560.

Leys, C., Ley, C., Klein, O., Bernard, P., Licata, L., 2013. Detecting outliers: Do not use standard deviation around the mean, use absolute deviation around the median. Journal of Experimental Social Psychology 49, 764-766.

Maciejowska, K., 2020. Assessing the impact of renewable energy sources on the electricity price level and variability: A quantile regression approach. Energy Economics 85, 104532.

Marshman, D., Brear, M., Jeppesen, M., Ring, B., 2020. Performance of wholesale electricity markets with high wind penetration. Energy Economics 89, 104803.

Maryniak, P., Trück, S., Weron, R., 2019. Carbon pricing and electricity markets: The case of the Australian Clean Energy Bill. Energy Economics 79, 45-58.

Mauritzen, J., 2010. What happens when it's windy in Denmark? An empirical analysis of wind power on price volatility in the Nordic electricity market. Discussion Papers 2010/18. Department of Business and Management Science, Norwegian School of Economics.

Mehrang, S., Helander, E., Pavel, M., Chieh, A., Korhonen, I., 2015. Outlier detection in weight time series of connected scales, in: 2015 IEEE International Conference on Bioinformatics and Biomedicine (BIBM), IEEE. pp. 1489-1496.

Moritz, S., Bartz-Beielstein, T., 2017. imputeTS: Time series missing value imputation in R. The R Journal 9, 207-218. doi:10.32614/RJ-2017-009. 
Mountain, B., Percy, S., 2019. The exercise of market power in Australia's National Electricity Market following the closure of the Hazelwood power station. VEPC working paper series 1901, Victoria Energy Policy Centre, Melbourne, Australia.

Mugele, C., Rachev, S., Trück, S., 2005. Stable modeling of different European power markets. Investment Management \& Financial Innovations 2, 65-83.

Nazifi, F., 2016. The pass-through rates of carbon costs on to electricity prices within the Australian National Electricity Market. Environmental Economics and Policy Studies 18, 41-62.

Nelson, D.B., 1991. Conditional heteroskedasticity in asset returns: A new approach. Econometrica $59,347-370$.

NEOpoint, 2020. Analysis and reporting on the web. http://products.iesys.com/NEO/ NEOpoint, Accessed December 2019.

O'Gorman, M., Jotzo, F., 2014. Impact of the carbon price on Australia's electricity demand, supply and emissions. CCEP working paper series 1411, Crawford School of Public Policy, The Australian National University.

Paraschiv, F., Erni, D., Pietsch, R., 2014. The impact of renewable energies on EEX day-ahead electricity prices. Energy Policy 73, 196-210.

Pereira, J.P., Rodrigues, P.M., 2015. The impact of wind generation on the mean and volatility of electricity prices in Portugal, in: 2015 12th International Conference on the European Energy Market (EEM), IEEE. pp. 1-5.

R Core Team, 2019. R: A language and environment for statistical computing. R Foundation for Statistical Computing. Vienna, Austria. https://www.R-project.org/.

Rai, A., Nunn, O., 2020. On the impact of increasing penetration of variable renewables on electricity spot price extremes in Australia. Economic Analysis and Policy 67, 67-86.

Rintamäki, T., Siddiqui, A.S., Salo, A., 2017. Does renewable energy generation decrease the volatility of electricity prices? An analysis of Denmark and Germany. Energy Economics 62, 270-282.

Rousseeuw, P.J., Croux, C., 1993. Alternatives to the median absolute deviation. Journal of the American Statistical association 88, 1273-1283.

Ruiz, E., Peña, D., Carnero, M.Á., et al., 2001. Outliers and conditional autoregressive heteroscedasticity in time series. Technical Report. Universidad Carlos III de Madrid. Departamento de Estadística. 
Schneider, S., 2011. Power spot price models with negative prices. Journal of Energy Markets 4, $77-102$.

Pereira da Silva, P., Horta, P., 2019. The effect of variable renewable energy sources on electricity price volatility: The case of the Iberian market. International Journal of Sustainable Energy 38, 794-813.

Simshauser, P., Gilmore, J., 2020. Is the NEM broken? Policy discontinuity and the 2017-2020 investment megacycle. Technical Report. Faculty of Economics, University of Cambridge.

Stocks, M., Baldwin, K., Blakers, A., 2019. Powering ahead: Australia leading the world in renewable energy build rates. https://energy.anu.edu.au/files/ renewable-energy-target-report-september-2019.pdf, Accessed January 2020.

Tang, J., Sriboonditta, S., Yuan, X., Wu, B., 2014. Dynamic copula-based GARCH model analysis China outbound tourism demand, in: Innovative Management in Information and Production. Springer, pp. 123-139.

Taylor, J.W., Buizza, R., 2004. A comparison of temperature density forecasts from GARCH and atmospheric models. Journal of Forecasting 23, 337-355.

Thomas, S., Mitchell, H., 2005. GARCH modeling of high-frequency volatility in Australia's National Electricity Market. Discussion Paper. Melbourne Centre for Financial Studies.

Thomas, S., Ramiah, V., Mitchell, H., Heaney, R., 2011. Seasonal factors and outlier effects in rate of return on electricity spot prices in Australia's National Electricity Market. Applied Economics 43, 355-369.

Trueck, S., Weron, R., Wolff, R., 2007. Outlier treatment and robust approaches for modeling electricity spot prices. Hugo Steinhaus Center, Wroclaw University of Technology.

Tveten, Å.G., Bolkesjø, T.F., Martinsen, T., Hvarnes, H., 2013. Solar feed-in tariffs and the merit order effect: Astudy of the German electricity market. Energy Policy 61, 761-770.

Uniejewski, B., Weron, R., Ziel, F., 2017. Variance stabilizing transformations for electricity spot price forecasting. IEEE Transactions on Power Systems 33, 2219-2229.

Ward, K., Green, R., Staffell, I., 2019. Getting prices right in structural electricity market models. Energy Policy 129, 1190-1206.

Weron, R., 2007. Modeling and forecasting electricity loads and prices: A statistical approach. volume 403. John Wiley \& Sons. 
Woo, C.K., Horowitz, I., Moore, J., Pacheco, A., 2011. The impact of wind generation on the electricity spot-market price level and variance: The Texas experience. Energy Policy 39, 39393944 .

Wood, T., Blowers, D., 2016. Keeping the lights on: Lessons from South Australia's power shock. Grattan Institute. https://grattan.edu.au/wp-content/uploads/2016/09/ 877-Keeping-the-lights-on.pdf, Accessed May 2020.

Worthington, A., Kay-Spratley, A., Higgs, H., 2005. Transmission of prices and price volatility in Australian electricity spot markets: A multivariate GARCH analysis. Energy Economics 27, $337-350$.

Yan, G., Trück, S., 2020. A dynamic network analysis of spot electricity prices in the Australian national electricity market. Energy Economics 92, 104972.

Ziel, F., Weron, R., 2018. Day-ahead electricity price forecasting with high-dimensional structures: Univariate vs. multivariate modeling frameworks. Energy Economics 70, 396-420.

Zivot, E., 2009. Practical issues in the analysis of univariate GARCH models, in: Handbook of financial time series. Springer, pp. 113-155. 


\section{Appendices}

\section{A Data}

\section{A.1 Preliminary analysis}

Table 9: Interconnectors capabilities in the NEM. Source AEMO (2017)

\begin{tabular}{lllc}
\hline Interconnector & From & To & Nominal Capacity (MW) \\
\hline Terranora (N-Q-MNSP1) & & & \\
& NSW & QLD & 107 \\
NSW1-QLD1 (QNI) & QLD & NSW & 210 \\
& NSW & QLD & $300-600$ \\
& QLD & NSW & 1078 \\
VIC1-NSW1 (VNI) & & & \\
& VIC & NSW & $700-1600$ \\
Basslink (T-V-MNSP1) & NSW & VIC & $400-1350$ \\
& TAS & VIC & 594 \\
& VIC & TAS & 478 \\
Heywood (V-SA) & & & 600 \\
& VIC & SA & 500 \\
Murraylink (V-S-MNSP1) & SA & VIC & 220 \\
& VIC & SA & 200 \\
\hline
\end{tabular}




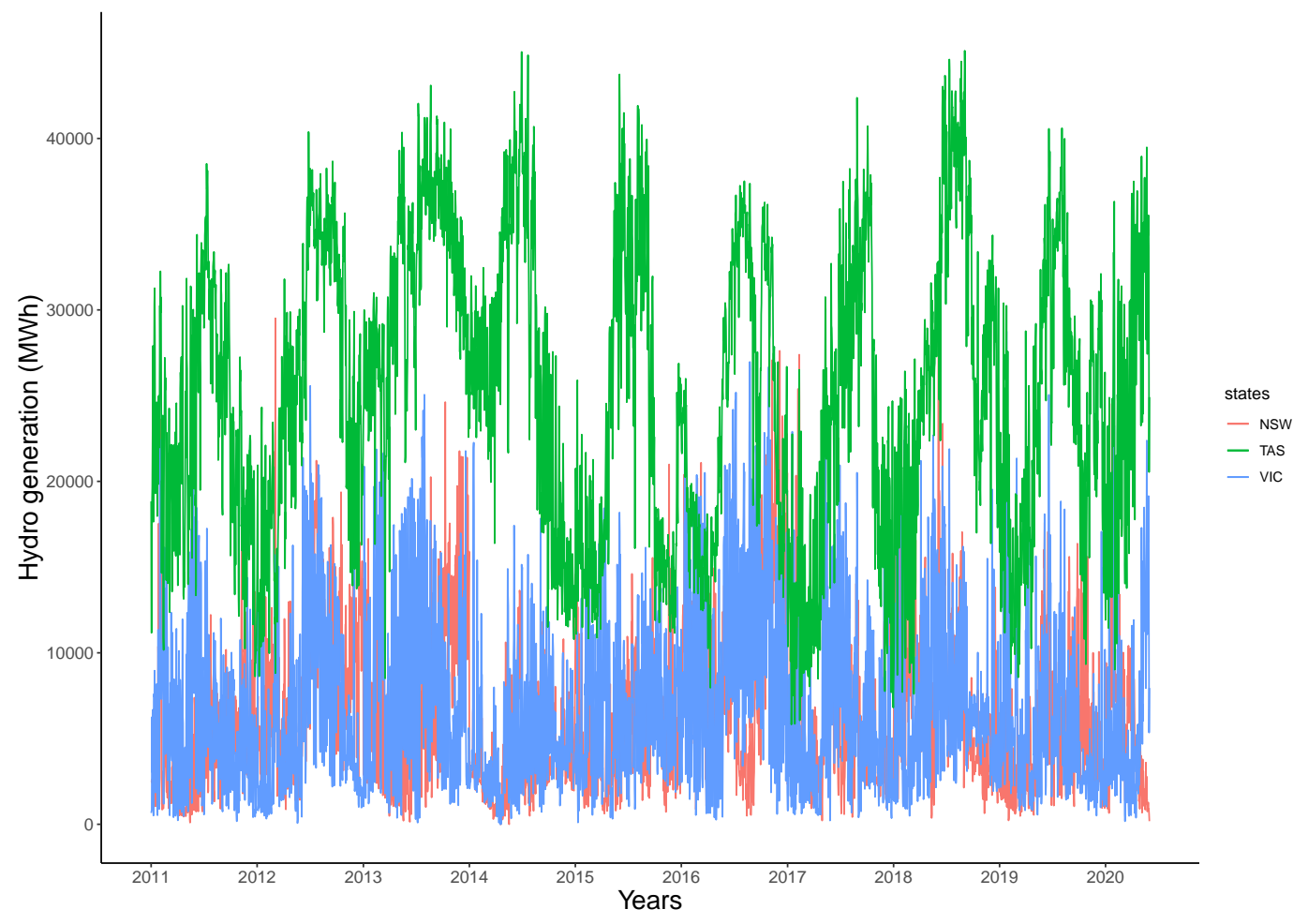

Figure 6: The daily hydro generation for NSW, SA, VIC, and TAS from January 1, 2020, to May 31, 2020 .

\section{A.2 Adjustment of price spikes}

We filter outliers using median absolute deviation (MAD) as the dispersion measure and follow Mugele et al. (2005), Bierbrauer et al. (2007), and Ketterer (2014). In particular, we create a time series of the original price series for each weekday to take into account cyclic nature of prices within a week. We then construct the threshold for filtering outliers as $F=\operatorname{med} \pm 3 \cdot M A D$, where med is the median of the weekday prices, and the $\mathrm{MAD}^{39}$ is defined as

$$
M A D_{i}=b \cdot \operatorname{med}_{i}\left(\left|x_{i}-\operatorname{med}_{j}\left(x_{j}\right)\right|\right),
$$

where $x_{j}$ is the weekday electricity price series, $\operatorname{med}_{i}$ is the median of the series, $b=1.4826$ is a constant defined in the presence of outliers to make the distribution normal (Rousseeuw and Croux, 1993). Any observation surpassing the filter $F$ is classified as an outlier. The number of outlying values identified for each regional market are presented in Table 10. The total number of outliers in the NEM during the sample period is 599. TAS accounts for more than half of the

\footnotetext{
${ }^{39}$ Leys et al. (2013) noted that median is more robust to outliers compared to arithmetic mean (see also Weron (2007) and Mehrang et al. (2015)). Therefore, MAD and not standard deviation should be used as the measure of dispersion. Furthermore, we set the thresholds to three (described by Leys et al. (2013) as very conservative) in order to include many observations, and it is a typical threshold which is widely applied in the previous literature (Mugele et al., 2005; Bierbrauer et al., 2007; Ketterer, 2014; Bublitz et al., 2017).
} 
Table 10: Occurrences of extreme spikes in prices by region and Weekday.

\begin{tabular}{lrrrrr}
\hline Weekday & NSW & SA & VIC & TAS & TOTAL \\
\hline & & & & & \\
Monday & 9 & 19 & 11 & 43 & 82 \\
Tuesday & 13 & 17 & 13 & 41 & 84 \\
Wednesday & 10 & 24 & 20 & 49 & 103 \\
Thursday & 17 & 23 & 22 & 48 & 110 \\
Friday & 12 & 23 & 15 & 49 & 99 \\
Saturday & 4 & 13 & 93 & 8 & 64 \\
Sunday & 2 & 10 & 7 & 38 & 57 \\
& & & & & \\
TOTAL & 67 & 129 & 97 & 306 & 599 \\
& $11.19 \%$ & $21.54 \%$ & $16.19 \%$ & $51.09 \%$ & $100 \%$ \\
\hline
\end{tabular}

total spikes, and NSW has the lowest number of instances where prices exceeded the limit $(11.19 \%$ of the total sample spikes). Furthermore, price spikes are more pronounced during business days than at the weekends. All values in Table 10 are then replaced by the median of the respective weekday (Ketterer, 2014; Kyritsis et al., 2017).

\section{A.3 Deseasonalizing and detrending the data}

We assume that the time series $p_{t}$ can be decomposed as a sum of the stochastic component $y_{t}$ and the seasonal component $s_{t}$, that is, $p_{t}=y_{t}+s_{t}, t>0$ (Bierbrauer et al., 2007; Trueck et al., 2007; Ketterer, 2014; Pereira and Rodrigues, 2015). ${ }^{40}$ We then apply the ordinary least squares (OLS) approach by creating dummy variables for the days $\left(d_{a}, i=1,2, \ldots, 7\right)$ corresponding to Monday to Sunday, months $\left(\right.$ mont $\left._{j}, j=1,2, \ldots, 12\right)$ corresponding to January to December and years $\left(\right.$ year $\left._{k}, k=1,2, \ldots, 10\right)$ corresponding to 2011 to 2020 , and specify the OLS as

$$
p_{t}=\hat{c}+\sum_{i=2}^{p} \hat{\phi} \cdot \text { day }_{i}+\sum_{j=2}^{q} \hat{\zeta} \cdot \text { mont }_{j}+\sum_{k=2}^{r} \hat{\eta} \cdot \text { year }_{k}+\epsilon_{t}
$$

where $p_{t}$ is the variable of interest and where applicable adjusted for the outlier effect. $p, q$ and $r$ are the total number of days in a week, months, and years, $\hat{c}$ is the estimate of the intercept, and $\hat{\phi}, \hat{\zeta}$, and $\hat{\eta}$ are the parameter estimates of the weekly, monthly and yearly regressors. The deseasonalized time series of electricity prices and other explanatory variables is captured by the

\footnotetext{
${ }^{40}$ In literature, researchers dealt with seasonal effect in different ways. This includes adding seasonal dummies (model seasonality) in the mean equation (Black, 2006; Hickey et al., 2012; Tang et al., 2014; Pereira da Silva and Horta, 2019). In this respect, the seasonal component is explained by dummies, and the GARCH part is free to model deseasonalized volatility. Also, there are those who add dummy variables (or model seasonality) in the variance (Higgs and Worthington (2005)) or both the mean and variance equation (Taylor and Buizza, 2004; Byström, 2005; Castagneto Gissey, 2014; Auer, 2014).
} 
regression residuals $\epsilon_{t}$. Similar to Ketterer (2014) we then align the mean of actual and the adjusted series. We apply the OLS approach separately for all the variables prior to fitting the ARX-eGARCHX models. The reason for the two-stage approach is because inclusion of seasonal dummies together with other explanatory variables in the same ARX-eGARCHX specification creates a complex model. Also, the rugarch package which is employed for our analysis supports only ARFIMA-GARCH based models (R Core Team, 2019; Ghalanos, 2020). The results for the deseasonalized and detrended time series are presented in Tables 11 to 18.

We specify Monday, January, and the year 2011 in Table 11 as our reference variables for weekdays, months, and years, respectively. Prices are relatively higher for all regions during workdays, although not statistically significantly different from that of Monday. For SA and VIC, we find some evidence that prices peak on Thursday. On Saturday and Sunday, prices are negative and statistically significant for almost all states indicating relatively lower price levels at the end of the week. We also observe variation in electricity prices across months of the year. The results for NSW, SA, and VIC suggest that prices in summer are relatively higher than that of winter and other months. TAS exhibits a slightly different behavior where prices in autumn, especially March and April, exceed summer month prices.

After accounting for price spikes in Table 12, the coefficients of monthly seasonality and year dummies become relatively more statistically significant. From this, we conclude that when the market is operating under typical conditions, electricity prices tend to be relatively higher during winter months. Further, we see from the year dummies that prices for all states dropped markedly in the year 2014 and 2015 though not statistically significant for all states. ${ }^{41}$ This is mostly accounted for by the repeal of the carbon pricing mechanism on July, 12014.

${ }^{41}$ The year 2020 dummy does not cover the whole year but the sample period from January 1, 2020, to May 31, 2020. 
Table 11: Seasonal and trend adjustment of daily electricity electricity prices not adjusted for price spikes.

\begin{tabular}{|c|c|c|c|c|c|c|c|c|c|c|}
\hline \multirow[b]{3}{*}{ Intercept (c) } & Estimate & Std. Error & $t$ value & $\operatorname{Pr}(>|t|)$ & & Estimate & Std. Error & $t$ value & $\operatorname{Pr}(>|t|)$ & \\
\hline & \multicolumn{4}{|c|}{ NSW } & & \multicolumn{5}{|c|}{ SA } \\
\hline & 46.8946 & 4.7001 & 9.977 & $<2 e-16$ & $* * *$ & 66.508 & 8.262 & 8.050 & $1.14 e-15$ & $* * *$ \\
\hline Tuesday & 2.4696 & 3.4676 & 0.712 & 0.476387 & & -5.175 & 6.096 & -0.849 & 0.395953 & \\
\hline Wednesday & 2.7243 & 3.4677 & 0.786 & 0.432143 & & -1.253 & 6.096 & -0.205 & 0.837210 & \\
\hline Thursday & 1.9126 & 3.4677 & 0.552 & 0.581297 & & 12.925 & 6.096 & 2.120 & 0.034051 & * \\
\hline Friday & 5.3469 & 3.4678 & 1.542 & 0.123195 & & -1.710 & 6.096 & -0.280 & 0.779144 & \\
\hline Saturday & -3.6419 & 3.4659 & -1.051 & 0.293433 & & -18.318 & 6.093 & -3.007 & 0.002661 & $* *$ \\
\hline Sunday & -9.0805 & 3.4658 & -2.620 & 0.008831 & $* *$ & -20.991 & 6.092 & -3.445 & 0.000577 & *** \\
\hline February & 4.7119 & 4.4668 & 1.055 & 0.291557 & & -20.690 & 7.852 & -2.635 & 0.008453 & $* *$ \\
\hline March & -16.4177 & 4.3640 & -3.762 & 0.000171 & $* * *$ & -30.679 & 7.671 & -3.999 & $6.49 e-05$ & $* * *$ \\
\hline April & -12.1218 & 4.4001 & -2.755 & 0.005903 & $* *$ & -31.091 & 7.735 & -4.020 & $5.96 e-05$ & $* * *$ \\
\hline May & -13.2085 & 4.3639 & -3.027 & 0.002490 & $* *$ & -26.694 & 7.671 & -3.480 & 0.000508 & $* * *$ \\
\hline June & -3.3494 & 4.5465 & -0.737 & 0.461355 & & -15.482 & 7.992 & -1.937 & 0.052817 & . \\
\hline July & -7.9612 & 4.5076 & -1.766 & 0.077453 & . & -2.384 & 7.924 & -0.301 & 0.763551 & \\
\hline August & -7.7437 & 4.5075 & -1.718 & 0.085899 & . & -28.954 & 7.924 & -3.654 & 0.000262 & $* * *$ \\
\hline September & -6.3475 & 4.5465 & -1.396 & 0.162771 & & -33.491 & 7.992 & -4.190 & $2.86 e-05$ & $* * *$ \\
\hline October & -8.6893 & 4.5075 & -1.928 & 0.053971 & . & -37.566 & 7.924 & -4.741 & $2.21 e-06$ & $* * *$ \\
\hline November & -7.6952 & 4.5465 & -1.693 & 0.090633 & . & -35.970 & 7.992 & -4.501 & $7.00 e-06$ & $* * *$ \\
\hline December & -15.1619 & 4.5076 & -3.364 & 0.000778 & $* * *$ & -26.869 & 7.924 & -3.391 & 0.000705 & $* * *$ \\
\hline 2012 & 4.1253 & 4.0189 & 1.026 & 0.304749 & & 6.789 & 7.065 & 0.961 & 0.336650 & \\
\hline 2013 & 14.9803 & 4.0217 & 3.725 & 0.000199 & $* * *$ & 34.240 & 7.070 & 4.843 & $1.33 e-06$ & $* * *$ \\
\hline 2014 & 3.8526 & 4.0217 & 0.958 & 0.338150 & & 10.673 & 7.070 & 1.510 & 0.131227 & \\
\hline 2015 & 0.2348 & 4.0217 & 0.058 & 0.953449 & & 12.083 & 7.070 & 1.709 & 0.087516 & \\
\hline 2016 & 20.0209 & 4.0189 & 4.982 & $6.62 e-07$ & $* * *$ & 43.163 & 7.065 & 6.110 & $1.11 e-09$ & $* * *$ \\
\hline 2017 & 56.5887 & 4.0217 & 14.071 & $<2 e-16$ & $* * *$ & 67.926 & 7.070 & 9.608 & $<2 e-16$ & $* * *$ \\
\hline 2018 & 43.4131 & 4.0217 & 10.795 & $<2 e-16$ & $* * *$ & 62.431 & 7.070 & 8.831 & $<2 e-16$ & $* * *$ \\
\hline 2019 & 45.9243 & 4.0217 & 11.419 & $<2 e-16$ & $* * *$ & 61.485 & 7.070 & 8.697 & $<2 e-16$ & $* * *$ \\
\hline 2020 & 28.6670 & 5.3646 & 5.344 & $9.70 e-08$ & $* * *$ & 13.241 & 9.430 & 1.404 & 0.160402 & \\
\hline \multirow{3}{*}{$\begin{array}{l}\text { Multiple R-squared } \\
\text { Adjusted R-squared }\end{array}$} & \multicolumn{5}{|c|}{0.1383} & \multicolumn{5}{|c|}{0.0882} \\
\hline & \multicolumn{4}{|c|}{0.1317} & & \multicolumn{5}{|c|}{0.0812} \\
\hline & \multicolumn{4}{|c|}{ VIC } & & \multicolumn{4}{|c|}{ TAS } & \\
\hline Intercept (c) & 53.908 & 6.673 & 8.078 & $9.02 e-16$ & $* * *$ & 41.3443 & 2.8247 & 14.637 & $<2 e-16$ & $* * *$ \\
\hline Tuesday & 1.357 & 4.923 & 0.276 & 0.782818 & & 0.1746 & 2.0839 & 0.084 & 0.9332 & \\
\hline Wednesday & 2.683 & 4.923 & 0.545 & 0.585863 & & -0.3671 & 2.0840 & -0.176 & 0.8602 & \\
\hline Thursday & 11.764 & 4.923 & 2.389 & 0.016935 & * & -0.9230 & 2.0840 & -0.443 & 0.6579 & \\
\hline Friday & 7.754 & 4.924 & 1.575 & 0.115362 & & -2.8644 & 2.0841 & -1.374 & 0.1694 & \\
\hline Saturday & -8.234 & 4.921 & -1.673 & 0.094360 & . & -5.1073 & 2.0829 & -2.452 & 0.0143 & * \\
\hline Sunday & -11.068 & 4.921 & -2.249 & 0.024563 & * & -4.6960 & 2.0829 & -2.255 & 0.0242 & * \\
\hline February & -27.834 & 6.342 & -4.389 & $1.17 e-05$ & $* * *$ & 2.8378 & 2.6845 & 1.057 & 0.2905 & \\
\hline March & -29.312 & 6.196 & -4.731 & $2.33 e-06$ & $* * *$ & 11.2428 & 2.6227 & 4.287 & $1.86 e-05$ & $* * *$ \\
\hline April & -31.058 & 6.247 & -4.971 & $6.98 e-07$ & $* * *$ & 6.8530 & 2.6444 & 2.591 & 0.0096 & $* *$ \\
\hline May & -28.790 & 6.196 & -4.647 & $3.50 e-06$ & $* * *$ & -15.6316 & 2.6226 & -5.960 & $2.77 e-09$ & $* * *$ \\
\hline June & -19.045 & 6.455 & -2.950 & 0.003196 & $* *$ & -13.4544 & 2.7324 & -4.924 & $8.88 e-07$ & $* * *$ \\
\hline July & -21.558 & 6.400 & -3.368 & 0.000764 & $* * *$ & -15.7293 & 2.7090 & -5.806 & $6.97 e-09$ & $* * *$ \\
\hline August & -25.537 & 6.400 & -3.990 & $6.74 e-05$ & $* * *$ & -25.8588 & 2.7090 & -9.546 & $<2 e-16$ & $* * *$ \\
\hline September & -26.472 & 6.455 & -4.101 & $4.21 e-05$ & $* * *$ & -25.1761 & 2.7324 & -9.214 & $<2 e-16$ & $* * *$ \\
\hline October & -30.492 & 6.400 & -4.765 & $1.97 e-06$ & $* * *$ & -15.9627 & 2.7089 & -5.893 & $4.17 e-09$ & $* * *$ \\
\hline November & -28.551 & 6.455 & -4.423 & $1.00 e-05$ & $* * *$ & -13.2618 & 2.7324 & -4.854 & $1.27 e-06$ & $* * *$ \\
\hline December & -33.241 & 6.400 & -5.194 & $2.18 e-07$ & $* * *$ & -16.5307 & 2.7090 & -6.102 & $1.16 e-09$ & $* * *$ \\
\hline 2012 & 15.044 & 5.706 & 2.636 & 0.008416 & $* *$ & 12.6772 & 2.4153 & 5.249 & $1.63 e-07$ & $* * *$ \\
\hline 2013 & 23.463 & 5.710 & 4.109 & $4.06 e-05$ & $* * *$ & 17.0519 & 2.4170 & 7.055 & $2.08 e-12$ & $* * *$ \\
\hline 2014 & 12.219 & 5.710 & 2.140 & 0.032433 & $*$ & 9.7926 & 2.4170 & 4.052 & $5.20 e-05$ & $* * *$ \\
\hline 2015 & 4.438 & 5.710 & 0.777 & 0.437094 & & 18.3135 & 2.4170 & 7.577 & $4.52 e-14$ & $* * *$ \\
\hline 2016 & 18.048 & 5.706 & 3.163 & 0.001575 & $* *$ & 66.6363 & 2.4153 & 27.589 & $<2 e-16$ & $* * *$ \\
\hline 2017 & 62.858 & 5.710 & 11.008 & $<2 e-16$ & $* * *$ & 68.9337 & 2.4170 & 28.521 & $<2 e-16$ & $* * *$ \\
\hline 2018 & 61.067 & 5.710 & 10.695 & $<2 e-16$ & $* * *$ & 44.4992 & 2.4170 & 18.411 & $<2 e-16$ & $* * *$ \\
\hline 2019 & 79.968 & 5.710 & 14.005 & $<2 e-16$ & $* * *$ & 64.8003 & 2.4170 & 26.811 & $<2 e-16$ & $* * *$ \\
\hline 2020 & 30.663 & 7.617 & 4.026 & $5.80 e-05$ & $* * *$ & -1.9709 & 3.2240 & -0.611 & 0.5410 & \\
\hline Multiple R-squared & \multicolumn{5}{|c|}{0.1267} & \multicolumn{5}{|c|}{0.4335} \\
\hline Adjusted R-squared & \multicolumn{4}{|c|}{0.1200} & & & & .4292 & & \\
\hline
\end{tabular}

${ }^{* * *} p<0.001,{ }^{* *} p<0.01,{ }^{*} p<0.05, . p<0.1, p<1$ 
Table 12: Seasonal and trend adjustment of daily electricity prices adjusted for the outliers effect. The threshold is set at $3 \times$ MAD.

\begin{tabular}{|c|c|c|c|c|c|c|c|c|c|c|}
\hline \multirow[b]{3}{*}{ Intercept (c) } & Estimate & Std. Error & $t$ value & $\operatorname{Pr}(>|t|)$ & & Estimate & Std. Error & $t$ value & $\operatorname{Pr}(>|t|)$ & \\
\hline & \multicolumn{5}{|c|}{ NSW } & \multicolumn{5}{|c|}{$\mathrm{SA}$} \\
\hline & 27.44988 & 1.17291 & 23.403 & $<2 e-16$ & $* * *$ & 29.30708 & 2.02722 & 14.457 & $<2 e-16$ & $* * *$ \\
\hline Tuesday & 0.46801 & 0.86533 & 0.541 & 0.58864 & & 0.53909 & 1.49561 & 0.360 & 0.718533 & \\
\hline Wednesday & 1.16181 & 0.86535 & 1.343 & 0.17950 & & -0.83688 & 1.49565 & -0.560 & 0.575830 & \\
\hline Thursday & 0.48761 & 0.86537 & 0.563 & 0.57315 & & -0.35234 & 1.49568 & -0.236 & 0.813780 & \\
\hline Friday & 0.02506 & 0.86538 & 0.029 & 0.97690 & & -1.86234 & 1.49570 & -1.245 & 0.213170 & \\
\hline Saturday & -3.54185 & 0.86491 & -4.095 & $4.32 e-05$ & $* * *$ & -9.05673 & 1.49488 & -6.058 & $1.52 e-09$ & $* * *$ \\
\hline Sunday & -6.07831 & 0.86489 & -7.028 & $2.52 e-12$ & $* * *$ & -10.81304 & 1.49486 & -7.233 & $5.78 e-13$ & $* * *$ \\
\hline February & 1.22860 & 1.11470 & 1.102 & 0.27046 & & 3.03549 & 1.92661 & 1.576 & 0.115219 & \\
\hline March & -0.83418 & 1.08902 & -0.766 & 0.44374 & & -1.02483 & 1.88224 & -0.544 & 0.586150 & \\
\hline April & 3.53910 & 1.09805 & 3.223 & 0.00128 & $* *$ & 3.68740 & 1.89785 & 1.943 & 0.052106 & \\
\hline May & 2.73904 & 1.08901 & 2.515 & 0.01194 & $*$ & 6.12862 & 1.88221 & 3.256 & 0.001141 & $* *$ \\
\hline June & 6.97931 & 1.13459 & 6.151 & $8.57 e-10$ & $* * *$ & 14.25939 & 1.96099 & 7.272 & $4.39 e-13$ & $* * *$ \\
\hline July & 5.79924 & 1.12486 & 5.156 & $2.67 e-07$ & $* * *$ & 11.42628 & 1.94417 & 5.877 & $4.57 e-09$ & $* * *$ \\
\hline August & 6.05115 & 1.12486 & 5.379 & $7.97 e-08$ & $* * *$ & 7.17426 & 1.94417 & 3.690 & 0.000228 & $* * *$ \\
\hline September & 5.38983 & 1.13459 & 4.750 & $2.11 e-06$ & $* * *$ & 3.94292 & 1.96099 & 2.011 & 0.044438 & * \\
\hline October & 4.82532 & 1.12485 & 4.290 & $1.84 e-05$ & $* * *$ & -1.10023 & 1.94415 & -0.566 & 0.571486 & \\
\hline November & 3.59369 & 1.13458 & 3.167 & 0.00155 & $* *$ & 0.82835 & 1.96097 & 0.422 & 0.672748 & \\
\hline December & -1.34481 & 1.12488 & -1.196 & 0.23197 & & 0.04488 & 1.94420 & 0.023 & 0.981585 & \\
\hline 2012 & 13.52476 & 1.00293 & 13.485 & $<2 e-16$ & $* * *$ & 13.70430 & 1.73343 & 7.906 & $3.56 e-15$ & $* * *$ \\
\hline 2013 & 23.66874 & 1.00361 & 23.584 & $<2 e-16$ & $* * *$ & 32.94324 & 1.73461 & 18.992 & $<2 e-16$ & $* * *$ \\
\hline 2014 & 13.22754 & 1.00361 & 13.180 & $<2 e-16$ & $* * *$ & 15.43573 & 1.73461 & 8.899 & $<2 e-16$ & $* * *$ \\
\hline 2015 & 7.91299 & 1.00361 & 7.885 & $4.21 e-15$ & $* * *$ & 16.66478 & 1.73461 & 9.607 & $<2 e-16$ & $* * *$ \\
\hline 2016 & 25.46557 & 1.00292 & 25.391 & $<2 e-16$ & $* * *$ & 28.36201 & 1.73343 & 16.362 & $<2 e-16$ & $* * *$ \\
\hline 2017 & 56.91209 & 1.00361 & 56.707 & $<2 e-16$ & $* * *$ & 60.52080 & 1.73461 & 34.890 & $<2 e-16$ & $* * *$ \\
\hline 2018 & 50.18483 & 1.00361 & 50.004 & $<2 e-16$ & $* * *$ & 56.46360 & 1.73461 & 32.551 & $<2 e-16$ & $* * *$ \\
\hline 2019 & 49.67861 & 1.00361 & 49.500 & $<2 e-16$ & $* * *$ & 49.25717 & 1.73461 & 28.397 & $<2 e-16$ & $* * *$ \\
\hline 2020 & 19.49527 & 1.33874 & 14.562 & $<2 e-16$ & $* * *$ & 13.47634 & 2.31384 & 5.824 & $6.27 e-09$ & $* * *$ \\
\hline Multiple R-squared & \multicolumn{5}{|c|}{0.6759} & \multicolumn{5}{|c|}{0.4435} \\
\hline \multirow[t]{2}{*}{ Adjusted R-squared } & \multicolumn{5}{|c|}{0.6734} & \multicolumn{5}{|c|}{0.4392} \\
\hline & \multicolumn{4}{|c|}{ VIC } & & \multicolumn{4}{|c|}{ TAS } & \\
\hline Intercept (c) & 23.263909 & 1.457538 & 15.961 & $<2 e-16$ & $* * *$ & 35.6563 & 1.6176 & 22.043 & $<2 e-16$ & $* * *$ \\
\hline Tuesday & 1.294187 & 1.075319 & 1.204 & 0.228852 & & 0.7119 & 1.1934 & 0.597 & 0.550877 & \\
\hline Wednesday & 0.115687 & 1.075352 & 0.108 & 0.914335 & & -0.8263 & 1.1934 & -0.692 & 0.488759 & \\
\hline Thursday & -0.001834 & 1.075370 & -0.002 & 0.998640 & & -1.1672 & 1.1935 & -0.978 & 0.328147 & \\
\hline Friday & -0.142540 & 1.075383 & -0.133 & 0.894558 & & -2.8070 & 1.1935 & -2.352 & 0.018734 & * \\
\hline Saturday & -6.603647 & 1.074799 & -6.144 & $8.97 e-10$ & $* * *$ & -3.6022 & 1.1928 & -3.020 & 0.002548 & $* *$ \\
\hline Sunday & -9.149048 & 1.074779 & -8.512 & $<2 e-16$ & $* * *$ & -3.2630 & 1.1928 & -2.736 & 0.006260 & $* *$ \\
\hline February & 4.299361 & 1.385202 & 3.104 & 0.001926 & $* *$ & -2.5420 & 1.5373 & -1.653 & 0.098322 & . \\
\hline March & 3.494963 & 1.353301 & 2.583 & 0.009849 & $* *$ & -5.0036 & 1.5019 & -3.331 & 0.000873 & $* * *$ \\
\hline April & 5.918268 & 1.364523 & 4.337 & $1.48 e-05$ & $* * *$ & -8.7109 & 1.5144 & -5.752 & $9.59 e-09$ & $* * *$ \\
\hline May & 7.635450 & 1.353279 & 5.642 & $1.82 e-08$ & $* * *$ & -5.7597 & 1.5019 & -3.835 & 0.000128 & $* * *$ \\
\hline June & 14.152060 & 1.409925 & 10.037 & $<2 e-16$ & $* * *$ & -0.8454 & 1.5648 & -0.540 & 0.589032 & \\
\hline July & 11.731422 & 1.397831 & 8.393 & $<2 e-16$ & $* * *$ & -5.2629 & 1.5513 & -3.392 & 0.000701 & $* * *$ \\
\hline August & 8.907235 & 1.397831 & 6.372 & $2.11 e-10$ & $* * *$ & -10.4975 & 1.5513 & -6.767 & $1.54 e-11$ & $* * *$ \\
\hline September & 7.148357 & 1.409923 & 5.070 & $4.19 \mathrm{e}-07$ & $* * *$ & -11.3172 & 1.5648 & -7.233 & $5.82 e-13$ & $* * *$ \\
\hline October & 4.968516 & 1.397817 & 3.554 & 0.000384 & $* * *$ & -3.1881 & 1.5513 & -2.055 & 0.039949 & $*$ \\
\hline November & 5.649593 & 1.409910 & 4.007 & $6.28 e-05$ & $* * *$ & 1.0644 & 1.5647 & 0.680 & 0.496391 & \\
\hline December & 0.779054 & 1.397852 & 0.557 & 0.577344 & & -1.6799 & 1.5514 & -1.083 & 0.278945 & \\
\hline 2012 & 14.261363 & 1.246310 & 11.443 & $<2 e-16$ & $* * *$ & 11.8581 & 1.3832 & 8.573 & $<2 e-16$ & $* * *$ \\
\hline 2013 & 24.163109 & 1.247158 & 19.375 & $<2 e-16$ & $* * *$ & 15.6919 & 1.3841 & 11.337 & $<2 e-16$ & $* * *$ \\
\hline 2014 & 12.231857 & 1.247158 & 9.808 & $<2 e-16$ & $* * *$ & 9.4193 & 1.3841 & 6.805 & $1.19 e-11$ & $* * *$ \\
\hline 2015 & 6.137143 & 1.247158 & 4.921 & $9.02 e-07$ & $* * *$ & 17.3408 & 1.3841 & 12.528 & $<2 e-16$ & $* * *$ \\
\hline 2016 & 17.041951 & 1.246307 & 13.674 & $<2 e-16$ & $* * *$ & 19.2404 & 1.3832 & 13.910 & $<2 e-16$ & $* * *$ \\
\hline 2017 & 59.124508 & 1.247158 & 47.407 & $<2 e-16$ & $* * *$ & 49.0737 & 1.3841 & 35.455 & $<2 e-16$ & $* * *$ \\
\hline 2018 & 55.354707 & 1.247158 & 44.385 & $<2 e-16$ & $* * *$ & 39.3860 & 1.3841 & 28.456 & $<2 e-16$ & $* * *$ \\
\hline 2019 & 55.798515 & 1.247158 & 44.741 & $<2 e-16$ & $* * *$ & 38.6620 & 1.3841 & 27.933 & $<2 e-16$ & $* * *$ \\
\hline 2020 & 17.740404 & 1.663615 & 10.664 & $<2 e-16$ & $* * *$ & 9.2253 & 1.8463 & 4.997 & $6.13 e-07$ & $* * *$ \\
\hline Multiple R-squared & \multirow{2}{*}{\multicolumn{5}{|c|}{$\begin{array}{l}0.6364 \\
0.6337\end{array}$}} & \multicolumn{5}{|c|}{0.4189} \\
\hline Adjusted R-squared & & & & & & & & .4144 & & \\
\hline
\end{tabular}

${ }^{* * *} p<0.001,{ }^{* *} p<0.01,{ }^{*} p<0.05, . p<0.1, p<1$ 
Table 13: Seasonal and trend adjustment of daily gas prices.

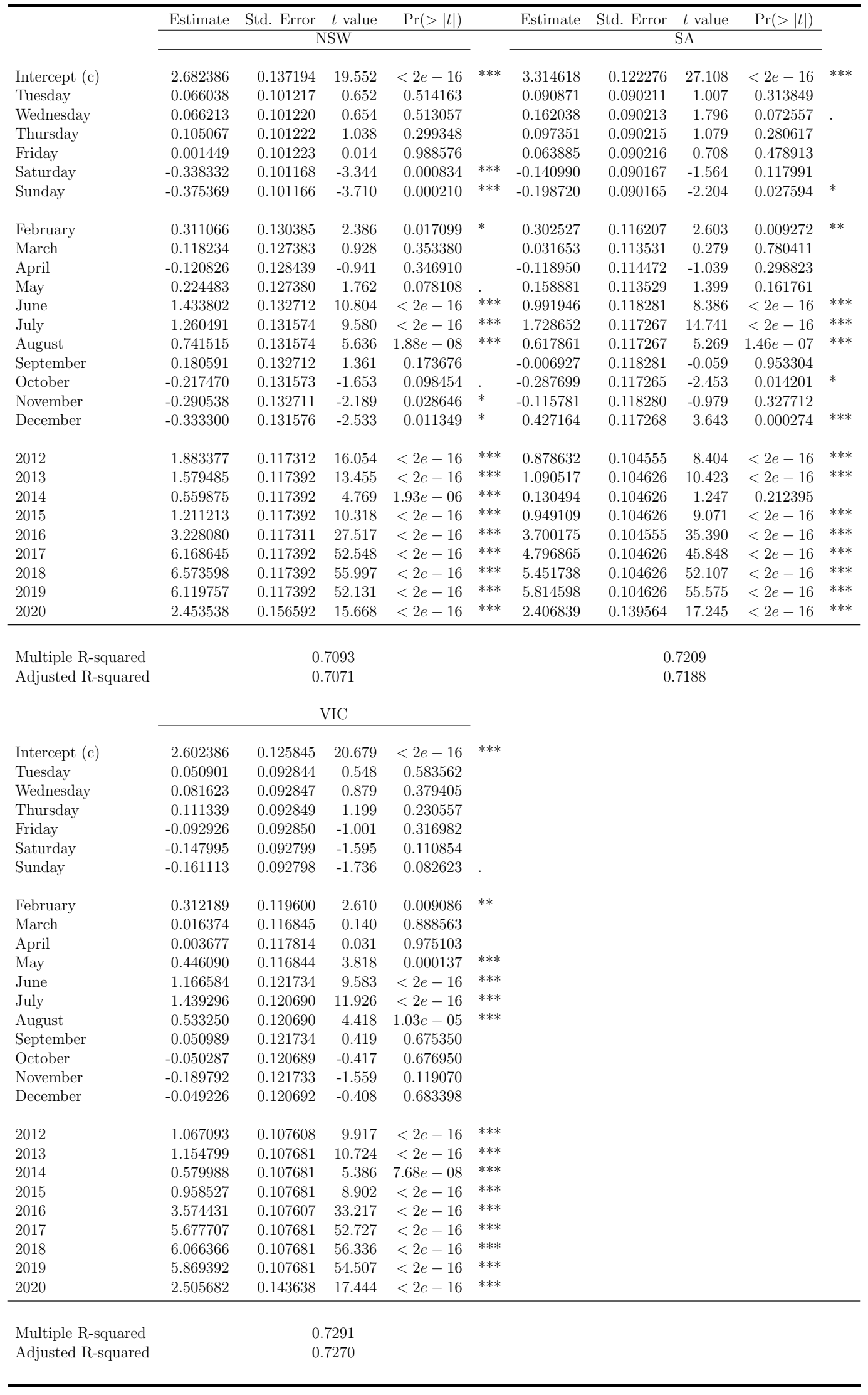

${ }^{* * *} p<0.001,{ }^{* *} p<0.01,{ }^{*} p<0.05, . p<0.1, p<1$ 
Table 14: Seasonal and trend adjustment of daily electricity consumption.

\begin{tabular}{|c|c|c|c|c|c|c|c|c|c|c|}
\hline \multirow[b]{3}{*}{ Intercept (c) } & Estimate & Std. Error & $t$ value & $\operatorname{Pr}(>|t|)$ & & Estimate & Std. Error & $t$ value & $\operatorname{Pr}(>|t|)$ & \\
\hline & \multicolumn{5}{|c|}{ NSW } & \multicolumn{5}{|c|}{ SA } \\
\hline & 220035.5 & 970.3 & 226.768 & $<2 e-16$ & $* * *$ & 38962.0 & 358.6 & 108.657 & $<2 e-16$ & $* * *$ \\
\hline Tuesday & 2986.5 & 715.9 & 4.172 & $3.10 e-05$ & $* * *$ & 698.1 & 264.5 & 2.639 & 0.008359 & $* *$ \\
\hline Wednesday & 2061.0 & 715.9 & 2.879 & 0.004015 & $* *$ & 848.7 & 264.6 & 3.208 & 0.001349 & $* *$ \\
\hline Thursday & 2692.8 & 715.9 & 3.761 & 0.000172 & $* * *$ & 973.5 & 264.6 & 3.680 & 0.000237 & $* * *$ \\
\hline Friday & 1476.8 & 715.9 & 2.063 & 0.039196 & $*$ & 307.7 & 264.6 & 1.163 & 0.244952 & \\
\hline Saturday & -12850.0 & 715.5 & -17.959 & $<2 e-16$ & $* * *$ & -3172.5 & 264.4 & -11.998 & $<2 e-16$ & $* * *$ \\
\hline Sunday & -17955.6 & 715.5 & -25.095 & $<2 e-16$ & $* * *$ & -4106.7 & 264.4 & -15.531 & $<2 e-16$ & $* * *$ \\
\hline February & -727.1 & 922.2 & -0.789 & 0.430448 & & 101.7 & 340.8 & 0.298 & 0.765353 & \\
\hline March & -10456.3 & 900.9 & -11.606 & $<2 e-16$ & $* * *$ & -2674.2 & 332.9 & -8.032 & $1.31 e-15$ & $* * *$ \\
\hline April & -20063.5 & 908.4 & -22.087 & $<2 e-16$ & $* * *$ & -4419.3 & 335.7 & -13.165 & $<2 e-16$ & $* * *$ \\
\hline May & -6742.5 & 900.9 & -7.484 & $9.11 e-14$ & $* * *$ & -2423.9 & 332.9 & -7.280 & $4.11 e-13$ & $* * *$ \\
\hline June & 8419.6 & 938.6 & 8.970 & $<2 e-16$ & $* * *$ & 317.0 & 346.9 & 0.914 & 0.360838 & \\
\hline July & 10210.9 & 930.6 & 10.973 & $<2 e-16$ & $* * *$ & 167.1 & 343.9 & 0.486 & 0.626985 & \\
\hline August & 1328.6 & 930.6 & 1.428 & 0.153456 & & -1078.2 & 343.9 & -3.135 & 0.001731 & $* *$ \\
\hline September & -16116.4 & 938.6 & -17.170 & $<2 e-16$ & $* * *$ & -4756.7 & 346.9 & -13.714 & $<2 e-16$ & $* * *$ \\
\hline October & -22610.6 & 930.6 & -24.298 & $<2 e-16$ & $* * *$ & -6244 & 1343.9 & -18.157 & $<2 e-16$ & $* * *$ \\
\hline November & -17654.1 & 938.6 & -18.809 & $<2 e-16$ & $* * *$ & -4870.6 & 346.9 & -14.042 & $<2 e-16$ & $* * *$ \\
\hline December & -14804.0 & 930.6 & -15.908 & $<2 e-16$ & $* * *$ & -3373.2 & 343.9 & -9.809 & $<2 e-16$ & $* * *$ \\
\hline 2012 & -11411.4 & 829.7 & -13.754 & $<2 e-16$ & $* * *$ & -420.1 & 306.6 & -1.370 & 0.170737 & \\
\hline 2013 & -17963.5 & 830.3 & -21.636 & $<2 e-16$ & $* * *$ & -1644.5 & 306.8 & -5.360 & $8.89 e-08$ & $* * *$ \\
\hline 2014 & -19491.4 & 830.3 & -23.476 & $<2 e-16$ & $* * *$ & -2203.3 & 306.8 & -7.181 & $8.45 e-13$ & $* * *$ \\
\hline 2015 & -18006.2 & 830.3 & -21.688 & $<2 e-16$ & $* * *$ & -2318.7 & 306.8 & -7.557 & $5.26 e-14$ & $* * *$ \\
\hline 2016 & -18037.0 & 829.7 & -21.740 & $<2 e-16$ & $* * *$ & -3660.7 & 306.6 & -11.939 & $<2 e-16$ & $* * *$ \\
\hline 2017 & -16171.4 & 830.3 & -19.478 & $<2 e-16$ & $* * *$ & -4141.2 & 306.8 & -13.497 & $<2 e-16$ & $* * *$ \\
\hline 2018 & -17515.0 & 830.3 & -21.096 & $<2 e-16$ & $* * *$ & -4757.9 & 306.8 & -15.507 & $<2 e-16$ & $* * *$ \\
\hline 2019 & -18372.4 & 830.3 & -22.129 & $<2 e-16$ & $* * *$ & -4562.0 & 306.8 & -14.869 & $<2 e-16$ & $* * *$ \\
\hline 2020 & -25563.5 & 1107.5 & -23.082 & $<2 e-16$ & $* * *$ & -6932.5 & 409.3 & -16.938 & $<2 e-16$ & $* * *$ \\
\hline Multiple R-squared & \multicolumn{5}{|c|}{0.6296} & \multicolumn{5}{|c|}{0.6268} \\
\hline \multirow[t]{2}{*}{ Adjusted R-squared } & \multicolumn{5}{|c|}{0.4093} & \multicolumn{5}{|c|}{0.4048} \\
\hline & \multicolumn{5}{|c|}{ VIC } & \multicolumn{4}{|c|}{ TAS } & \\
\hline Intercept (c) & 140518.2 & 777.1 & 180.819 & $<2 e-16$ & $* * *$ & 26306.24 & 123.60 & 212.839 & $<2 e-16$ & $* * *$ \\
\hline Tuesday & 2524.0 & 573.3 & 4.402 & $1.10 e-05$ & $* * *$ & -57.27 & 91.19 & -0.628 & 0.529989 & \\
\hline Wednesday & 2927.0 & 573.3 & 5.105 & $3.49 e-07$ & $* * *$ & -238.45 & 91.19 & -2.615 & 0.008963 & $* *$ \\
\hline Thursday & 3541.2 & 573.4 & 6.176 & $7.34 e-10$ & $* * *$ & -161.52 & 91.19 & -1.771 & 0.076600 & . \\
\hline Friday & 1667.9 & 573.4 & 2.909 & 0.00365 & $* *$ & -302.66 & 91.19 & -3.319 & 0.000913 & $* * *$ \\
\hline Saturday & -11926.6 & 573.1 & -20.812 & $<2 e-16$ & $* * *$ & -1203.57 & 91.14 & -13.206 & $<2 e-16$ & $* * *$ \\
\hline Sunday & -15954.2 & 573.0 & -27.841 & $<2 e-16$ & $* * *$ & -1231.13 & 91.14 & -13.508 & $<2 e-16$ & $* * *$ \\
\hline February & 2099.8 & 738.6 & 2.843 & 0.00449 & $* *$ & -87.95 & 117.46 & -0.749 & 0.454047 & \\
\hline March & -2903.0 & 721.5 & -4.023 & $5.86 e-05$ & $* * *$ & -499.80 & 114.76 & -4.355 & $1.37 e-05$ & $* * *$ \\
\hline April & -7065.6 & 727.5 & -9.712 & $<2 e-16$ & $* * *$ & 749.23 & 115.71 & 6.475 & $1.08 e-10$ & $* * *$ \\
\hline May & 1847.6 & 721.5 & 2.561 & 0.01049 & $*$ & 2683.41 & 114.76 & 23.384 & $<2 e-16$ & $* * *$ \\
\hline June & 9709.8 & 751.7 & 12.917 & $<2 e-16$ & $* * *$ & 4559.91 & 119.56 & 38.139 & $<2 e-16$ & $* * *$ \\
\hline July & 9485.4 & 745.3 & 12.727 & $<2 e-16$ & $* * *$ & 4709.67 & 118.53 & 39.733 & $<2 e-16$ & $* * *$ \\
\hline August & 6060.3 & 745.3 & 8.131 & $5.87 e-16$ & $* * *$ & 3990.67 & 118.53 & 33.667 & $<2 e-16$ & $* * *$ \\
\hline September & -3059.6 & 751.7 & -4.070 & $4.81 e-05$ & $* * *$ & 2151.91 & 119.56 & 17.999 & $<2 e-16$ & $* * *$ \\
\hline October & -7923.3 & 745.3 & -10.631 & $<2 e-16$ & $* * *$ & 720.72 & 118.53 & 6.080 & $1.33 e-09$ & $* * *$ \\
\hline November & -7616.8 & 751.7 & -10.132 & $<2 e-16$ & $* * *$ & 605.78 & 119.56 & 5.067 & $4.26 e-07$ & $* * *$ \\
\hline December & -8427.8 & 745.3 & -11.308 & $<2 e-16$ & $* * *$ & -469.86 & 118.54 & -3.964 & $7.53 e-05$ & $* * *$ \\
\hline 2012 & -1603.8 & 664.5 & -2.414 & 0.01585 & * & -1071.92 & 105.69 & -10.143 & $<2 e-16$ & $* * *$ \\
\hline 2013 & -5132.1 & 664.9 & -7.718 & $1.54 e-14$ & $* * *$ & -350.52 & 105.76 & -3.314 & 0.000928 & $* * *$ \\
\hline 2014 & -9629.9 & 664.9 & -14.482 & $<2 e-16$ & $* * *$ & -818.70 & 105.76 & -7.741 & $1.29 e-14$ & $* * *$ \\
\hline 2015 & -12747.8 & 664.9 & -19.171 & $<2 e-16$ & $* * *$ & -136.16 & 105.76 & -1.287 & 0.198026 & \\
\hline 2016 & -15405.7 & 664.5 & -23.184 & $<2 e-16$ & $* * *$ & -1880.05 & 105.68 & -17.789 & $<2 e-16$ & $* * *$ \\
\hline 2017 & -18410.8 & 664.9 & -27.688 & $<2 e-16$ & $* * *$ & -421.94 & 105.76 & -3.990 & $6.75 e-05$ & $* * *$ \\
\hline 2018 & -18597.1 & 664.9 & -27.968 & $<2 e-16$ & $* * *$ & 38.72 & 105.76 & 0.366 & 0.714318 & \\
\hline 2019 & -19475.1 & 664.9 & -29.288 & $<2 e-16$ & $* * *$ & -1096.73 & 105.76 & -10.370 & $<2 e-16$ & $* * *$ \\
\hline 2020 & -24182.4 & 887.0 & -27.263 & $<2 e-16$ & $* * *$ & -849.28 & 141.07 & -6.020 & $1.93 e-09$ & $* * *$ \\
\hline Multiple R-squared & \multicolumn{5}{|c|}{0.6519} & \multicolumn{5}{|c|}{0.6685} \\
\hline Adjusted R-squared & \multicolumn{5}{|c|}{0.6493} & & & .6659 & & \\
\hline
\end{tabular}

${ }^{* * *} p<0.001,{ }^{* *} p<0.01,{ }^{*} p<0.05, . p<0.1, p<1$ 
Table 15: Seasonal and trend adjustment of daily wind generation.

\begin{tabular}{|c|c|c|c|c|c|c|c|c|c|c|}
\hline \multirow[b]{3}{*}{ Intercept (c) } & Estimate & Std. Error & $t$ value & $\operatorname{Pr}(>|t|)$ & & Estimate & Std. Error & $t$ value & $\operatorname{Pr}(>|t|)$ & \\
\hline & \multicolumn{5}{|c|}{ NSW } & \multicolumn{5}{|c|}{ SA } \\
\hline & 518.945 & 297.807 & 1.743 & 0.08150 & . & 8910.947 & 596.586 & 14.937 & $<2 e-16$ & $* * *$ \\
\hline Tuesday & 103.379 & 219.711 & 0.471 & 0.63801 & & 3.067 & 440.139 & 0.007 & 0.994441 & \\
\hline Wednesday & -5.124 & 219.718 & -0.023 & 0.98139 & & 223.418 & 440.153 & 0.508 & 0.611773 & \\
\hline Thursday & -61.861 & 219.722 & -0.282 & 0.77831 & & 26.107 & 440.160 & 0.059 & 0.952707 & \\
\hline Friday & 213.505 & 219.724 & 0.972 & 0.33127 & & -51.750 & 440.166 & -0.118 & 0.906417 & \\
\hline Saturday & 189.357 & 219.605 & 0.862 & 0.38860 & & -297.917 & 439.926 & -0.677 & 0.498326 & \\
\hline Sunday & -53.193 & 219.601 & -0.242 & 0.80862 & & -141.553 & 439.918 & -0.322 & 0.747646 & \\
\hline February & 414.918 & 283.027 & 1.466 & 0.14274 & & -961.439 & 566.978 & -1.696 & 0.090029 & \\
\hline March & 138.663 & 276.509 & 0.501 & 0.61607 & & -1043.075 & 553.920 & -1.883 & 0.059775 & \\
\hline April & -133.539 & 278.802 & -0.479 & 0.63199 & & -1897.138 & 558.513 & -3.397 & 0.000690 & $* * *$ \\
\hline May & 1081.833 & 276.504 & 3.913 & $9.31 e-05$ & $* * *$ & 355.412 & 553.911 & 0.642 & 0.521149 & \\
\hline June & 758.929 & 288.078 & 2.634 & 0.00847 & $* *$ & -446.529 & 577.097 & -0.774 & 0.439132 & \\
\hline July & 2415.231 & 285.607 & 8.456 & $<2 e-16$ & $* * *$ & 3118.416 & 572.147 & 5.450 & $5.38 e-08$ & $* * *$ \\
\hline August & 2405.825 & 285.607 & 8.424 & $<2 e-16$ & $* * *$ & 2211.721 & 572.147 & 3.866 & 0.000113 & $* * *$ \\
\hline September & 1992.295 & 288.078 & 6.916 & $5.53 e-12$ & $* * *$ & 1523.121 & 577.096 & 2.639 & 0.008346 & $* *$ \\
\hline October & 1439.187 & 285.605 & 5.039 & $4.92 e-07$ & $* * *$ & 805.808 & 572.141 & 1.408 & 0.159102 & \\
\hline November & 1627.597 & 288.075 & 5.650 & $1.74 e-08$ & $* * *$ & -197.576 & 577.091 & -0.342 & 0.732096 & \\
\hline December & 1522.535 & 285.612 & 5.331 & $1.04 e-07$ & $* * *$ & 163.039 & 572.155 & 0.285 & 0.775695 & \\
\hline 2012 & 160.412 & 254.648 & 0.630 & 0.52878 & & 820.376 & 510.128 & 1.608 & 0.107889 & \\
\hline 2013 & 474.258 & 254.822 & 1.861 & 0.06281 & . & 1140.676 & 510.475 & 2.235 & 0.025512 & * \\
\hline 2014 & 864.492 & 254.822 & 3.393 & 0.00070 & $* * *$ & 1974.621 & 510.475 & 3.868 & 0.000112 & $* * *$ \\
\hline 2015 & 2912.945 & 254.822 & 11.431 & $<2 e-16$ & $* * *$ & 2355.695 & 510.475 & 4.615 & $4.08 e-06$ & $* * *$ \\
\hline 2016 & 3826.350 & 254.648 & 15.026 & $<2 e-16$ & $* * *$ & 3270.596 & 510.126 & 6.411 & $1.64 e-10$ & $* * *$ \\
\hline 2017 & 3501.339 & 254.822 & 13.740 & $<2 e-16$ & $* * *$ & 4180.024 & 510.475 & 8.189 & $3.70 e-16$ & $* * *$ \\
\hline 2018 & 6688.913 & 254.822 & 26.249 & $<2 e-16$ & $* * *$ & 6396.801 & 510.475 & 12.531 & $<2 e-16$ & $* * *$ \\
\hline 2019 & 10192.236 & 254.822 & 39.998 & $<2 e-16$ & $* * *$ & 6379.013 & 510.475 & 12.496 & $<2 e-16$ & $* * *$ \\
\hline 2020 & 11170.534 & 339.913 & 32.863 & $<2 e-16$ & $* * *$ & 6652.503 & 680.935 & 9.770 & $<2 e-16$ & $* * *$ \\
\hline \multirow{2}{*}{$\begin{array}{l}\text { Multiple R-squared } \\
\text { Adjusted R-squared }\end{array}$} & \multicolumn{5}{|c|}{0.5228} & \multicolumn{5}{|c|}{0.1248} \\
\hline & \multicolumn{5}{|c|}{ VIC } & \multicolumn{4}{|c|}{ TAS } & \\
\hline Intercept (c) & 2013.71 & 494.57 & 4.072 & $4.77 e-05$ & $* * *$ & 1022.953 & 138.393 & 7.392 & $1.81 e-13$ & $* * *$ \\
\hline Tuesday & -88.23 & 364.88 & -0.242 & 0.8089 & & 64.277 & 102.102 & 0.630 & 0.529039 & \\
\hline Wednesday & -161.97 & 364.89 & -0.444 & 0.6571 & & 6.491 & 102.105 & 0.064 & 0.949317 & \\
\hline Thursday & 149.58 & 364.89 & 0.410 & 0.6819 & & 90.801 & 102.106 & 0.889 & 0.373917 & \\
\hline Friday & 11.53 & 364.90 & 0.032 & 0.9748 & & 114.602 & 102.108 & 1.122 & 0.261784 & \\
\hline Saturday & 31.67 & 364.70 & 0.087 & 0.9308 & & 198.086 & 102.052 & 1.941 & 0.052337 & . \\
\hline Sunday & -102.66 & 364.69 & -0.281 & 0.7783 & & 102.278 & 102.050 & 1.002 & 0.316302 & \\
\hline February & -135.84 & 470.02 & -0.289 & 0.7726 & & 14.029 & 131.525 & 0.107 & 0.915060 & \\
\hline March & 215.16 & 459.20 & 0.469 & 0.6394 & & -233.330 & 128.496 & -1.816 & 0.069480 & . \\
\hline April & -674.56 & 463.01 & -1.457 & 0.1452 & & -327.817 & 129.561 & -2.530 & 0.011444 & * \\
\hline May & 1920.45 & 459.19 & 4.182 & $2.96 e-05$ & $* * *$ & 140.178 & 128.494 & 1.091 & 0.275381 & \\
\hline June & 721.59 & 478.41 & 1.508 & 0.1316 & & 31.343 & 133.872 & 0.234 & 0.814903 & \\
\hline July & 4163.88 & 474.31 & 8.779 & $<2 e-16$ & $* * *$ & 589.327 & 132.724 & 4.440 & $9.27 e-06$ & $* * *$ \\
\hline August & 3071.29 & 474.31 & 6.475 & $1.08 e-10$ & $* * *$ & 380.244 & 132.724 & 2.865 & 0.004197 & $* *$ \\
\hline September & 2295.18 & 478.41 & 4.797 & $1.68 e-06$ & $* * *$ & 435.289 & 133.872 & 3.252 & 0.001159 & $* *$ \\
\hline October & 1961.82 & 474.31 & 4.136 & $3.62 e-05$ & $* * *$ & 436.832 & 132.723 & 3.291 & 0.001007 & $* *$ \\
\hline November & 1207.66 & 478.41 & 2.524 & 0.0116 & $*$ & 444.150 & 133.871 & 3.318 & 0.000917 & $* * *$ \\
\hline December & 1093.98 & 474.32 & 2.306 & 0.0211 & $*$ & 403.187 & 132.726 & 3.038 & 0.002402 & $* *$ \\
\hline 2012 & 866.20 & 422.90 & 2.048 & 0.0406 & $*$ & -21.521 & 118.337 & -0.182 & 0.855701 & \\
\hline 2013 & 3760.67 & 423.18 & 8.887 & $<2 e-16$ & $* * *$ & 981.055 & 118.418 & 8.285 & $<2 e-16$ & $* * *$ \\
\hline 2014 & 3628.63 & 423.18 & 8.575 & $<2 e-16$ & $* * *$ & 1296.474 & 118.418 & 10.948 & $<2 e-16$ & $* * *$ \\
\hline 2015 & 5279.46 & 423.18 & 12.476 & $<2 e-16$ & $* * *$ & 1422.898 & 118.418 & 12.016 & $<2 e-16$ & $* * *$ \\
\hline 2016 & 6170.19 & 422.90 & 14.590 & $<2 e-16$ & $* * *$ & 1764.059 & 118.337 & 14.907 & $<2 e-16$ & $* * *$ \\
\hline 2017 & 6347.32 & 423.18 & 14.999 & $<2 e-16$ & $* * *$ & 1565.316 & 118.418 & 13.219 & $<2 e-16$ & $* * *$ \\
\hline 2018 & 8583.49 & 423.18 & 20.283 & $<2 e-16$ & $* * *$ & 1692.083 & 118.418 & 14.289 & $<2 e-16$ & $* * *$ \\
\hline 2019 & 10651.35 & 423.18 & 25.170 & $<2 e-16$ & $* * *$ & 2000.780 & 118.418 & 16.896 & $<2 e-16$ & $* * *$ \\
\hline 2020 & 12653.26 & 564.50 & 22.415 & $<2 e-16$ & $* * *$ & 2269.684 & 157.960 & 14.369 & $<2 e-16$ & $* * *$ \\
\hline Multiple R-squared & & \multicolumn{5}{|c|}{0.1845} \\
\hline Adjusted R-squared & \multicolumn{5}{|c|}{$\begin{array}{l}0.2952 \\
0.2899\end{array}$} & \multicolumn{5}{|c|}{0.1783} \\
\hline
\end{tabular}

${ }^{* * *} p<0.001,{ }^{* *} p<0.01,{ }^{*} p<0.05, . p<0.1, p<1$ 
Table 16: Seasonal and trend adjustment of aggregated hydro generation.

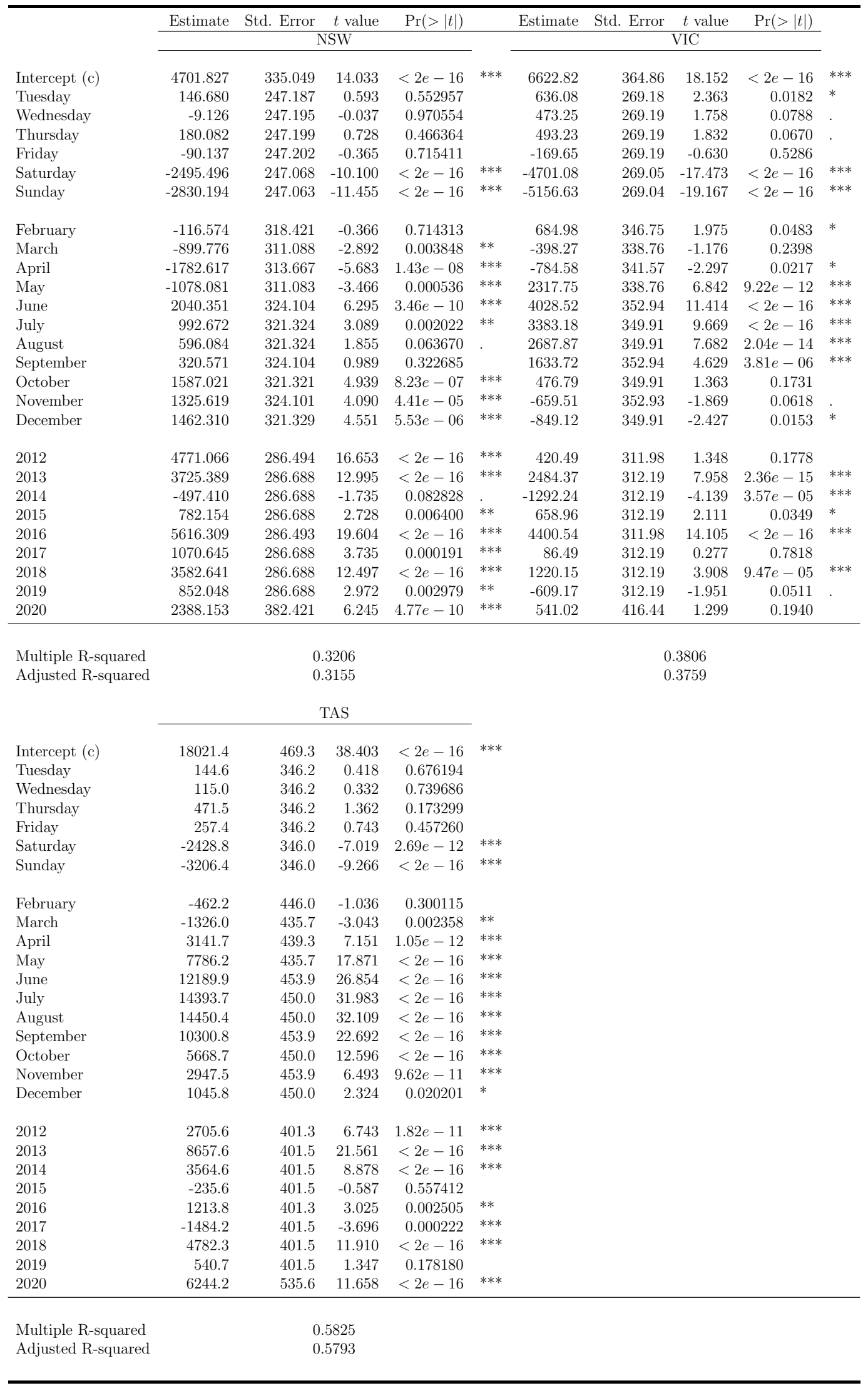

${ }^{* * *} p<0.001,{ }^{* *} p<0.01,{ }^{*} p<0.05, . p<0.1, p<1$ 
Table 17: Seasonal and trend adjustment of daily cross-boarder interconnectors flows.

\begin{tabular}{|c|c|c|c|c|c|c|c|c|c|c|}
\hline \multirow[b]{3}{*}{ Intercept (c) } & Estimate & Std. Error & $t$ value & $\operatorname{Pr}(>|t|)$ & & Estimate & Std. Error & $t$ value & $\operatorname{Pr}(>|t|)$ & \\
\hline & \multicolumn{5}{|c|}{ Basslink } & \multicolumn{5}{|c|}{ Heywood } \\
\hline & -3929.4 & 430.7 & -9.124 & $<2 e-16$ & $* * *$ & 3698.181 & 355.443 & 10.404 & $<2 e-16$ & $* * *$ \\
\hline Tuesday & 283.0 & 317.7 & 0.891 & 0.373190 & & -75.339 & 262.233 & -0.287 & 0.773903 & \\
\hline Wednesday & 370.5 & 317.7 & 1.166 & 0.243697 & & -248.992 & 262.241 & -0.949 & 0.342445 & \\
\hline Thursday & 688.5 & 317.7 & 2.167 & 0.030304 & $*$ & -89.794 & 262.246 & -0.342 & 0.732068 & \\
\hline Friday & 583.6 & 317.7 & 1.837 & 0.066330 & . & -209.086 & 262.249 & -0.797 & 0.425343 & \\
\hline Saturday & -1170.0 & 317.6 & -3.684 & 0.000233 & $* * *$ & -233.379 & 262.106 & -0.890 & 0.373314 & \\
\hline Sunday & -1987.1 & 317.6 & -6.258 & $4.40 e-10$ & $* * *$ & -277.434 & 262.102 & -1.058 & 0.289903 & \\
\hline February & 297.4 & 409.3 & 0.727 & 0.467474 & & -8.867 & 337.803 & -0.026 & 0.979060 & \\
\hline March & -553.5 & 399.9 & -1.384 & 0.166353 & & -48.543 & 330.024 & -0.147 & 0.883069 & \\
\hline April & 2245.8 & 403.2 & 5.570 & $2.74 e-08$ & $* * *$ & 720.962 & 332.760 & 2.167 & 0.030333 & * \\
\hline May & 3781.3 & 399.8 & 9.457 & $<2 e-16$ & $* * *$ & 123.700 & 330.018 & 0.375 & 0.707811 & \\
\hline June & 5457.4 & 416.6 & 13.100 & $<2 e-16$ & $* * *$ & 823.502 & 343.832 & 2.395 & 0.016671 & * \\
\hline July & 7171.1 & 413.0 & 17.363 & $<2 e-16$ & $* * *$ & -1092.988 & 340.883 & -3.206 & 0.001357 & $* *$ \\
\hline August & 7371.6 & 413.0 & 17.848 & $<2 e-16$ & $* * *$ & -239.662 & 340.883 & -0.703 & 0.482065 & \\
\hline September & 5416.3 & 416.6 & 13.002 & $<2 e-16$ & $* * *$ & -1142.807 & 343.832 & -3.324 & 0.000898 & $* * *$ \\
\hline October & 2341.0 & 413.0 & 5.668 & $1.56 e-08$ & $* * *$ & -2112.728 & 340.879 & -6.198 & $6.41 e-10$ & $* * *$ \\
\hline November & 597.9 & 416.6 & 1.435 & 0.151286 & & -1801.794 & 343.828 & -5.240 & $1.70 e-07$ & $* * *$ \\
\hline December & 183.4 & 413.0 & 0.444 & 0.657097 & & -489.178 & 340.888 & -1.435 & 0.151375 & \\
\hline 2012 & 3731.9 & 368.2 & 10.135 & $<2 e-16$ & $* * *$ & -786.363 & 303.932 & -2.587 & 0.009714 & $* *$ \\
\hline 2013 & 8246.4 & 368.5 & 22.379 & $<2 e-16$ & $* * *$ & 2004.670 & 304.139 & 6.591 & $5.03 e-11$ & $* * *$ \\
\hline 2014 & 3601.9 & 368.5 & 9.775 & $<2 e-16$ & $* * *$ & 1145.025 & 304.139 & 3.765 & 0.000169 & $* * *$ \\
\hline 2015 & -2943.6 & 368.5 & -7.988 & $1.85 e-15$ & $* * *$ & 2049.797 & 304.139 & 6.740 & $1.86 e-11$ & $* * *$ \\
\hline 2016 & 2661.7 & 368.2 & 7.228 & $6.01 e-13$ & $* * *$ & 3001.316 & 303.931 & 9.875 & $<2 e-16$ & $* * *$ \\
\hline 2017 & -275.6 & 368.5 & -0.748 & 0.454642 & & -1580.376 & 304.139 & -5.196 & $2.15 e-07$ & $* * *$ \\
\hline 2018 & 3582.2 & 368.5 & 9.721 & $<2 e-16$ & $* * *$ & -2209.189 & 304.139 & -7.264 & $4.64 e-13$ & $* * *$ \\
\hline 2019 & 558.7 & 368.5 & 1.516 & 0.129568 & & -5353.895 & 304.139 & -17.603 & $<2 e-16$ & $* * *$ \\
\hline 2020 & 4032.3 & 491.5 & 8.203 & $3.28 e-16$ & $* * *$ & -3701.436 & 405.698 & -9.124 & $<2 e-16$ & $* * *$ \\
\hline \multirow{2}{*}{$\begin{array}{l}\text { Multiple R-squared } \\
\text { Adjusted R-squared }\end{array}$} & \multicolumn{5}{|c|}{0.4118} & \multicolumn{5}{|c|}{0.2932} \\
\hline & \multicolumn{4}{|c|}{ VNI } & & \multicolumn{4}{|c|}{ Murrylink } & \\
\hline Intercept (c) & 9545.7 & 653.7 & 14.602 & $<2 e-16$ & $* * *$ & -548.215 & 95.328 & -5.751 & $9.66 e-09$ & $* * *$ \\
\hline Tuesday & -513.1 & 482.3 & -1.064 & 0.287430 & & -13.329 & 70.330 & -0.190 & 0.849699 & \\
\hline Wednesday & -778.1 & 482.3 & -1.613 & 0.106762 & & 23.507 & 70.332 & 0.334 & 0.738228 & \\
\hline Thursday & -779.6 & 482.3 & -1.616 & 0.106079 & & 8.775 & 70.333 & 0.125 & 0.900718 & \\
\hline Friday & -439.5 & 482.3 & -0.911 & 0.362236 & & 36.838 & 70.334 & 0.524 & 0.600479 & \\
\hline Saturday & 1505.9 & 482.1 & 3.124 & 0.001799 & $* *$ & -136.081 & 70.296 & -1.936 & 0.052971 & . \\
\hline Sunday & 2691.2 & 482.0 & 5.583 & $2.55 e-08$ & $* * *$ & -175.316 & 70.294 & -2.494 & 0.012677 & * \\
\hline February & -1058.2 & 621.3 & -1.703 & 0.088604 & . & -20.276 & 90.597 & -0.224 & 0.822923 & \\
\hline March & -1330.4 & 607.0 & -2.192 & 0.028449 & $*$ & 98.930 & 88.511 & 1.118 & 0.263767 & \\
\hline April & -402.4 & 612.0 & -0.657 & 0.510907 & & 181.915 & 89.245 & 2.038 & 0.041588 & $*$ \\
\hline May & -4256.8 & 607.0 & -7.013 & $2.79 e-12$ & $* * *$ & 84.900 & 88.509 & 0.959 & 0.337514 & \\
\hline June & -6002.1 & 632.4 & -9.492 & $<2 e-16$ & $* * *$ & 449.118 & 92.214 & 4.870 & $1.16 e-06$ & $* * *$ \\
\hline July & -4457.4 & 626.9 & -7.110 & $1.41 e-12$ & $* * *$ & 616.111 & 91.423 & 6.739 & $1.86 e-11$ & $* * *$ \\
\hline August & -2805.5 & 626.9 & -4.475 & $7.89 e-06$ & $* * *$ & 453.830 & 91.423 & 4.964 & $7.24 e-07$ & $* * *$ \\
\hline September & -1743.7 & 632.4 & -2.757 & 0.005857 & $* *$ & 350.948 & 92.214 & 3.806 & 0.000144 & $* * *$ \\
\hline October & 258.9 & 626.9 & 0.413 & 0.679630 & & 160.891 & 91.422 & 1.760 & 0.078520 & . \\
\hline November & -2220.0 & 632.3 & -3.511 & 0.000453 & $* * *$ & 73.989 & 92.213 & 0.802 & 0.422397 & \\
\hline December & -799.0 & 626.9 & -1.274 & 0.202614 & & 215.268 & 91.425 & 2.355 & 0.018599 & * \\
\hline 2012 & -391.1 & 559.0 & -0.700 & 0.484212 & & -53.895 & 81.513 & -0.661 & 0.508542 & \\
\hline 2013 & 2186.1 & 559.4 & 3.908 & $9.48 e-05$ & $* * *$ & 689.708 & 81.569 & 8.456 & $<2 e-16$ & $* * *$ \\
\hline 2014 & 4851.4 & 559.4 & 8.673 & $<2 e-16$ & $* * *$ & 8.423 & 81.569 & 0.103 & 0.917757 & \\
\hline 2015 & 3513.4 & 559.4 & 6.281 & $3.79 e-10$ & $* * *$ & 457.485 & 81.569 & 5.609 & $2.20 e-08$ & $* * *$ \\
\hline 2016 & 7753.5 & 559.0 & 13.871 & $<2 e-16$ & $* * *$ & 936.150 & 81.513 & 11.485 & $<2 e-16$ & $* * *$ \\
\hline 2017 & -3339.8 & 559.4 & -5.971 & $2.60 e-09$ & $* * *$ & 96.588 & 81.569 & 1.184 & 0.236445 & \\
\hline 2018 & -5194.5 & 559.4 & -9.287 & $<2 e-16$ & $* * *$ & 405.154 & 81.569 & 4.967 & $7.13 e-07$ & $* * *$ \\
\hline 2019 & -7465.1 & 559.4 & -13.346 & $<2 e-16$ & $* * *$ & 284.582 & 81.569 & 3.489 & 0.000491 & $* * *$ \\
\hline 2020 & -1999.3 & 746.1 & -2.679 & 0.007409 & $* *$ & 1326.159 & 108.806 & 12.188 & $<2 e-16$ & $* * *$ \\
\hline Multiple R-squared & \multicolumn{5}{|c|}{0.3126} & \multicolumn{5}{|c|}{0.1249} \\
\hline Adjusted R-squared & \multicolumn{5}{|c|}{0.3073} & \multicolumn{5}{|c|}{0.1182} \\
\hline
\end{tabular}

${ }^{* * *} p<0.001,{ }^{* *} p<0.01,{ }^{*} p<0.05, . p<0.1, p<1$ 
Table 18: Seasonal and trend adjustment of daily cross-boarder interconnectors flows.

\begin{tabular}{|c|c|c|c|c|c|c|c|c|c|c|}
\hline & Estimate & Std. Error & $t$ value & $\operatorname{Pr}(>|t|)$ & & Estimate & Std. Error & $t$ value & $\operatorname{Pr}(>|t|)$ & \\
\hline & & & QNI & & & & & ranora & & \\
\hline Intercept (c) & -7521.34 & 504.02 & -14.923 & $<2 e-16$ & $* * *$ & -1516.928 & 52.251 & -29.032 & $<2 e-16$ & $* * *$ \\
\hline Tuesday & -286.86 & 371.84 & -0.771 & 0.44049 & & -26.593 & 38.549 & -0.690 & 0.490332 & \\
\hline Wednesday & -62.32 & 371.86 & -0.168 & 0.86692 & & -15.449 & 38.550 & -0.401 & 0.688634 & \\
\hline Thursday & -244.22 & 371.86 & -0.657 & 0.51139 & & -38.010 & 38.550 & -0.986 & 0.324211 & \\
\hline Friday & -334.79 & 371.87 & -0.900 & 0.36803 & & -38.445 & 38.551 & -0.997 & 0.318708 & \\
\hline Saturday & -907.17 & 371.66 & -2.441 & 0.01470 & * & -131.548 & 38.530 & -3.414 & 0.000647 & $* * *$ \\
\hline Sunday & -1028.23 & 371.66 & -2.767 & 0.00569 & ** & -97.883 & 38.529 & -2.540 & 0.011114 & * \\
\hline February & -1088.72 & 479.00 & -2.273 & 0.02309 & * & -8.238 & 49.657 & -0.166 & 0.868252 & \\
\hline March & -1531.16 & 467.97 & -3.272 & 0.00108 & $* *$ & -184.474 & 48.514 & -3.803 & 0.000146 & $* * *$ \\
\hline April & -4783.79 & 471.85 & -10.138 & $<2 e-16$ & $* * *$ & -535.918 & 48.916 & -10.956 & $<2 e-16$ & $* * *$ \\
\hline May & -3206.04 & 467.96 & -6.851 & $8.66 e-12$ & $* * *$ & -461.333 & 48.513 & -9.509 & $<2 e-16$ & $* * *$ \\
\hline June & -5588.93 & 487.55 & -11.463 & $<2 e-16$ & $* * *$ & -451.847 & 50.544 & -8.940 & $<2 e-16$ & $* * *$ \\
\hline July & -5396.01 & 483.37 & -11.163 & $<2 e-16$ & $* * *$ & -293.507 & 50.110 & -5.857 & $5.15 e-09$ & $* * *$ \\
\hline August & -5804.77 & 483.37 & -12.009 & $<2 e-16$ & $* * *$ & -404.124 & 50.110 & -8.065 & $1.01 e-15$ & $* * *$ \\
\hline September & -4270.08 & 487.55 & -8.758 & $<2 e-16$ & $* * *$ & -289.311 & 50.544 & -5.724 & $1.13 e-08$ & $* * *$ \\
\hline October & -2843.94 & 483.36 & -5.884 & $4.40 e-09$ & $* * *$ & -292.928 & 50.110 & -5.846 & $5.52 e-09$ & $* * *$ \\
\hline November & -2583.59 & 487.55 & -5.299 & $1.24 e-07$ & *** & -275.456 & 50.543 & -5.450 & $5.40 e-08$ & $* * *$ \\
\hline December & -638.40 & 483.38 & -1.321 & 0.18669 & & -65.280 & 50.111 & -1.303 & 0.192761 & \\
\hline 2012 & -2018.13 & 430.97 & -4.683 & $2.94 e-06$ & $* * *$ & -177.215 & 44.678 & -3.966 & $7.44 e-05$ & $* * *$ \\
\hline 2013 & 8541.96 & 431.27 & 19.807 & $<2 e-16$ & $* * *$ & -177.215 & 44.678 & -3.966 & $7.44 e-05$ & $* * *$ \\
\hline 2014 & -507.35 & 431.27 & -1.176 & 0.23951 & & 55.202 & 44.709 & 1.235 & 0.217026 & \\
\hline 2015 & 1149.83 & 431.27 & 2.666 & 0.00771 & ** & 402.844 & 44.709 & 9.010 & $<2 e-16$ & $* * *$ \\
\hline 2016 & 5684.77 & 430.97 & 13.191 & $<2 e-16$ & $* * *$ & 819.372 & 44.678 & 18.339 & $<2 e-16$ & $* * *$ \\
\hline 2017 & -859.47 & 431.27 & -1.993 & 0.04635 & $*$ & 139.706 & 44.709 & 3.125 & 0.001794 & $* *$ \\
\hline 2018 & -223.89 & 431.27 & -0.519 & 0.60369 & & 341.283 & 44.709 & 7.633 & $2.95 e-14$ & $* * *$ \\
\hline 2019 & -202.69 & 431.27 & -0.470 & 0.63839 & & 500.302 & 44.709 & 11.190 & $<2 e-16$ & $* * *$ \\
\hline 2020 & 793.98 & 575.28 & 1.380 & 0.16762 & & 925.931 & 59.638 & 15.526 & $<2 e-16$ & $* * *$ \\
\hline Multiple R-squared & \multicolumn{5}{|c|}{0.2991} & \multicolumn{5}{|c|}{0.2954} \\
\hline Adjusted R-squared & \multicolumn{4}{|c|}{0.2913} & & \multicolumn{5}{|c|}{0.2901} \\
\hline
\end{tabular}

\section{A.4 Summary statistics and time-series tests of the data series}

The summary statistics and time-series tests of the deseasonalized and detrended electricity prices are given in Table 19. In Table 20, we apply the augmented Dickey-Fuller (ADF) unit root test and Kwiatkowski-Phillips-Schmidt-Shin (KPSS) test to determine if the time series is stationary (Dickey and Fuller, 1979; Kwiatkowski et al., 1992). For the former test, we reject the null hypothesis of the presence of unit root at $1 \%$ for all the variables. On the other hand, we fail to reject the null hypothesis of stationarity for all the variables at $5 \%$ using the KPSS test, therefore confirming the stationarity of the data series. This eliminates the possibility of spurious regression results. In either case, we assume a constant (no visible trend) and choose optimal lag lengths based on the Bayesian information criterion (BIC). The BIC is more stringent for optimal lag selection than the Akaike information criterion (AIC).

The Jarque-Bera test for normality in Table 19 suggests that the distribution of prices is nonnormal with positive skewness and pronounced positive kurtosis. It is apparent that price spikes in the data series influences the non-normality of electricity prices. This is evident by the decrease 
Table 19: Summary statistics of electricity prices and the corresponding JB tests for NSW, SA, VIC, and TAS.

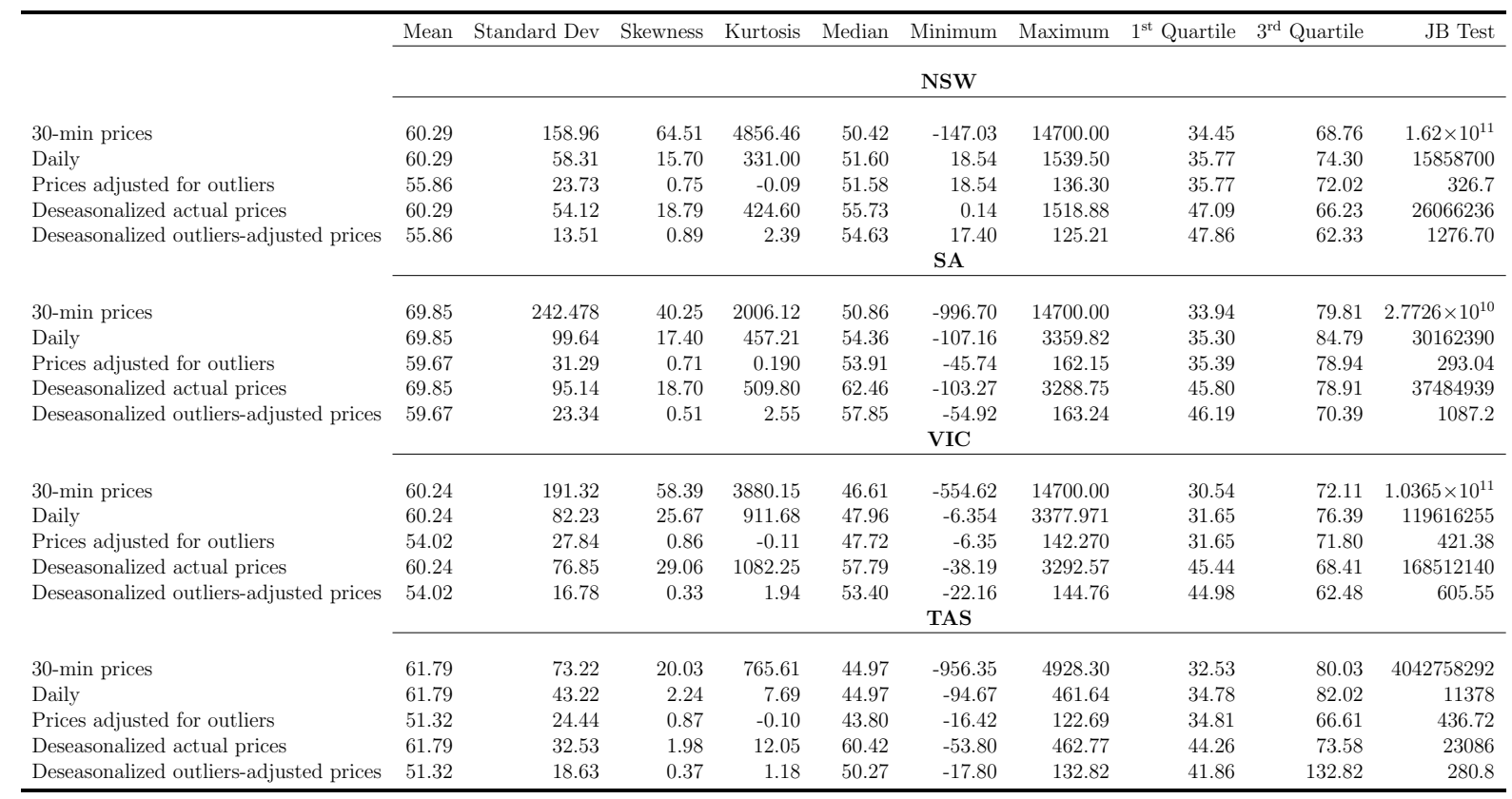

JB test stands for the Jarque-Bera test of normality. Its corresponding $p$ value is less than $2.2 \times 10^{-16}$ for all states. Hypothesis for JB test: $H_{0}$ : data are iid Normal, $H_{1}$ : data are Non-Normal. JB is asymptotically distributed as chi-square with 2 degrees of freedom.

of both values once the outliers are accounted for. However, the distribution of prices remains non-normal even after removal of outliers. This property suggests that ARCH type models may be appropriate to capture the volatility dynamics of electricity prices. This is further supported by clustering of price volatility as shown in Figures 7 and 8. We then apply the Ljung-Box or modified Q-statistic and the Engle (1982) autoregressive conditional heteroscedasticity-Lagrange multiplier (ARCH-LM) to check for the presence of autocorrelation and conditional heteroscedasticity (ARCH effects) in the time series. The estimated statistics for these tests for different lag values are given in Table 21. For the Ljung-Box test, we reject the null of no autocorrelation at a $1 \%$ level of significance for all lags and states. For the ARCH-LM test, we reject the null of no conditional heteroscedasticity at the same level of significance for NSW and TAS. The ARCH effect is, however, less pronounced in SA and VIC, where we find evidence only at lower lags. The significance of the estimated statistics for the series adjusted for price spikes reflects the impact of extreme observations and outliers in the actual price series. The results overall support the appropriateness of GARCH type models to adequately capture the conditional heteroscedasticity of the price series we examine. 
Table 20: The ADF and KPSS tests of stationarity.

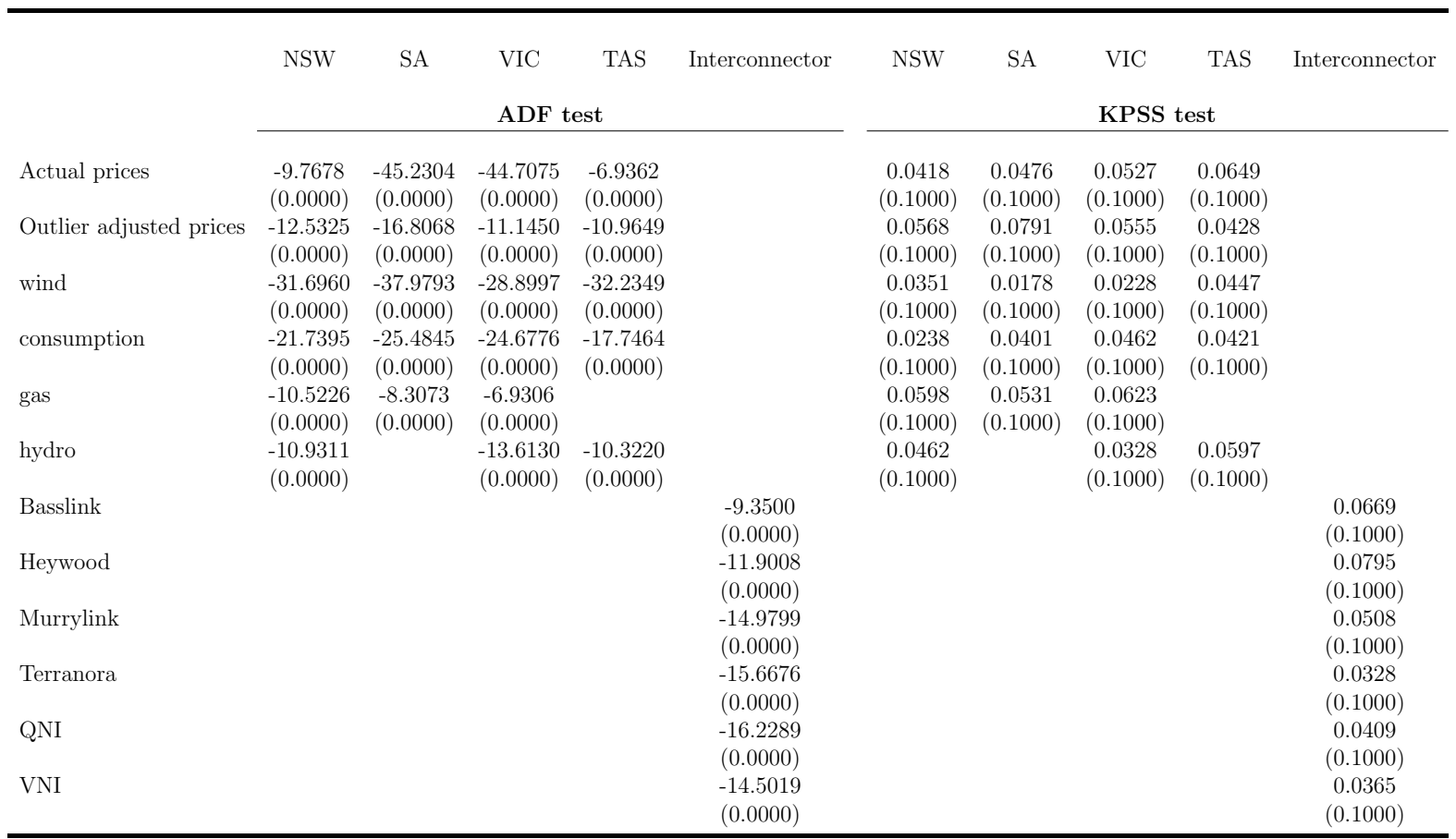

Hypothesis for ADF test: $H_{0}$ : unit root (non-stationary); $H_{1}$ : no unit root (stationary). Hypothesis for KPSS test: $H_{0}$ : the data is stationary and $H_{1}$ : the data is non-stationary.

Table 21: Tests for the autocorrelation and the conditional heteroscedasticity (ARCH effects) in prices series.

\begin{tabular}{|c|c|c|c|c|c|c|c|c|c|c|c|c|}
\hline \multirow[b]{3}{*}{ Lag } & \multicolumn{12}{|c|}{ Actual Prices } \\
\hline & \multicolumn{3}{|c|}{ NSW } & \multicolumn{3}{|c|}{$\mathrm{SA}$} & \multicolumn{3}{|c|}{ VIC } & \multicolumn{3}{|c|}{ TAS } \\
\hline & 1 & 7 & 30 & 1 & 7 & 30 & 1 & 7 & 30 & 1 & 7 & 30 \\
\hline \multirow[t]{2}{*}{$\begin{array}{l}\text { ARCH-LM Test } \\
p \text {-value }\end{array}$} & $\begin{array}{c}492.46 \\
\left(<2.2 \times 10^{-16}\right) \\
148.12 \\
\left(<2.2 \times 10^{-16}\right)\end{array}$ & $\begin{array}{c}685.61 \\
\left(<2.2 \times 10^{-16}\right) \\
154.85 \\
\left(<2.2 \times 10^{-16}\right)\end{array}$ & $\begin{array}{c}804.77 \\
\left(<2.2 \times 10^{-16}\right) \\
403.97 \\
\left(<2.2 \times 10^{-16}\right)\end{array}$ & $\begin{array}{c}221.16 \\
\left(<2.2 \times 10^{-16}\right) \\
4.4592 \\
(0.0347)\end{array}$ & $\begin{array}{c}286.13 \\
\left(<2.2 \times 10^{-16}\right) \\
4.5278 \\
(0.4788)\end{array}$ & $\begin{array}{c}327.37 \\
\left(<2.2 \times 10^{-16}\right) \\
4.7178 \\
(1.0000)\end{array}$ & $\begin{array}{c}240.49 \\
\left(<2.2 \times 10^{-16}\right) \\
9.4109 \\
(0.0022)\end{array}$ & $\begin{array}{c}267.84 \\
\left(<2.2 \times 10^{-16}\right) \\
9.4093 \\
(0.0938)\end{array}$ & $\begin{array}{c}293.67 \\
\left(<2.2 \times 10^{-16}\right) \\
9.4316 \\
(0.9999)\end{array}$ & $\begin{array}{c}2346.7 \\
\left(<2.2 \times 10^{-16}\right) \\
1650.9 \\
\left(<2.2 \times 10^{-16}\right)\end{array}$ & $\begin{array}{c}12620 \\
\left(<2.2 \times 10^{-16}\right) \\
1843.8 \\
\left(<2.2 \times 10^{-16}\right)\end{array}$ & $\begin{array}{c}33456 \\
\left(<2.2 \times 10^{-16}\right) \\
1882.5 \\
\left(<2.2 \times 10^{-16}\right)\end{array}$ \\
\hline & \multicolumn{12}{|c|}{ Adjusted Prices } \\
\hline
\end{tabular}

Hypothesis for Ljung-Box test: $H_{0}$ : the residuals are independently distributed (no autocorrelation); $H_{1}$ : the residuals exhibits autocorrelation. Hypothesis for ARCH-LM test: $H_{0}$ : the residuals does not exhibits conditional heteroscedasticity (ARCH effects) and $H_{1}$ : the residuals exhibits conditional heteroscedasticity (ARCH effects). 

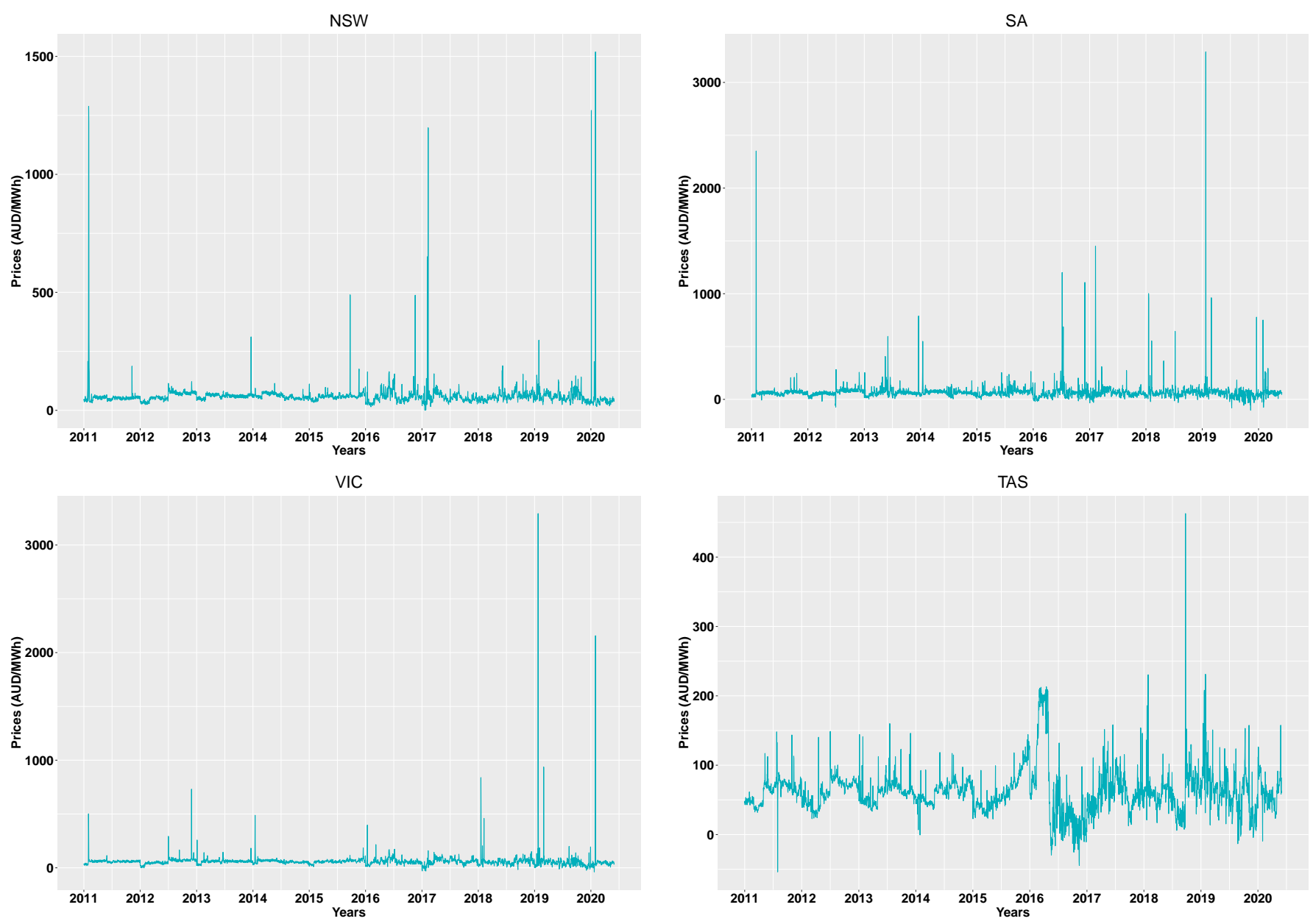

Figure 7: The daily average actual spot price adjusted for both the seasonal and trend effects for NSW, SA, VIC, and TAS from January 1, 2020, to May 31, 2020. 

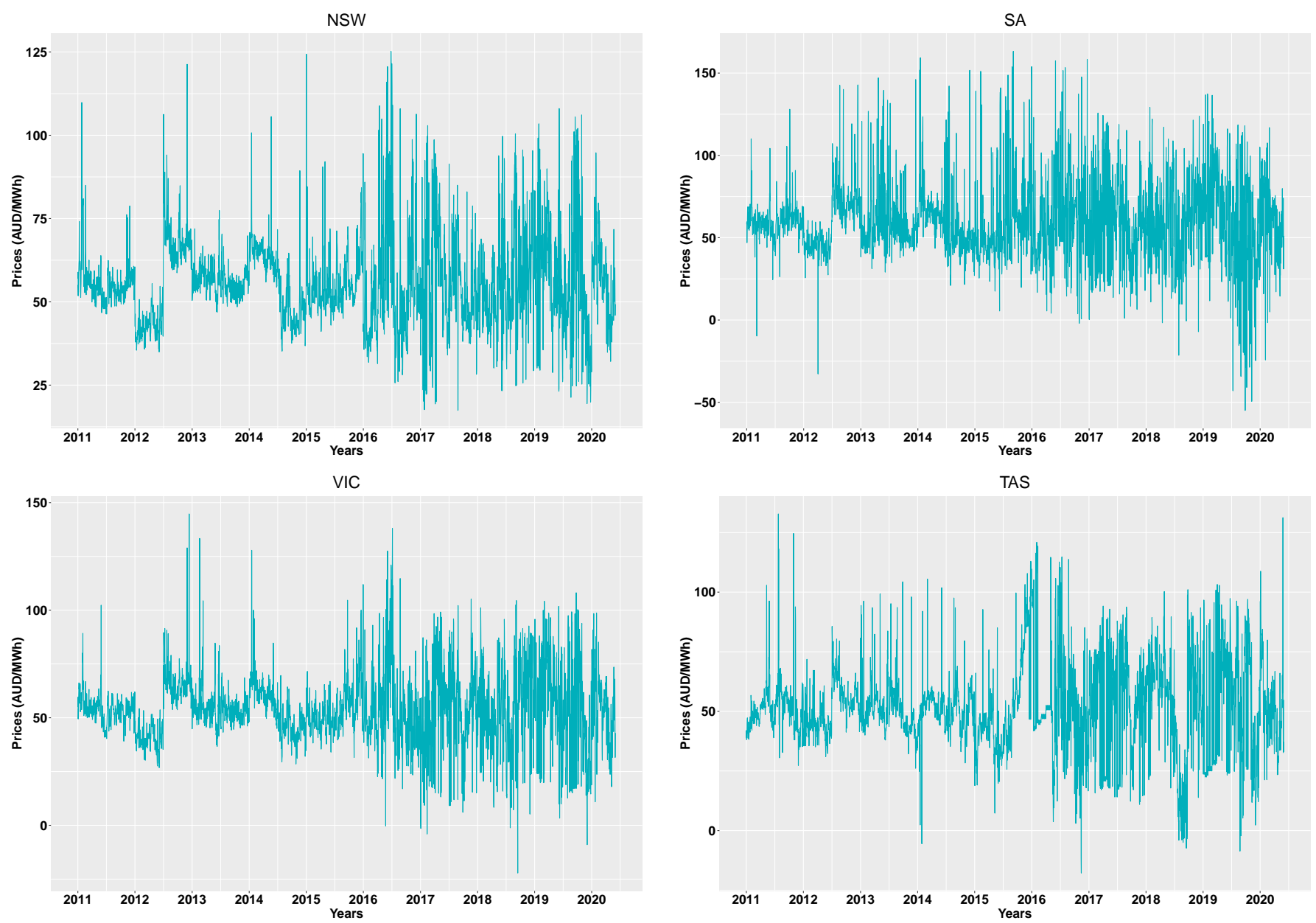

Figure 8: The daily average actual spot price adjusted for price spikes, seasonal and trend effects for NSW, SA, VIC, and TAS from January 1, 2020, to May 31, 2020.

Finally, we examined the regressors for collinearity using the correlation coefficient matrix (Figure 9 and 10) and variance inflation factors (VIF) in Table 22. Multicollinearity creates shared variance between variables, which inter-alia complicates attribution of causality amongst the regressors (Hair et al., 2019). It can also have substantial impact on the estimation of the regression coefficients and their statistical significance tests. Fixing the cut-off threshold of VIF at 3, we identify three variables for all states that might be the source of collinearity, that is, wind generation, electricity consumption, and wind penetration. In the same line, it is apparent that collinearity in TAS may also be brought about by having hydro generation and the Basslink interconnector flow in the same specification. To avoid multicollinearity issues we set up our models to study the effects of highly correlated variables separately. 

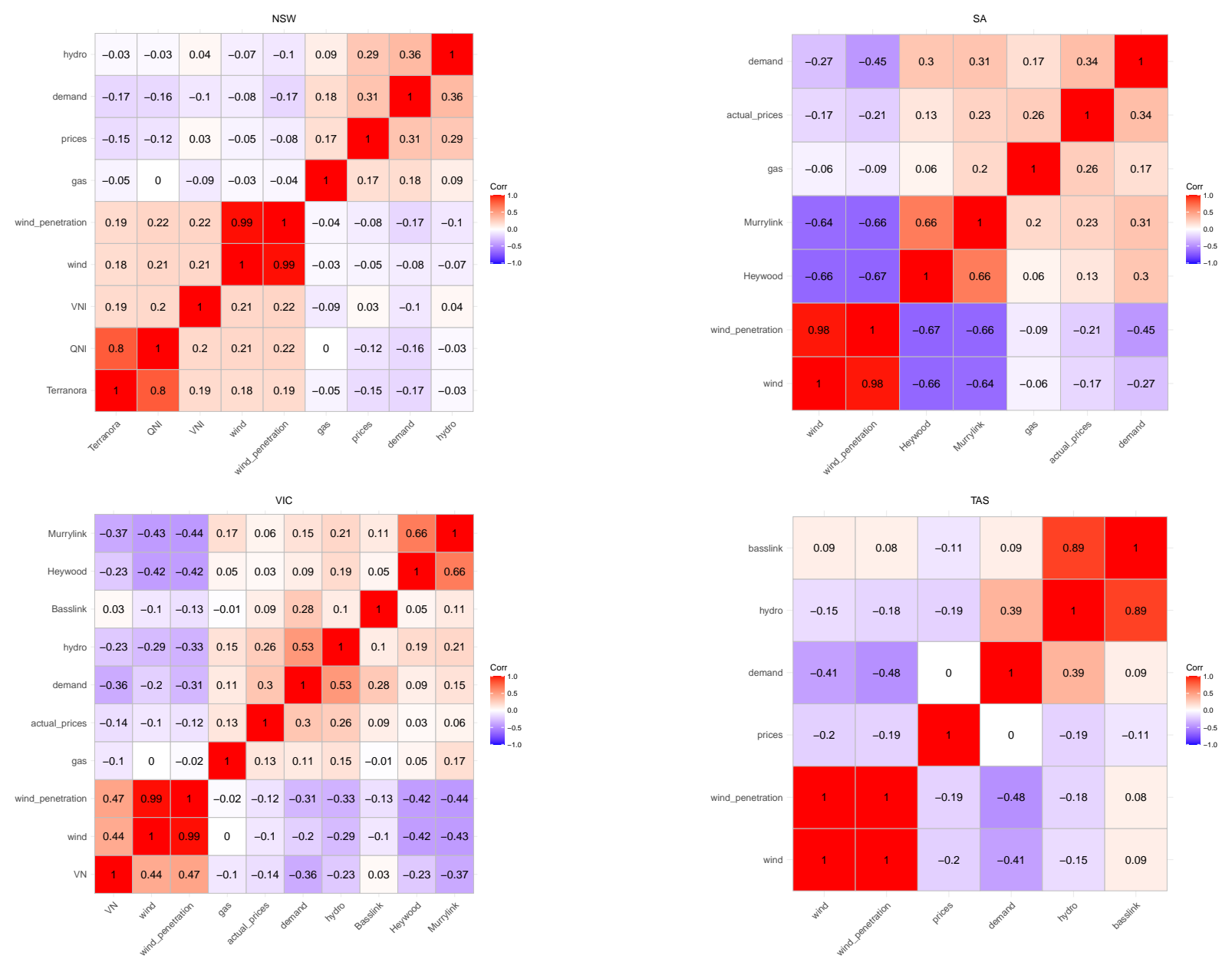

Figure 9: Correlation coefficient matrix of the variables. Prices stands for daily averaged prices adjusted for the seasonality and trend effects. 

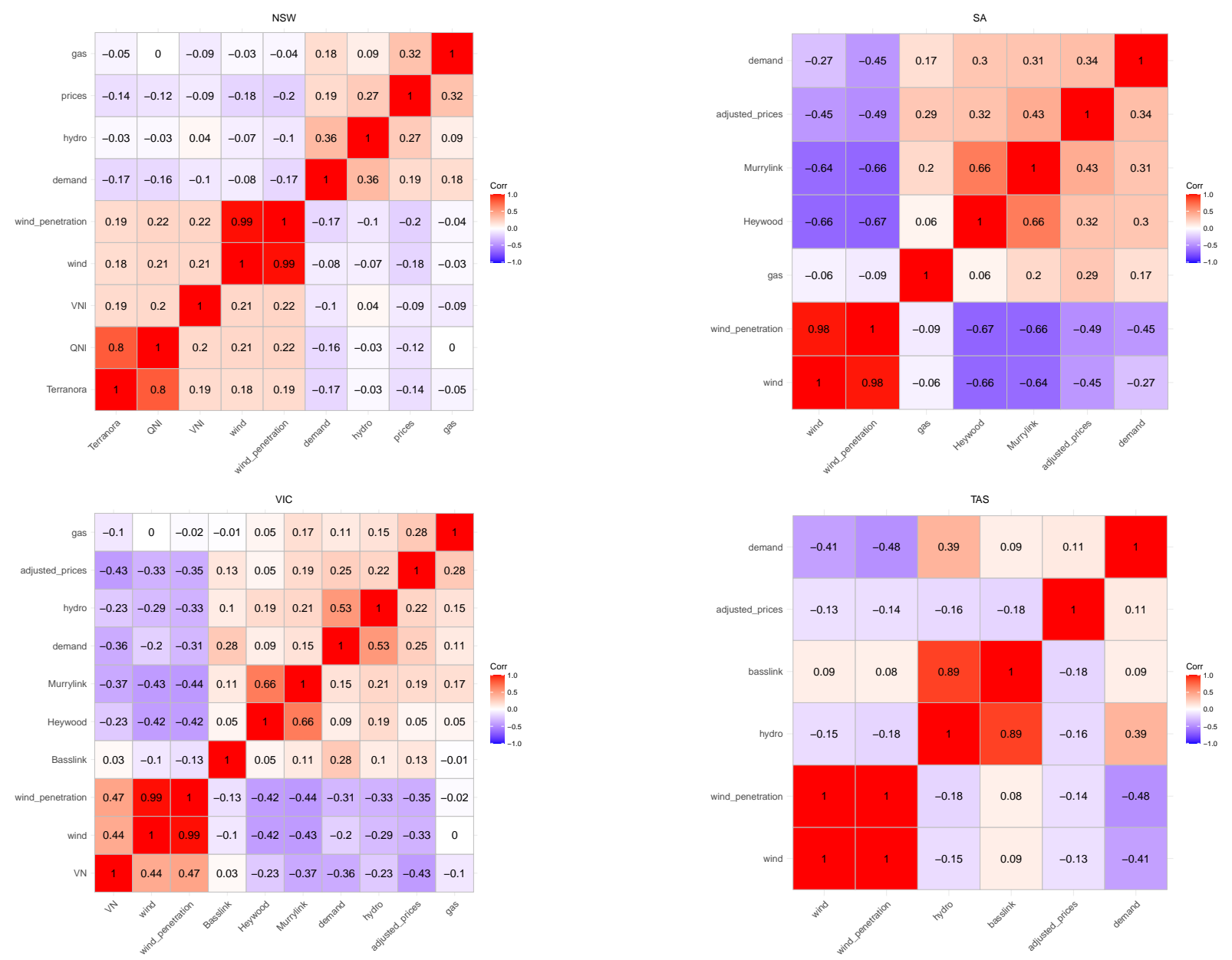

Figure 10: Correlation coefficient matrix of the variables. Prices stands for daily averaged prices adjusted for price spikes, seasonality and trend effects.

Table 22: VIF collinearity diagnostic measure.

\begin{tabular}{|c|c|c|c|c|c|c|c|c|c|}
\hline & NSW & $\mathrm{SA}$ & VIC & TAS & & NSW & $\mathrm{SA}$ & VIC & TAS \\
\hline & \multicolumn{5}{|c|}{ Actual Prices } & \multicolumn{4}{|c|}{ Adjusted Prices } \\
\hline wind & 379.5179 & 67.6639 & 229.6587 & 297.7076 & & 379.5179 & 67.6639 & 229.6587 & 297.7076 \\
\hline wind pen & 387.9440 & 77.8989 & 243.1950 & 321.5999 & & 387.9440 & 77.8989 & 243.1950 & 321.5999 \\
\hline consumption & 4.3269 & 4.1418 & 4.6484 & 4.1458 & & 4.3269 & 4.1418 & 4.6484 & 4.1458 \\
\hline gas & 1.0504 & 1.0728 & 1.0670 & & & 1.0504 & 1.0728 & 1.0670 & \\
\hline hydro & 1.1704 & & 1.5242 & 10.6125 & & 1.1704 & & 1.5242 & 10.6125 \\
\hline QNI & 2.7879 & & & & & 2.7879 & & & \\
\hline VNI & 1.0966 & & 1.5193 & & & 1.0957 & & 1.5193 & \\
\hline Terranora & 2.7589 & & & & & 2.7589 & & & \\
\hline Heywood & & 2.1895 & 1.9058 & & & & 2.1868 & 1.9058 & \\
\hline Murrylink & & 2.1794 & 2.0920 & & & & 2.1783 & 2.0920 & \\
\hline Basslink & & & & 1.1436 & 9.2441 & & & 1.1436 & 9.2441 \\
\hline
\end{tabular}




\section{B Choosing the optimal ARMA structure and distribution of the standardized residuals}

Guided by the literature, we apply eGARCH(1,1) as an adequate model of the conditional variance of electricity prices. We then add the autoregressive terms to capture the autocorrelation in electricity prices. This choice is supported by visual inspection of the autocorrelation (ACF) and partial autocorrelation (PACF) functions, which suggest insignificance of the moving average terms. Studies such as Woo et al. (2011), Ketterer (2014), and Kyritsis et al. (2017) come to the similar conclusions. We choose the order of $\operatorname{AR}(p)$ and the distribution of the standardized innovation by jointly estimating the AR-eGARCH model. We consider three common distributions, namely, the normal distribution, Nelson (1991) generalized error distribution (GED), and the Student distribution. We investigate the adequacy of the model fit using the weighted Ljung-Box test on standardized squared residuals and weighted ARCH LM tests (Fisher and Gallagher, 2012). The former is the portmanteau test with null the adequacy of the ARMA fit, and the latter adequately fitted the ARCH process (Ghalanos, 2020). The optimal lag is then adapted for the rest of the models, and the adequacy of the model fit assessed in the same manner.

The AR-eGARCH estimates of the actual prices adjusted for the seasonal and trend effects suggest adequate model fit using a single AR component. Both the Ljung-Box and the ARCHLM test in Table 23 suggests the model is correctly specified as both the autocorrelation (with a slight exception of TAS) and the ARCH effects are well captured. We further inspects the ACF and PACF of the standardized residuals and square standardized residuals (see Figure 11) which suggests little autocorrelation and absence of particular pattern due to the non-stationarity or seasonality of time series (Kyritsis et al., 2017). However, this is not the case for prices adjusted for outliers (see Figure 12), and the inclusion of a single AR structure fails to adequately capture the autocorrelations and the ARCH effects. Therefore, we choose the lag order $p$ that minimizes the BIC, that is, $p=7$ (see Figure 13, Table 24 and Table 25). Based on the BIC information criterion, the Student distribution outperforms the Normal Distribution (see Table 24 and 26) reflecting the non-normality characteristics of the Australian electricity market, and Nelson (1991) generalized error distribution (GED). 
Table 23: The weighted Ljung-Box test on standardized residuals, standardized squared residuals, and the weighted ARCH LM tests of the AR-eGARCH fitted models for NSW, SA, VIC, and TAS. The models estimated using actual prices adjusted for the seasonality and trend effect, one autoregressive component, and Student distribution. Corresponding $p$ value in parenthesis.

\begin{tabular}{|c|c|c|c|c|c|c|c|c|c|}
\hline & Lag 1 & Lag 4 & Lag 20 & Lag 1 & Lag 20 & Lag 36 & Lag 3 & Lag 5 & $\operatorname{Lag} 7$ \\
\hline \multirow[b]{2}{*}{ NSW } & \multicolumn{3}{|c|}{ Ljung-Box on $\hat{z}_{t}$} & \multicolumn{3}{|c|}{ Ljung-Box on $\hat{z}_{t}^{2}$} & \multicolumn{3}{|c|}{ ARCH LM Tests } \\
\hline & $\begin{array}{r}0.0003 \\
(0.98577\end{array}$ & $\begin{array}{r}0.6612 \\
(0.9136)\end{array}$ & $\begin{array}{r}1.35012 \\
(0.8815)\end{array}$ & $\begin{array}{r}0.0015 \\
(0.9693)\end{array}$ & $\begin{array}{r}0.0030 \\
(1.0000)\end{array}$ & $\begin{array}{r}0.0051 \\
(1.0000)\end{array}$ & $\begin{array}{r}0.0000 \\
(0.9941)\end{array}$ & $\begin{array}{r}0.0013 \\
(1.0000)\end{array}$ & $\begin{array}{r}0.0027 \\
(1.0000)\end{array}$ \\
\hline \multirow{2}{*}{$\mathrm{SA}$} & 0.0000 & 0.0250 & 0.3655 & 0.0067 & 0.0196 & 0.0367 & 0.0052 & 0.0197 & 0.0307 \\
\hline & $(0.9959)$ & $(1.0000)$ & $(0.9978)$ & $(0.9347)$ & $(0.9999)$ & $(1.0000)$ & $(0.9427)$ & $(0.9987)$ & $(1.0000)$ \\
\hline \multirow[t]{2}{*}{ VIC } & 0.7636 & 1.1207 & 1.5872 & 0.0041 & 0.0146 & 0.0332 & 0.0056 & 0.0203 & 0.0326 \\
\hline & $(0.3822)$ & (0.6658) & $\begin{array}{l}(0.8249) \\
58.240\end{array}$ & $(0.9490)$ & $\begin{array}{l}(1.0000) \\
1535\end{array}$ & $\begin{array}{r}(1.0000) \\
2.4107\end{array}$ & $\begin{array}{r}(0.9403) \\
0.6028\end{array}$ & $(0.9986)$ & $(1.0000)$ \\
\hline TAS & $\begin{array}{r}40.2000 \\
(0.0000)\end{array}$ & $\begin{array}{r}50.700000 \\
(0.0000)\end{array}$ & $\begin{array}{l}58.2400 \\
(0.0000)\end{array}$ & $\begin{array}{r}0.2426 \\
(0.6223)\end{array}$ & $\begin{array}{r}1.5357 \\
(0.7311)\end{array}$ & $\begin{array}{r}2.4107 \\
(0.8507)\end{array}$ & $\begin{array}{r}0.6028 \\
(0.4375)\end{array}$ & $\begin{array}{r}1.0905 \\
(0.7063)\end{array}$ & $\begin{array}{r}1.6395 \\
(0.7930)\end{array}$ \\
\hline
\end{tabular}
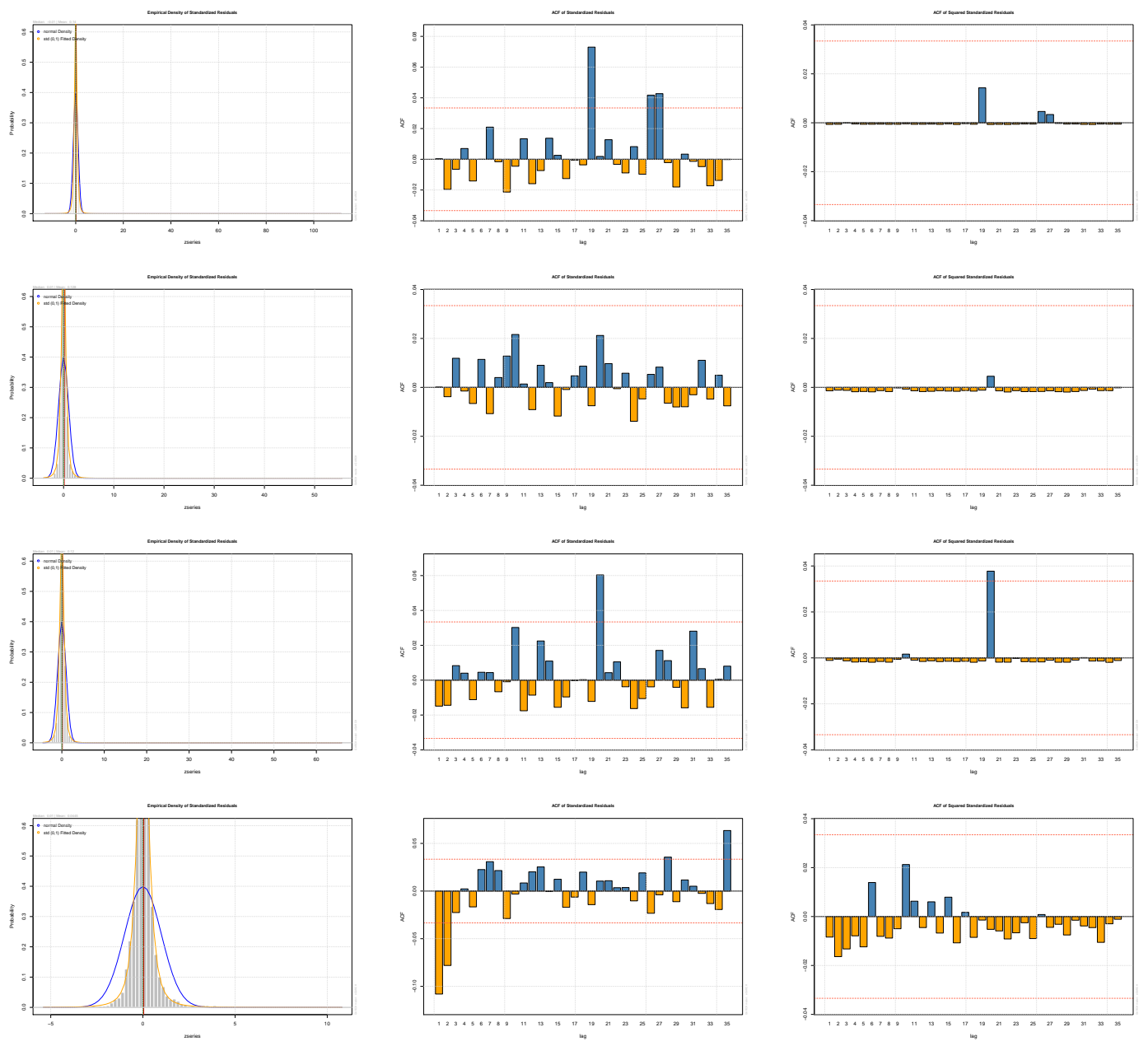

Figure 11: The empirical density of standardized residuals, ACF of standardized residuals, and ACF of standardized squared residuals of the AR-eGARCH fitted models for NSW (first row), SA (second row), VIC (third row), and TAS (fourth row). All models estimated using actual prices adjusted for the seasonality and trend effect, one autoregressive component, and Student distribution. 

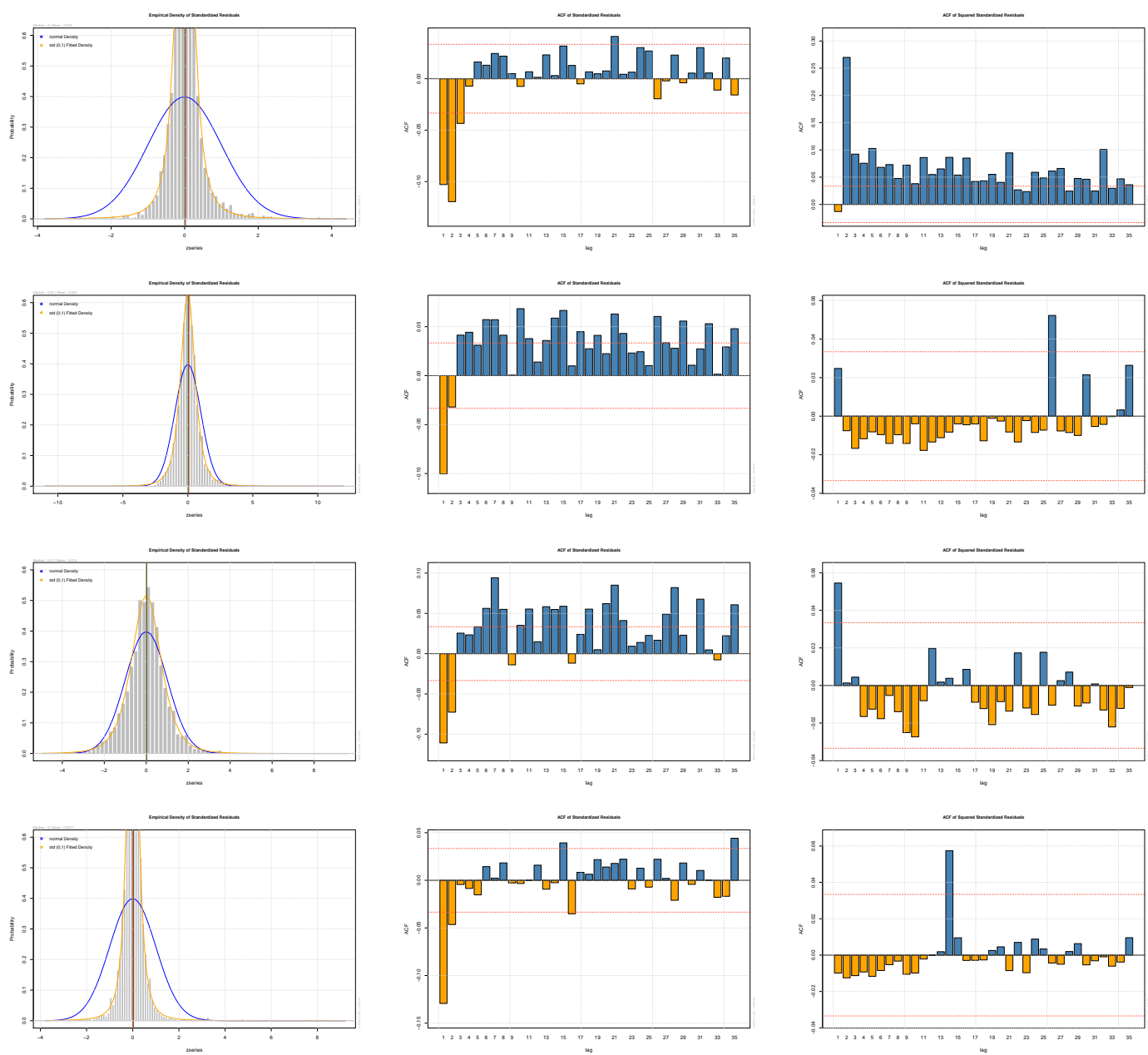

Figure 12: The empirical density of standardized residuals, ACF of standardized residuals, and ACF of standardized squared residuals of the AR-eGARCH models for NSW (first row), SA (second row), VIC (third row), and TAS (fourth row). All models estimated using prices adjusted for outliers, seasonality, and trend effect, one autoregressive component, and Student distribution. 
Table 24: Log-likelihood, BIC, and AIC estimates of the AR-eGARCH model for the outliers adjusted prices under the Normal Distribution (Normal), the Student Distribution (Student's-t), and Generalized Error Distribution (GED).

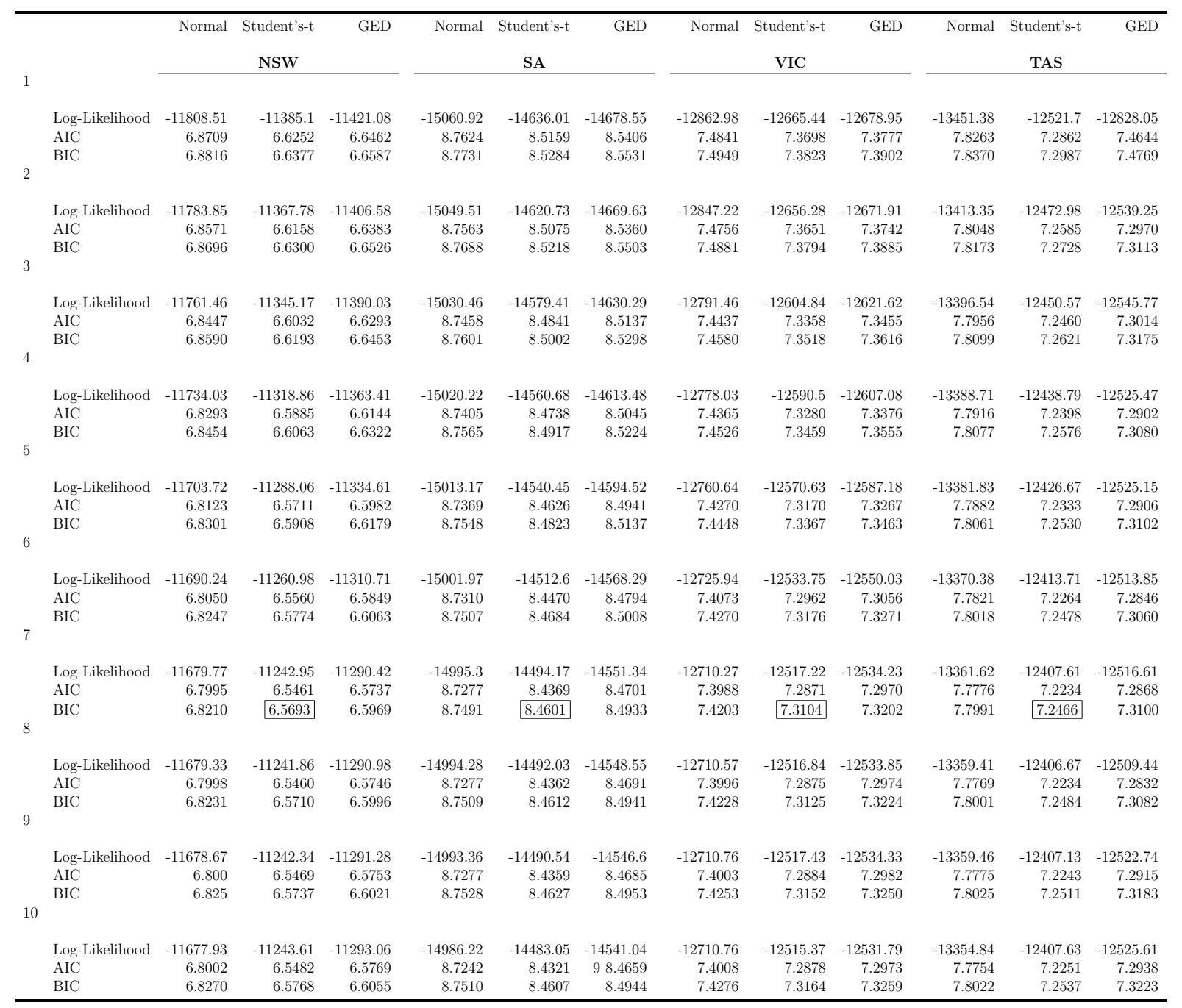

Table 25: The weighted Ljung-Box test on standardized residuals, standardized squared residuals, and the weighted ARCH LM tests of the AR-eGARCH fitted models for NSW, SA, VIC, and TAS. All models estimated using prices adjusted for outliers, seasonality and trend effect, seven autoregressive components, and Student distribution. Corresponding $p$ value in parenthesis.

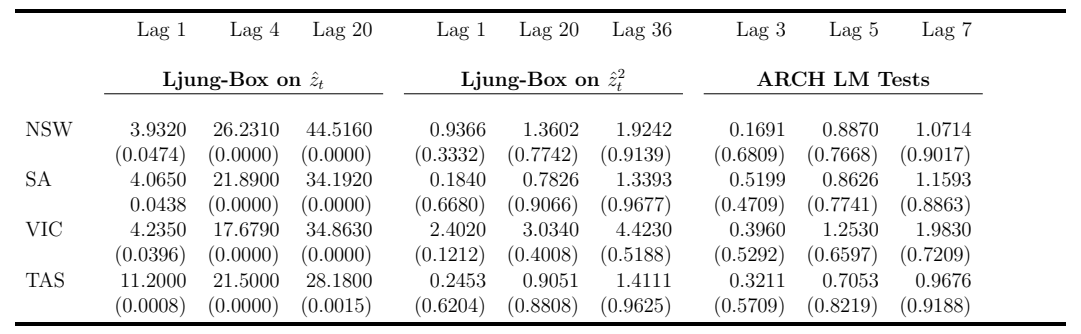



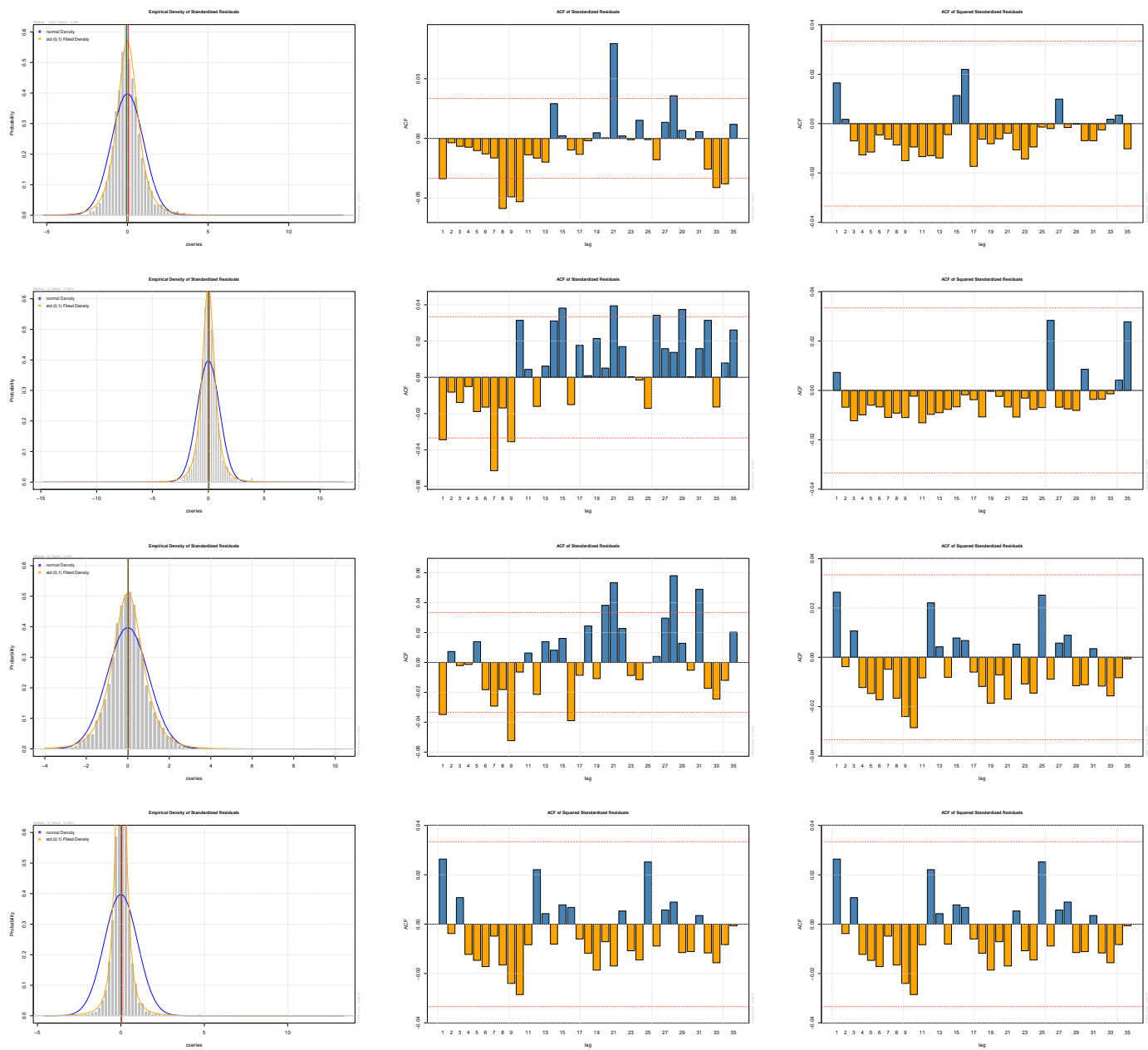

Figure 13: The empirical density of standardized residuals, ACF of standardized residuals, and ACF of standardized squared residuals of the AR-eGARCH models for NSW (first row), SA (second row), VIC (third row), and TAS (fourth row). All models estimated using prices adjusted for the outliers, seasonality, and trend effects, seven autoregressive components, and Student distribution.

Table 26: Log-likelihood, BIC, and AIC of AR-eGARCH for the actual prices adjusted for the seasonality and trend effects under the Normal Distribution (Normal), the Student Distribution (Student's-t), and Generalized Error Distribution (GED)

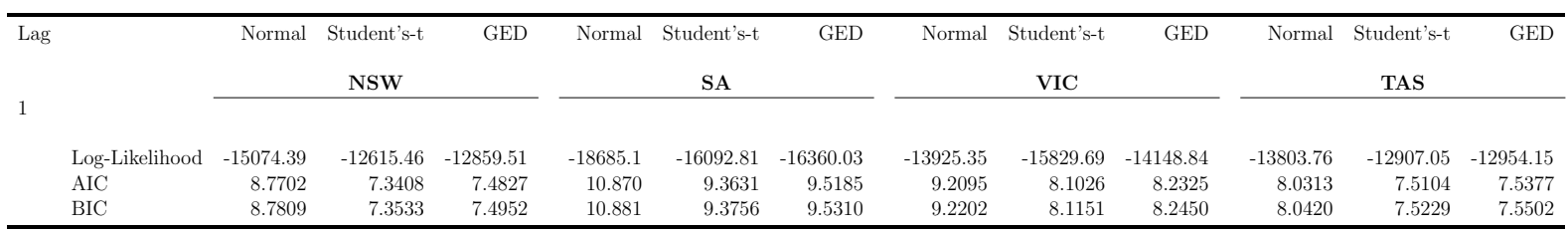




\section{Model Results}

Table 27: The effect of wind generation, electricity consumption, hydro generation, and interconnectors flow on New South Wales' electricity price behavior. The effect on price levels is given by the mean equation and on price volatility by the variance equation.

\begin{tabular}{|c|c|c|c|c|c|c|c|c|c|c|}
\hline & Model A & Model B & Model C & Model D & Model E & Model F & Model G & Model H & Model I & Model J \\
\hline \multicolumn{11}{|c|}{ Mean Equation } \\
\hline$\mu$ & $\begin{array}{r}54.4671 \\
(0.0000)\end{array}$ & $\begin{array}{r}56.7646 \\
(0.0000)\end{array}$ & $\begin{array}{r}16.4629 \\
(0.0000)\end{array}$ & $\begin{array}{r}18.4053 \\
(0.0000)\end{array}$ & $\begin{array}{r}57.0256 \\
(0.0000)\end{array}$ & $\begin{array}{r}52.6879 \\
(0.0000)\end{array}$ & $\begin{array}{r}51.5705 \\
(0.0000)\end{array}$ & $\begin{array}{r}54.3879 \\
(0.0000)\end{array}$ & $\begin{array}{r}22.8198 \\
(0.0000)\end{array}$ & $\begin{array}{r}52.4369 \\
(0.0000)\end{array}$ \\
\hline \multirow[t]{2}{*}{$\phi_{1}$} & 0.7231 & 0.7077 & 0.6815 & 0.6711 & 0.7033 & 0.7156 & 0.6836 & 0.73173 & 0.6671 & 0.6703 \\
\hline & $(0.0000)$ & $(0.0000)$ & $(0.0000)$ & $(0.0000)$ & $(0.0000)$ & $(0.0000)$ & $(0.0000)$ & $(0.0000)$ & $(0.0000)$ & $(0.0000)$ \\
\hline \multirow[t]{2}{*}{$\phi_{2}$} & 0.0023 & 0.0192 & 0.0075 & 0.0185 & 0.0240 & 0.0055 & 0.0176 & 0.0104 & 0.0327 & 0.0423 \\
\hline & $(0.6661)$ & $(0.0171)$ & $(0.6356)$ & $(0.2066)$ & $(0.0774)$ & $(0.1694)$ & $(0.1167)$ & $(0.1517)$ & $(0.0000)$ & $(0.0004)$ \\
\hline \multirow[t]{2}{*}{$\phi_{3}$} & 0.0132 & 0.0190 & 0.0267 & 0.0272 & 0.0186 & 0.0132 & 0.0168 & 0.0080 & 0.0228 & 0.0173 \\
\hline & $(0.5525)$ & $(0.2587)$ & $(0.0000)$ & $(0.0184)$ & $(0.1520)$ & $(0.1002)$ & $(0.1598)$ & $(0.6138)$ & $(0.0001)$ & $(0.1847)$ \\
\hline \multirow[t]{2}{*}{$\phi_{4}$} & 0.0215 & 0.0246 & 0.0262 & 0.0346 & 0.0249 & 0.0215 & 0.0283 & 0.0204 & 0.0307 & 0.0321 \\
\hline & $(0.3697)$ & $(0.0591)$ & $(0.0000)$ & $(0.0387)$ & $(0.0000)$ & $(0.2349)$ & $(0.0059)$ & $(0.4410)$ & $(0.0025)$ & $(0.0019)$ \\
\hline \multirow[t]{2}{*}{$\phi_{5}$} & 0.0463 & 0.0395 & 0.0558 & 0.0559 & 0.0410 & 0.0437 & 0.0448 & 0.0381 & 0.0492 & 0.0371 \\
\hline & $(0.0000)$ & $(0.0292)$ & $(0.0000)$ & $(0.0000)$ & $(0.0006)$ & $(0.0118)$ & $(0.0002)$ & $(0.0581)$ & $(0.0000)$ & $(0.0008)$ \\
\hline \multirow[t]{2}{*}{$\phi_{6}$} & 0.0558 & 0.0548 & 0.0688 & 0.0567 & 0.0540 & 0.0602 & 0.0633 & 0.0570 & 0.0595 & 0.0622 \\
\hline & $(0.0000)$ & $(0.0558)$ & $(0.0000)$ & $(0.0000)$ & $(0.0040)$ & $(0.0001)$ & $(0.0000)$ & $(0.0003)$ & $(0.0024)$ & $(0.0000)$ \\
\hline \multirow[t]{2}{*}{$\phi_{7}$} & 0.0912 & 0.0900 & 0.1015 & 0.1020 & 0.0908 & 0.0916 & 0.1008 & 0.0930 & 0.1032 & 0.0989 \\
\hline & $(0.0000)$ & $(0.0039)$ & $(0.0000)$ & $(0.0000)$ & $(0.0000)$ & $(0.0166)$ & $(0.0000)$ & $(0.0000)$ & $(0.0000)$ & $(0.0000)$ \\
\hline \multirow[t]{2}{*}{ wind } & & -4.6439 & & -4.4180 & & & & & -3.7232 & \\
\hline & & $(0.0000)$ & & $(0.0000)$ & & & & & $(0.0000)$ & \\
\hline demand & & & $\begin{array}{r}2.0378 \\
\end{array}$ & $\begin{array}{r}2.0087 \\
(0.0000)\end{array}$ & & & & & $\begin{array}{r}1.6472 \\
(0.0000)\end{array}$ & \\
\hline wind $_{p e n}$ & & & & & $\begin{array}{c}-98.6784 \\
(0.0000)\end{array}$ & & & & & $\begin{array}{c}-82.9010 \\
(0.0000)\end{array}$ \\
\hline gas & & & & & & 0.3170 & & & 0.1755 & 0.2473 \\
\hline & & & & & & $(0.0021)$ & & & $(0.0507)$ & $(0.0012)$ \\
\hline hydro & & & & & & & 3.9882 & & 1.6997 & 3.5790 \\
\hline & & & & & & & $(0.0000)$ & & $(0.0000)$ & $(0.0000)$ \\
\hline exim $_{\text {terra }}$ & & & & & & & & -1.7394 & -2.0088 & -1.7976 \\
\hline & & & & & & & & $(0.0238)$ & $(0.1630)$ & $(0.3410)$ \\
\hline $\operatorname{exim}_{Q N I}$ & & & & & & & & -1.2378 & -0.7030 & -0.8221 \\
\hline & & & & & & & & $(0.0000)$ & $(0.0000)$ & $(0.0010)$ \\
\hline $\operatorname{exim}_{V N I}$ & & & & & & & & -1.3227 & -0.9320 & -0.9937 \\
\hline & & & & & & & & $(0.0000)$ & $(0.0000)$ & $(0.0000)$ \\
\hline & & & & Var & iance Equat & ion & & & & \\
\hline$\omega$ & 0.1032 & 0.1439 & -0.3264 & -0.2773 & 0.1547 & 0.1153 & 0.1102 & 0.0947 & -0.2880 & 0.1232 \\
\hline & $(0.0000)$ & $(0.0000)$ & $(0.0348)$ & $(0.0000)$ & $(0.0000)$ & $(0.0000)$ & $(0.0000)$ & $(0.0000)$ & $(0.0000)$ & $(0.0000)$ \\
\hline$\alpha$ & 0.1228 & 0.1314 & 0.1003 & 0.1018 & 0.1309 & 0.1212 & 0.0978 & 0.1286 & 0.0969 & 0.1067 \\
\hline & $(0.0000)$ & $(0.0000)$ & $(0.0000)$ & $(0.0000)$ & $(0.0000)$ & $(0.0000)$ & $(0.0000)$ & $(0.0000)$ & $(0.0000)$ & $(0.0000)$ \\
\hline$\beta$ & 0.9725 & 0.9656 & 0.9685 & 0.9598 & 0.9647 & 0.9728 & 0.9666 & 0.9705 & 0.9495 & 0.9535 \\
\hline & $(0.0000)$ & $(0.0000)$ & $(0.0000)$ & $(0.0000)$ & $(0.0000)$ & $(0.0000)$ & $(0.0000)$ & $(0.0000)$ & $(0.0000)$ & $(0.0000)$ \\
\hline$\gamma$ & 0.3150 & 0.3323 & 0.3296 & 0.3571 & 0.3343 & 0.3174 & 0.3638 & 0.3157 & 0.4075 & 0.3942 \\
\hline & $(0.0000)$ & $(0.0000)$ & $(0.0000)$ & $(0.0000)$ & $(0.0000)$ & $(0.0000)$ & $(0.0000)$ & $(0.0000)$ & $(0.0000)$ & $(0.0000)$ \\
\hline wind & & -0.0311 & & $\begin{array}{r}-0.0451 \\
(0.0177\end{array}$ & & & & & -0.0396 & \\
\hline & & $(0.3657)$ & & $(0.2177)$ & & & & & $(0.3211)$ & \\
\hline demand & & & $\begin{array}{r}0.0229 \\
(0.0040)\end{array}$ & $\begin{array}{r}0.0231 \\
(0.0000)\end{array}$ & & & & & $\begin{array}{r}0.0236 \\
(0.0031)\end{array}$ & \\
\hline wind $_{p e n}$ & & & & & $\begin{array}{r}-0.8859 \\
(0.1768)\end{array}$ & & & & & $\begin{array}{r}-0.6894 \\
(0.3651)\end{array}$ \\
\hline gas & & & & & & -0.0023 & & & 0.0015 & 0.0034 \\
\hline & & & & & & $(0.5819)$ & & & $(0.7866)$ & $(0.4909)$ \\
\hline hydro & & & & & & & 0.0221 & & 0.0155 & 0.031 \\
\hline & & & & & & & $(0.2535)$ & & $(0.5162)$ & $(0.1300)$ \\
\hline exim $_{\text {terra }}$ & & & & & & & & 0.0307 & 0.1254 & 0.0723 \\
\hline & & & & & & & & $(0.8761)$ & $(0.6149)$ & $(0.7675)$ \\
\hline $\operatorname{exim}_{Q N I}$ & & & & & & & & -0.0182 & -0.0316 & -0.0330 \\
\hline & & & & & & & & $(0.3583)$ & $(0.2063)$ & $(0.1743)$ \\
\hline $\operatorname{exim}_{V N I}$ & & & & & & & & 0.0028 & 0.0070 & 0.0052 \\
\hline & & & & & & & & $(0.7662)$ & $(0.5602)$ & $(0.6624)$ \\
\hline Shape & 3.4368 & 3.3929 & 3.4182 & 3.3359 & 3.3722 & 3.4476 & 3.6069 & 3.3588 & 3.3574 & 3.4859 \\
\hline & $(0.0000)$ & $(0.0000)$ & $(0.0000)$ & $(0.0000)$ & $(0.0000)$ & $(0.0000)$ & $(0.0000)$ & $(0.0000)$ & $(0.0000)$ & $(0.0000)$ \\
\hline log likelihood & -11242.95 & -11148.33 & -11054.17 & -10957.75 & -11122.25 & -11235.37 & -11175.04 & -11166.32 & -10902.65 & -11008.81 \\
\hline$A I C$ & 6.5461 & 6.4922 & 6.4374 & 6.3825 & 6.4770 & 6.5428 & 6.5077 & 6.5050 & 6.3563 & 6.4169 \\
\hline$B I C$ & 6.5693 & 6.5190 & 6.4642 & 6.4129 & 6.5038 & 6.5696 & 6.5345 & 6.5389 & 6.4045 & 6.4615 \\
\hline$Q(40)$ & 27.5400 & 27.5930 & 26.5570 & 27.4930 & 27.8320 & 25.6490 & 27.5780 & 29.2200 & 50.4120 & 30.4650 \\
\hline & $(0.0000)$ & $(0.0000)$ & $(0.0000)$ & $(0.0000)$ & $(0.0000)$ & $(0.0000)$ & $(0.0000)$ & $(0.0000)$ & $(0.0000)$ & $(0.0000)$ \\
\hline$Q^{2}(36)$ & 1.9236 & 1.5490 & 1.9610 & 1.4263 & 1.4587 & 1.7955 & 2.1241 & 1.9506 & 1.4449 & 1.5353 \\
\hline & $(0.9139)$ & $(0.9515)$ & $(0.9096)$ & $(0.9614)$ & $(0.9589)$ & $(0.9280)$ & $(0.8897)$ & $(0.9108)$ & $(0.9599)$ & $(0.9526)$ \\
\hline ARCH-LM Test & 1.0712 & 1.2162 & 1.3015 & 1.3158 & 1.2072 & 0.9922 & 1.5474 & 1.2131 & 1.5726 & 1.6648 \\
\hline & $(0.9017)$ & $(0.8760)$ & $(0.8602)$ & $(0.8574)$ & $(0.8777)$ & $(0.9148)$ & $(0.8118)$ & $(0.8766)$ & $(0.8067)$ & $(0.7878)$ \\
\hline Observations & 3439 & 3439 & 3439 & 3439 & 3439 & 3439 & 3439 & 3439 & 3439 & 3439 \\
\hline
\end{tabular}

Wind generation, electricity consumption, hydro generation, and the cross-border interconnector flows are scaled by $10^{4}$ to clarify the presentation of the results. The corresponding coefficients should, therefore, be multiplied by $0.1 \mathrm{AUD} / \mathrm{MWh}$ and 0.1 for a $1 \mathrm{GWh}$ increase in either variable for the mean equation and the variance equation, respectively. AIC denotes the Akaike information criterion, BIC is the Bayesian information criterion and ARCH $\mathrm{LM}$ is the Lagrange multiplier test for $\mathrm{ARCH}$ effect. The $p$ values are in parentheses. 
Table 28: The effect of wind generation, electricity consumption, hydro generation, and interconnectors flow on Victoria's electricity price behavior. The effect on price levels is given by the mean equation and on price volatility by the variance equation.

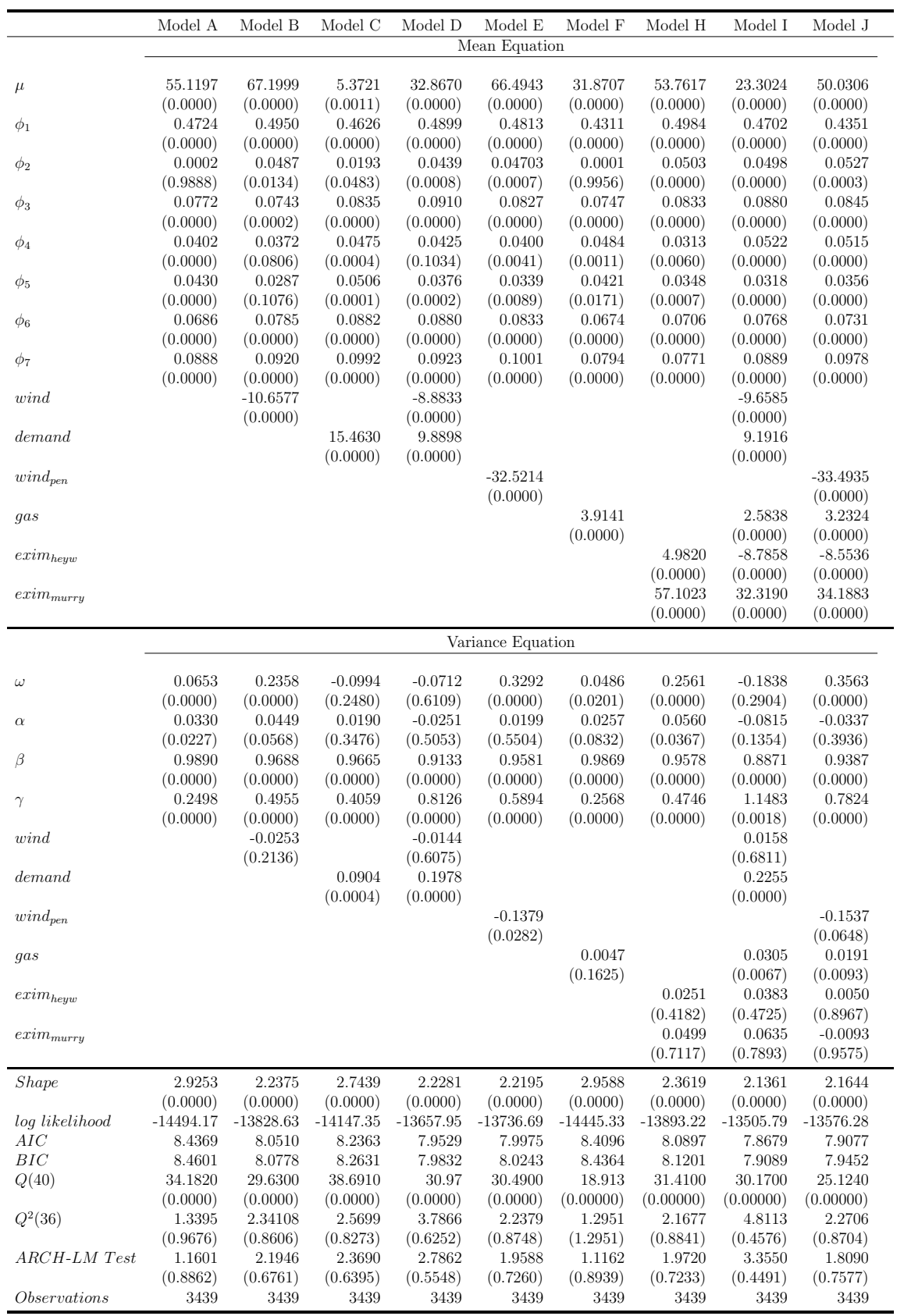

Wind generation, electricity consumption, hydro generation, and the cross-border interconnector flows are scaled by $10^{4}$ to clarify the presentation of the results. The corresponding coefficients should, therefore, be multiplied by $0.1 \mathrm{AUD} / \mathrm{MWh}$ and 0.1 for a $1 \mathrm{GWh}$ increase in either variable for the mean equation and the variance equation, respectively. AIC denotes the Akaike information criterion, BIC is the Bayesian information criterion and ARCH LM is the Lagrange multiplier test for ARCH effect. The $p$ values are in parentheses. 
Table 29: The effect of wind generation, electricity consumption, hydro generation, and interconnectors flow on South Australia's electricity price behavior. The effect on price levels is given by the mean equation and on price volatility by the variance equation.

\begin{tabular}{|c|c|c|c|c|c|c|c|c|c|c|}
\hline & Model A & Model B & Model C & Model D & Model E & Model F & Model G & Model H & Model I & Model J \\
\hline & \multicolumn{10}{|c|}{ Mean Equation } \\
\hline \multirow[t]{2}{*}{$\mu$} & 52.3733 & 57.6046 & 3.7017 & 20.5258 & 57.4160 & 45.2958 & 47.0058 & 55.2372 & 39.9271 & 48.8940 \\
\hline & $(0.0000)$ & $(0.0000)$ & $(0.0032)$ & $(0.0000)$ & $(0.0000)$ & $(0.0000)$ & $(0.0000)$ & $(0.0000)$ & $(0.0000)$ & $(0.0000)$ \\
\hline \multirow[t]{2}{*}{$\phi_{1}$} & 0.6389 & 0.6481 & 0.5999 & 0.6135 & 0.6368 & 0.6215 & 0.6137 & 0.6233 & 0.5736 & 0.5751 \\
\hline & $(0.0000)$ & $(0.0000)$ & $(0.0000)$ & $(0.0000)$ & $(0.0000)$ & $(0.0000)$ & $(0.0000)$ & $(0.0000)$ & $(0.0000)$ & $(0.0000)$ \\
\hline \multirow[t]{2}{*}{$\phi_{2}$} & -0.0578 & -0.0323 & -0.0350 & -0.0222 & -0.0249 & -0.0463 & -0.0481 & -0.0429 & -0.0276 & -0.0252 \\
\hline & $(0.0003)$ & $(0.8079)$ & $(0.0047)$ & $(0.4908)$ & $(0.0018)$ & $(0.0051)$ & $(0.0000)$ & $(0.0068)$ & $(0.0212)$ & $(0.1486)$ \\
\hline \multirow[t]{2}{*}{$\phi_{3}$} & 0.0990 & 0.0857 & 0.1116 & 0.0984 & 0.0824 & 0.0966 & 0.1002 & 0.0796 & 0.0919 & 0.0858 \\
\hline & $(0.0000)$ & $(0.5303)$ & $(0.0000)$ & $(0.0000)$ & $(0.0000)$ & $(0.0000)$ & $(0.0000)$ & $(0.0000)$ & $(0.0000)$ & $(0.0000)$ \\
\hline \multirow[t]{2}{*}{$\phi_{4}$} & 0.0142 & 0.0222 & 0.0183 & 0.0262 & 0.0274 & 0.0158 & 0.0252 & 0.0093 & 0.0338 & 0.0348 \\
\hline & $(0.1661)$ & $(0.8851)$ & $(0.0494)$ & $(0.3330)$ & $(0.0002)$ & $(0.0029)$ & $(0.0142)$ & $(0.4510)$ & $(0.0000)$ & $(0.0008)$ \\
\hline \multirow[t]{2}{*}{$\phi_{5}$} & 0.0226 & 0.0078 & 0.0113 & -0.0019 & 0.0064 & 0.0205 & 0.0247 & -0.0026 & -0.0118 & -0.0104 \\
\hline & $(0.0796)$ & $(0.8400)$ & $(0.0969)$ & $(0.9642)$ & $(0.0540)$ & $(0.1077)$ & $(0.0001)$ & $(0.6595)$ & $(0.0205)$ & $(0.1891)$ \\
\hline \multirow[t]{2}{*}{$\phi_{6}$} & 0.0828 & 0.0901 & 0.0977 & 0.1004 & 0.0914 & 0.0842 & 0.0990 & 0.0921 & 0.1049 & 0.1048 \\
\hline & $(0.0000)$ & $(0.0887)$ & $(0.0000)$ & $(0.0000)$ & $(0.0000)$ & $(0.0000)$ & $(0.0000)$ & $(0.0000)$ & $(0.0000)$ & $(0.0000)$ \\
\hline$\phi_{7}$ & 0.0974 & 0.0951 & 0.1158 & 0.1106 & 0.0973 & 0.1004 & 0.1016 & 0.1398 & 0.1483 & 0.1471 \\
\hline & $(0.0000)$ & $(0.3142)$ & $(0.0000)$ & $(0.0000)$ & $(0.0000)$ & $(0.0000)$ & $(0.0000)$ & $(0.0000)$ & $(0.0000)$ & $(0.0000)$ \\
\hline wind & & $\begin{array}{r}-6.7633 \\
-0.0000)\end{array}$ & & $\begin{array}{r}-5.5992 \\
-0.0009)\end{array}$ & & & & & $\begin{array}{r}-3.9581 \\
-(0.0000\end{array}$ & \\
\hline demand & & $(0.4$ & 3.8937 & $\begin{array}{r}(0.0000) \\
2.8274\end{array}$ & & & & & $\begin{array}{r}(0.0000) \\
0.7467\end{array}$ & \\
\hline 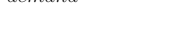 & & & $(0.0000)$ & $(0.0000)$ & & & & & $(0.0000)$ & \\
\hline wind $_{p e n}$ & & & & & $\begin{array}{r}-84.5162 \\
(0.0000)\end{array}$ & & & & & $\begin{array}{r}-48.9434 \\
(0.0000)\end{array}$ \\
\hline gas & & & & & & 1.2524 & & & 1.0410 & 1.0593 \\
\hline & & & & & & $(0.0000)$ & & & $(0.0000)$ & $(0.0000)$ \\
\hline hydro & & & & & & & 7.6591 & & 3.4482 & 3.8860 \\
\hline & & & & & & & $(0.0000)$ & & $(0.0000)$ & $(0.0000)$ \\
\hline $\operatorname{exim}_{\text {bass }}$ & & & & & & & & 5.4234 & 3.5435 & 3.6762 \\
\hline & & & & & & & & $(0.0000)$ & $(0.0000)$ & $(0.0000)$ \\
\hline exim $_{\text {heyw }}$ & & & & & & & & -0.2851 & -2.4048 & -2.4072 \\
\hline & & & & & & & & $(0.4763)$ & $(0.0000)$ & $(0.0000)$ \\
\hline $\operatorname{exim}_{V N I}$ & & & & & & & & -5.0591 & -3.1865 & -3.3607 \\
\hline & & & & & & & & $(0.0000)$ & $(0.0000)$ & $(0.0000)$ \\
\hline exim $_{\text {murr }}$ & & & & & & & & 3.6669 & 1.4308 & 1.0712 \\
\hline & & & & & & & & $(0.0014)$ & $(0.2597)$ & $(0.3191)$ \\
\hline & & & & & iance Equat & & & & & \\
\hline$\omega$ & 0.1018 & 0.2277 & -0.4748 & -0.5004 & 0.2443 & 0.1126 & 0.0798 & 0.1180 & -0.4061 & 0.1173 \\
\hline & $(0.0000)$ & $(0.0000)$ & $(0.0000)$ & $(0.0000)$ & $(0.0000)$ & $(0.0000)$ & $(0.0000)$ & $(0.0000)$ & $(0.0612)$ & $(0.0492)$ \\
\hline$\alpha$ & 0.0562 & 0.0345 & 0.0388 & 0.0158 & 0.0254 & 0.0559 & 0.0317 & 0.0183 & -0.0018 & -0.0084 \\
\hline & (0.0019) & $(0.0130)$ & $(0.0333)$ & $(0.4660)$ & $(0.2163)$ & $(0.0025)$ & $(0.1041)$ & $(0.3292)$ & $(0.9326)$ & $(0.6869)$ \\
\hline$\beta$ & 0.9777 & 0.9634 & 0.9724 & 0.9546 & 0.9623 & 0.9773 & 0.9642 & 0.9710 & 0.9522 & 0.9537 \\
\hline & $(0.0000)$ & $(0.0000)$ & $(0.0000)$ & $(0.0000)$ & $(0.0000)$ & $(0.0000)$ & $(0.0000)$ & $(0.0000)$ & $(0.0000)$ & $(0.0000)$ \\
\hline$\gamma$ & 0.3691 & 0.4537 & 0.4085 & 0.5056 & 0.4600 & 0.3705 & 0.4688 & 0.3983 & 0.5121 & 0.5068 \\
\hline & $(0.0000)$ & $(0.0000)$ & $(0.0000)$ & $(0.0000)$ & $(0.0000)$ & $(0.0000)$ & $(0.0000)$ & $(0.0000)$ & $(0.0000)$ & $(0.0000)$ \\
\hline wind & & -0.0753 & & -0.0750 & & & & & -0.0575 & \\
\hline & & $(0.0027)$ & & $(0.0051)$ & & & & & $(0.0740)$ & \\
\hline demand & & & 0.0477 & 0.0607 & & & & & 0.0426 & \\
\hline & & & $(0.0000)$ & $(0.0000)$ & & & & & $(0.0230)$ & \\
\hline wind $_{p e n}$ & & & & & $\begin{array}{r}-1.1093 \\
(0.0000)\end{array}$ & & & & & $\begin{array}{r}-0.7805 \\
(0.0443)\end{array}$ \\
\hline gas & & & & & & -0.0016 & & & 0.0061 & 0.0061 \\
\hline & & & & & & $(0.7276)$ & & & $(0.4037)$ & $(0.4041)$ \\
\hline hydro & & & & & & & 0.1137 & & 0.0937 & 0.1173 \\
\hline & & & & & & & $(0.0004)$ & & $(0.0032)$ & $(0.0003)$ \\
\hline exim $_{\text {bass }}$ & & & & & & & & 0.0237 & 0.0121 & 0.0250 \\
\hline & & & & & & & & $(0.0792)$ & $(0.5083)$ & $(0.1367)$ \\
\hline exim $_{\text {heyw }}$ & & & & & & & & 0.0837 & 0.0874 & 0.0815 \\
\hline & & & & & & & & $(0.0058)$ & $(0.0270)$ & $(0.0364)$ \\
\hline $\operatorname{exim}_{V N I}$ & & & & & & & & -0.0202 & -0.0058 & -0.0137 \\
\hline & & & & & & & & $(0.0973)$ & $(0.7248)$ & $(0.4034)$ \\
\hline exim $_{\text {murr }}$ & & & & & & & & -0.2703 & -0.3346 & -0.3545 \\
\hline & & & & & & & & $(0.0394)$ & $(0.0505)$ & $(0.0384)$ \\
\hline Shape & 4.3361 & 3.5155 & 3.9659 & 3.5518 & 3.5114 & 4.2910 & 3.9738 & 3.3547 & 3.4325 & 3.4263 \\
\hline & $(0.0$ & $(0.0000)$ & $(0.0$ & $(0.0$ & $(0 . c$ & 00) & & & $(0.0$ & $(0.0000)$ \\
\hline log likelihood & -12517.22 & -12108.07 & -12236.63 & -11935.77 & -12060.80 & -12493.68 & -12263.25 & -11964.87 & -11692.29 & -11702.40 \\
\hline$A I C$ & 7.2871 & 7.0503 & 7.1251 & 6.9513 & 7.0229 & 7.2746 & 7.1406 & 6.9706 & 6.8167 & 6.8214 \\
\hline$B I C$ & 7.3104 & 7.0771 & 7.1519 & 6.9817 & 7.0496 & 7.3014 & 7.1674 & 7.0081 & 6.8685 & 6.8696 \\
\hline$Q(40)$ & 17.6610 & 18.794 & 20.543 & 18.1550 & 18.0700 & 17.7610 & 22.1480 & 25.5500 & 21.4390 & 22.6700 \\
\hline & $(0.0000)$ & $(0.0000)$ & $(0.0000)$ & $(0.0000)$ & $(0.0000)$ & $(0.0000)$ & $(0.0000)$ & $(0.0000)$ & $(0.0000)$ & $(0.0000)$ \\
\hline$Q^{2}(36)$ & 4.4210 & 2.6504 & 9.1040 & 4.0244 & 2.3855 & 4.3300 & 5.6070 & 1.1140 & 3.2740 & 3.0125 \\
\hline & $(0.5190)$ & $(0.8150)$ & $(0.0774)$ & $(0.5847)$ & $(0.8543)$ & $(0.5338)$ & $(0.3459)$ & $(0.9810)$ & $(0.7130)$ & $(0.7569)$ \\
\hline ARCH-LM Test & 1.9836 & 1.7143 & 5.3290 & 3.1130 & 1.6288 & 2.1935 & 2.9195 & 0.8132 & 2.2460 & 2.0653 \\
\hline & $(0.7208)$ & $(0.7775)$ & $(0.1934)$ & $(0.4924)$ & $(0.7952)$ & $(0.6764)$ & $(0.5289)$ & $(0.9419)$ & $(0.6652)$ & $(0.7035)$ \\
\hline Observations & 3439 & 3439 & 3439 & 3439 & 3439 & 3439 & 3439 & 3439 & 3439 & 3439 \\
\hline
\end{tabular}

Wind generation, electricity consumption, hydro generation, and the cross-border interconnector flows are scaled by $10^{4}$ to clarify the presentation of the results. The corresponding coefficients should, therefore, be multiplied by $0.1 \mathrm{AUD} / \mathrm{MWh}$ and 0.1 for a $1 \mathrm{GWh}$ increase in either variable for the mean equation and the variance equation, respectively. AIC denotes the Akaike information criterion, BIC is the Bayesian information criterion and ARCH $\mathrm{LM}$ is the Lagrange multiplier test for ARCH effect. The $p$ values are in parentheses. 
Table 30: The effect of wind generation, electricity consumption, hydro generation, and interconnectors flow on Tasmania's electricity price behavior. The effect on price levels is given by the mean equation and on price volatility by the variance equation.

\begin{tabular}{|c|c|c|c|c|c|c|c|c|c|}
\hline & Model A & Model B & Model C & Model D & Model E & Model G & Model H & Model I & Model J \\
\hline & \multicolumn{9}{|c|}{ Mean Equation } \\
\hline$\mu$ & $\begin{array}{r}47.0315 \\
(0.0000)\end{array}$ & $\begin{array}{r}46.5598 \\
(0.0000)\end{array}$ & $\begin{array}{r}11.3323 \\
(0.0162)\end{array}$ & $\begin{array}{r}18.6648 \\
(0.0000)\end{array}$ & $\begin{array}{l}46.2901 \\
(0.0000)\end{array}$ & $\begin{array}{c}46.2105 \\
(0.0000)\end{array}$ & $\begin{array}{c}46.9814 \\
(0.0000)\end{array}$ & $\begin{array}{r}18.7611 \\
(0.0000)\end{array}$ & $\begin{array}{c}45.8133 \\
(0.0000)\end{array}$ \\
\hline \multirow[t]{2}{*}{$\phi_{1}$} & 0.6666 & 0.6728 & 0.6782 & 0.6757 & 0.6738 & 0.6623 & 0.6708 & 0.6713 & 0.6835 \\
\hline & $(0.0000)$ & $(0.0000)$ & $(0.0000)$ & $(0.0000)$ & $(0.0000)$ & $(0.0000)$ & $(0.0000)$ & $(0.0000)$ & $(0.0000)$ \\
\hline$\phi_{2}$ & $\begin{array}{r}0.0849 \\
(0.0061)\end{array}$ & $\begin{array}{r}0.0816 \\
(0.0000)\end{array}$ & $\begin{array}{r}0.0819 \\
(0.0094)\end{array}$ & $\begin{array}{r}0.0797 \\
(0.0000)\end{array}$ & $\begin{array}{r}0.0816 \\
(0.0000)\end{array}$ & $\begin{array}{r}0.0847 \\
(0.0000)\end{array}$ & $\begin{array}{r}0.0853 \\
(0.0000)\end{array}$ & $\begin{array}{r}0.0800 \\
(0.0001)\end{array}$ & $\begin{array}{r}0.0777 \\
(0.0021)\end{array}$ \\
\hline$\phi_{3}$ & $\begin{array}{r}0.0489 \\
(0.0000)\end{array}$ & $\begin{array}{r}0.0449 \\
(0.0000)\end{array}$ & $\begin{array}{r}0.0481 \\
(0.0006)\end{array}$ & $\begin{array}{r}0.0487 \\
(0.0000)\end{array}$ & $\begin{array}{r}0.0446 \\
(0.0048)\end{array}$ & $\begin{array}{r}0.0508 \\
(0.0000)\end{array}$ & $\begin{array}{r}0.0484 \\
(0.0002)\end{array}$ & $\begin{array}{r}0.0498 \\
(0.0028)\end{array}$ & $\begin{array}{r}0.0452 \\
(0.0289)\end{array}$ \\
\hline$\phi_{4}$ & $\begin{array}{r}(0.0000) \\
0.0266 \\
(0.0000)\end{array}$ & $\begin{array}{r}0.0266 \\
(0.0258)\end{array}$ & $\begin{array}{r}0.0306 \\
(0.0000)\end{array}$ & $\begin{array}{r}(0.0000) \\
0.0280 \\
(0.0123)\end{array}$ & $\begin{array}{r}(0.0048) \\
0.0259 \\
(0.0000)\end{array}$ & $\begin{array}{r}0.0273 \\
(0.0295)\end{array}$ & $\begin{array}{r}0.0235 \\
(0.0000)\end{array}$ & $\begin{array}{r}0.0297 \\
(0.0368)\end{array}$ & $\begin{array}{r}0.0243 \\
(0.0027)\end{array}$ \\
\hline$\phi_{5}$ & $\begin{array}{r}0.0320 \\
(0.0358)\end{array}$ & $\begin{array}{r}0.0368 \\
(0.0000)\end{array}$ & $\begin{array}{r}0.0377 \\
(0.0000)\end{array}$ & $\begin{array}{r}0.0400 \\
(0.0012)\end{array}$ & $\begin{array}{r}0.0381 \\
(0.0074)\end{array}$ & $\begin{array}{r}0.0331 \\
(0.0104)\end{array}$ & $\begin{array}{r}0.0338 \\
(0.0000)\end{array}$ & $\begin{array}{r}0.0416 \\
(0.0349)\end{array}$ & $\begin{array}{r}0.0384 \\
(0.0000)\end{array}$ \\
\hline$\phi_{6}$ & $\begin{array}{r}0.0446 \\
(0.0000)\end{array}$ & $\begin{array}{r}0.0522 \\
(0.0000)\end{array}$ & $\begin{array}{r}0.0408 \\
(0.0000)\end{array}$ & $\begin{array}{r}0.0447 \\
(0.0000)\end{array}$ & $\begin{array}{r}0.0512 \\
(0.0000)\end{array}$ & $\begin{array}{r}0.0454 \\
(0.0000)\end{array}$ & $\begin{array}{r}0.0434 \\
(0.0003)\end{array}$ & $\begin{array}{r}0.0423 \\
(0.0001)\end{array}$ & $\begin{array}{r}0.0489 \\
(0.0012)\end{array}$ \\
\hline$\phi_{7}$ & $\begin{array}{r}0.0402 \\
(0.0093)\end{array}$ & $\begin{array}{r}0.0425 \\
(0.0000)\end{array}$ & $\begin{array}{r}0.0418 \\
(0.0000)\end{array}$ & $\begin{array}{r}0.0434 \\
(0.0001)\end{array}$ & $\begin{array}{r}0.0427 \\
(0.0001)\end{array}$ & $\begin{array}{r}0.0409 \\
(0.0000)\end{array}$ & $\begin{array}{r}0.0387 \\
(0.0002)\end{array}$ & $\begin{array}{r}0.0449 \\
(0.0016)\end{array}$ & $\begin{array}{r}0.0411 \\
(0.0000)\end{array}$ \\
\hline wind & & $\begin{array}{r}-8.1098 \\
(0.0000)\end{array}$ & & $\begin{array}{r}-3.8676 \\
(0.0000)\end{array}$ & & & & $\begin{array}{r}-4.0573 \\
(0.0000)\end{array}$ & \\
\hline demand & & $\begin{array}{r}12.2871 \\
(0.0000)\end{array}$ & $\begin{array}{r}9.7754 \\
(0.0000)\end{array}$ & & & & & $\begin{array}{r}9.5098 \\
(0.0000)\end{array}$ & \\
\hline wind $_{p e n}$ & & & & & $\begin{array}{r}-21.5690 \\
(0.0000)\end{array}$ & & & & $\begin{array}{c}-22.1955 \\
(0.0000)\end{array}$ \\
\hline hydro & & & & & & $\begin{array}{r}0.8854 \\
(0.0000)\end{array}$ & & $\begin{array}{r}1.11433 \\
(0.0020)\end{array}$ & \\
\hline \multirow[t]{2}{*}{ exim $_{\text {bass }}$} & & & & & & & $\begin{array}{r}1.0686 \\
(0.0000) \\
\end{array}$ & & $\begin{array}{r}1.4303 \\
(0.0000) \\
\end{array}$ \\
\hline & \multicolumn{9}{|c|}{ Variance Equation } \\
\hline$\omega$ & $\begin{array}{r}0.6014 \\
(0.0000)\end{array}$ & $\begin{array}{r}0.7769 \\
(0.0000)\end{array}$ & $\begin{array}{r}0.5400 \\
(0.0426)\end{array}$ & $\begin{array}{r}0.8031 \\
(0.0056)\end{array}$ & $\begin{array}{r}0.7841 \\
(0.0000)\end{array}$ & $\begin{array}{r}0.5972 \\
(0.0000)\end{array}$ & $\begin{array}{r}0.6224 \\
(0.0000)\end{array}$ & $\begin{array}{r}0.7994 \\
(0.0060)\end{array}$ & $\begin{array}{r}0.8150 \\
(0.0000)\end{array}$ \\
\hline$\alpha$ & $\begin{array}{r}-0.0957 \\
(0.0398)\end{array}$ & $\begin{array}{r}-0.1312 \\
(0.0199)\end{array}$ & $\begin{array}{r}-0.1413 \\
(0.0076)\end{array}$ & $\begin{array}{r}-0.1437 \\
(0.0069)\end{array}$ & $\begin{array}{r}-0.1355 \\
(0.0104)\end{array}$ & $\begin{array}{r}-0.0974 \\
(0.0259)\end{array}$ & $\begin{array}{r}-0.1014 \\
(0.0214)\end{array}$ & $\begin{array}{r}-0.1502 \\
(0.0047)\end{array}$ & $\begin{array}{r}-0.1452 \\
(0.0061)\end{array}$ \\
\hline$\beta$ & $\begin{array}{r}0.8973 \\
(0.0000)\end{array}$ & $\begin{array}{r}0.8882 \\
(0.0000)\end{array}$ & $\begin{array}{r}0.8866 \\
(0.0000)\end{array}$ & $\begin{array}{r}0.8856 \\
(0.0000)\end{array}$ & $\begin{array}{r}0.8875 \\
(0.0000)\end{array}$ & $\begin{array}{r}0.8995 \\
(0.0000)\end{array}$ & $\begin{array}{r}0.8938 \\
(0.0000)\end{array}$ & $\begin{array}{r}0.8866 \\
(0.0000)\end{array}$ & $\begin{array}{r}0.8825 \\
(0.0000)\end{array}$ \\
\hline$\gamma$ & $\begin{array}{r}1.0338 \\
(0.0000)\end{array}$ & $\begin{array}{r}1.3613 \\
(0.0000)\end{array}$ & $\begin{array}{r}1.4363 \\
(0.0000)\end{array}$ & $\begin{array}{r}1.4619 \\
(0.0000)\end{array}$ & $\begin{array}{r}1.4058 \\
(0.0000)\end{array}$ & $\begin{array}{r}1.0264 \\
(0.0000)\end{array}$ & $\begin{array}{r}1.0247 \\
(0.0000)\end{array}$ & $\begin{array}{r}1.4671 \\
(0.0000)\end{array}$ & $\begin{array}{r}1.4696 \\
(0.0000)\end{array}$ \\
\hline wind & & $\begin{array}{r}-0.2768 \\
(0.0210)\end{array}$ & & $\begin{array}{r}-0.3009 \\
(0.0149)\end{array}$ & & & & $\begin{array}{r}-0.2953 \\
(0.0171)\end{array}$ & \\
\hline demand & & $\begin{array}{r}0.0697 \\
(0.4754)\end{array}$ & $\begin{array}{r}0.0023 \\
(0.9824)\end{array}$ & & & & & $\begin{array}{r}0.0013 \\
(0.9901)\end{array}$ & \\
\hline wind $_{\text {pen }}$ & & & & & $\begin{array}{r}-0.6763 \\
(0.0283)\end{array}$ & & & & $\begin{array}{r}-0.5472 \\
(0.0825)\end{array}$ \\
\hline hydro & & & & & & $\begin{array}{r}-0.0151 \\
(0.6787)\end{array}$ & & $\begin{array}{r}-0.0014 \\
(0.9713)\end{array}$ & \\
\hline exim $_{\text {bass }}$ & & & & & & & $\begin{array}{r}-0.0684 \\
(0.0053) \\
\end{array}$ & & $\begin{array}{r}-0.0578 \\
(0.0286) \\
\end{array}$ \\
\hline Shape & $\begin{array}{r}2.1983 \\
(0.0000)\end{array}$ & $\begin{array}{r}2.1152 \\
(0.0000)\end{array}$ & $\begin{array}{r}2.1000 \\
(0.0000)\end{array}$ & $\begin{array}{r}2.10000 \\
(0.0000)\end{array}$ & $\begin{array}{r}2.1074 \\
(0.0000)\end{array}$ & $\begin{array}{r}2.2031 \\
(0.0000)\end{array}$ & $\begin{array}{r}2.2074 \\
(0.0000)\end{array}$ & $\begin{array}{r}2.1000 \\
(0.0000)\end{array}$ & $\begin{array}{r}2.1000 \\
(0.0000)\end{array}$ \\
\hline log likelihood & -12407.61 & -12321.76 & -12281.24 & -12262.56 & -12315.69 & -12402.36 & -12398.72 & -12256.61 & -12305.23 \\
\hline$A I C$ & 7.2234 & 7.1746 & 7.1511 & 7.1414 & 7.1711 & 7.2215 & 7.2194 & 7.1391 & 7.1662 \\
\hline$B I C$ & 7.2466 & 7.2014 & 7.1778 & 7.1717 & 7.1979 & 7.2483 & 7.2462 & 7.1730 & 7.1965 \\
\hline$Q(40)$ & $\begin{array}{r}21.5000 \\
(0.00000)\end{array}$ & $\begin{array}{r}22.0400 \\
(0.00000)\end{array}$ & $\begin{array}{r}23.0100 \\
(0.00000)\end{array}$ & $\begin{array}{r}23.1000 \\
(0.00000)\end{array}$ & $\begin{array}{r}22.3000 \\
(0.00000)\end{array}$ & $\begin{array}{r}21.3200 \\
(0.00000)\end{array}$ & $\begin{array}{r}21.5200 \\
(0.0000)\end{array}$ & $\begin{array}{r}22.7100 \\
(0.00000)\end{array}$ & $\begin{array}{r}22.3600 \\
(0.0000)\end{array}$ \\
\hline$Q^{2}(36)$ & $\begin{array}{r}1.4111 \\
(0.9625)\end{array}$ & $\begin{array}{r}2.8414 \\
(0.7848)\end{array}$ & $\begin{array}{r}3.1730 \\
(0.7301)\end{array}$ & $\begin{array}{r}3.7720 \\
(0.6277)\end{array}$ & $\begin{array}{r}3.0038 \\
(0.7583)\end{array}$ & $\begin{array}{r}1.6117 \\
(0.9459)\end{array}$ & $\begin{array}{r}1.4689 \\
(0.9581)\end{array}$ & $\begin{array}{r}3.8835 \\
(0.6086)\end{array}$ & $\begin{array}{r}3.1583 \\
(0.7326)\end{array}$ \\
\hline ARCH-LM Test & $\begin{array}{r}0.9676 \\
(0.9188)\end{array}$ & $\begin{array}{r}1.7973 \\
(0.7601)\end{array}$ & $\begin{array}{r}2.0451 \\
(0.7078)\end{array}$ & $\begin{array}{r}2.3442 \\
(0.6447)\end{array}$ & $\begin{array}{r}1.8820 \\
(0.7424)\end{array}$ & $\begin{array}{r}1.1097 \\
(0.8951)\end{array}$ & $\begin{array}{r}0.9903 \\
(0.9151)\end{array}$ & $\begin{array}{r}2.4419 \\
(0.6244)\end{array}$ & $\begin{array}{r}1.9494 \\
(0.7280)\end{array}$ \\
\hline Observations & 3439 & 3439 & 3439 & 3439 & 3439 & 3439 & 3439 & 3439 & 3439 \\
\hline
\end{tabular}

Wind generation, electricity consumption, hydro generation, and the cross-border interconnector flows are scaled by $10^{4}$ to clarify the presentation of the results. The corresponding coefficients should, therefore, be multiplied by $0.1 \mathrm{AUD} / \mathrm{MWh}$ and 0.1 for a $1 \mathrm{GWh}$ increase in either variable for the mean equation and the variance equation, respectively. AIC denotes the Akaike information criterion, BIC is the Bayesian information criterion and ARCH $\mathrm{LM}$ is the Lagrange multiplier test for ARCH effect. The $p$ values are in parentheses. 

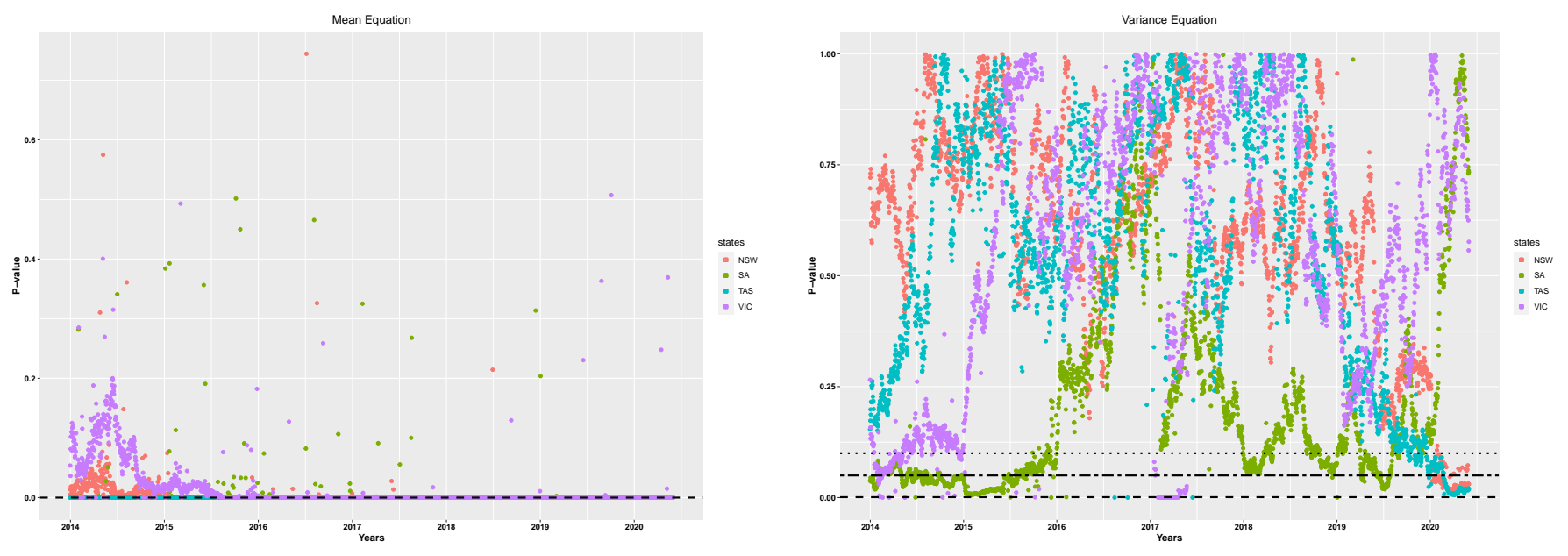

Figure 14: Estimated p-values for the volution of the impact of wind penetration from 2014 - May 2020 for NSW, SA, VIC, and TAS. The coefficients estimated using the rolling regression with three years windows while controlling for gas prices, hydro generation and the interconnectors. The effect on price level is given by the figures on the left and on price volatility by the figures on the right panel. 